Universitat Oberta de Catalunya

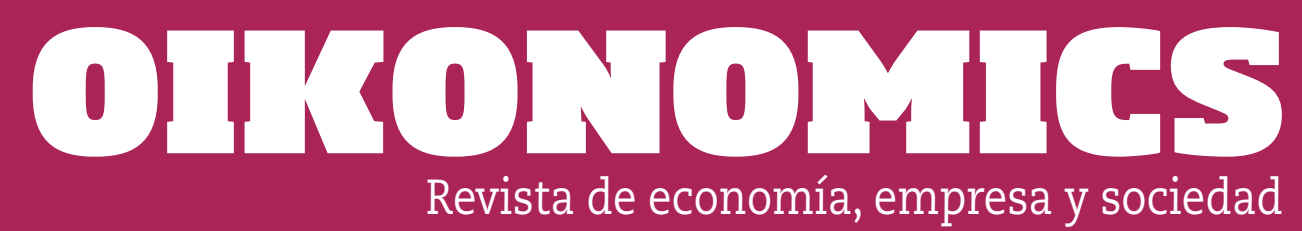

N. 8, noriembre de 2014 

ÍNDICE

\section{N. 8, noviembre de 2017}

\section{Editorial}

Dirigir personas para transformar las organizaciones en tiempos de incertidumbre Pilar Ficapal-Cusí . . . . . . . . . . . . . . . . . . . . . . . . . . . . . . 7-10

\section{Dossier: «Dirigir personas para transformar las organizaciones en tiempos de incertidumbre» coordinat per Pilar Ficapal-Cusí}

El objetivo de dirigir empresas es crear justicia

Natàlia Cugueró-Escofet y Josep Maria Rosanas. . . . . . . . . . . . . . . 13-23

Del yo al nosotros: nuevas formas de liderar

Francisco Fermín Mallén Broch y Emilio Domínguez Escrig . . . . . . . . . 24-34

Dirección de personas basada en evidencias. ¿Qué es, por qué importa, cómo implementarla?

Eva Rimbau-Gilabert . . . . . . . . . . . . . . . . . . . . . . . . . 35-48

Flexiseguridad o del paradigma del welfare al workfare en el actual contexto poscrisis español

Purificación Baldoví . . . . . . . . . . . . . . . . . . . . . . . . . . . 49-58

¿Hay empresas saludables? Tres maneras de responder

a esta pregunta

Helena Thomas Currás . . . . . . . . . . . . . . . . . . . . . . . . . . . . . 59-70

Pasión y adicción al trabajo

María José Serrano Fernández . . . . . . . . . . . . . . . . . . . . . . . 71-80

Digitalización de la gestión de personas

Verònica Platas Ruiz. . . . . . . . . . . . . . . . . . . . . . . . . . . . . . . . 81-89 
El empleo ante la nueva oleada digital: ¿robots humanos o recursos humanos?

Joan Torrent-Sellens . . . . . . . . . . . . . . . . . . . . . . . . . . . 90-102

\section{Trabajo final de grado}

La influencia de las Sense Girls en las mujeres de entre 25 y 45 años

Marina Sánchez Marcos . . . . . . . . . . . . . . . . . . . . . . . 103-115 


\section{Master en dirección y gestión de recursos humanos}

Es una titulación oficial que capacita a los futuros profesionales de los recursos humanos para afrontar las transformaciones empresariales, laborales y sociales a través de los nuevos paradigmas y metodologías de la dirección de personas. Con una aproximación interdisciplinaria y basada en la resolución de problemas, el Máster enfoca situaciones y orienta la toma de decisiones en función de las diferentes necesidades estratégicas y organizativas.

\section{Ejes principales}

Hoy en día, la dirección y la gestión de personas son fundamentales para hacer compatibles la innovación y la competitividad de las empresas, con el desarrollo y la empleabilidad de las personas, y con el bienestar y la calidad de vida en el trabajo. Estas dimensiones constituyen los ejes que fundamentan el Máster.

\section{Elementos centrales}

El objetivo es formar a futuros profesionales capaces de liderar y gestionar la función de recursos humanos a través de la aplicación de conocimientos y técnicas avanzadas del ámbito, un uso especializado de las TIC y un enfoque interdisciplinar. El Máster se centra en:

- La interpretación de las nuevas formas de empleo como resultado de las transformaciones del entorno económico y empresarial.

- El análisis de los nuevos conceptos, metodologías, políticas y prácticas de dirección y gestión de los recursos humanos.

- El estudio de la transformación digital y sus efectos sobre la función de recursos humanos.

- La implicación de RRHH en la estrategia empresarial.

- Las metodologías empíricas para evaluar los resultados organizativos y personales de las prácticas de recursos humanos y para interpretar los efectos de las prácticas de $\mathrm{RRHH}$ sobre las empresas y los empleados.

- Capacitar a futuros investigadores de recursos humanos.

\section{Salidas profesionales}

- Directores o técnicos superiores de recursos humanos en los equipos directivos de las empresas y las organizaciones.

- Responsables directos de las políticas de gestión y administración de los recursos humanos.

- Profesionales liberales en el ámbito de la consultoría y del asesoramiento de las empresas.

- Colectivos de personas que necesitan un liderazgo profesional en la gestión del capital humano.

- Profesionales implicados en procesos de cambio. 


\section{Relaciones laborales y empleo}

Existe un consenso amplio en señalar que las personas son el recurso más valioso de una empresa, o de cualquier organización en general. Son ellas las que proporcionan el trabajo, un factor imprescindible para la producción de bienes y servicios, un determinante clave de la competitividad empresarial y económica, y, además, un condicionante fundamental de la calidad de vida de una sociedad. Por todo ello, no es de extrañar que la gestión de recursos humanos haya adquirido una importancia vital.

Sin embargo, el hecho de que el trabajo sea indisoluble de la persona que lo presta le confiere a los recursos humanos unas particularidades, y una complejidad, especial. Básicamente, porque se requiere de profesionales altamente cualificados y multidisciplinares. Por ejemplo, es reduccionista contemplar a las personas como un mero factor económico obviando los aspectos psicosociológicos, del mismo modo que no es viable un departamento de recursos humanos que se limite a la asesoría jurídica ignorando la perspectiva económica del factor humano.

Para cubrir esta necesidad de profesionales polivalente, capaces de actuar en las distintas facetas que conforman las relaciones laborales, surge el Grado en Relaciones laborales y ocupación de la UOC. Esta titulación oficial sitúa en el centro el factor trabajo, con el objetivo de facilitar el desarrollo de todas aquellas competencias necesarias para su gestión. Así, a diferencia de otras titulaciones que versan en una única disciplina, esta titulación se caracteriza por la incorporación en su plan de estudios de asignaturas provenientes de diferentes ámbitos. Desde la economía hasta la organización del trabajo, pasando por la psicología y el derecho. El único rasgo en común, su interés por los recursos humanos, las personas y/o el trabajo. De este modo, se garantiza que, al final del proceso de aprendizaje, los titulados hayan adquirido unas capacidades poliédricas del factor humano que les permite abordar con éxito la compleja gestión de este recurso.

\section{Salidas profesionales}

Las salidas profesionales de nuestros titulados son múltiples y todas ellas caracterizadas por una elevada empleabilidad. Así, nuestros egresados están capacitados para ejercer la dirección y gestión de recursos humanos, el asesoramiento jurídico laboral, la actuación en el campo de las políticas sociolaborales, la consultoría sociolaboral, así como, la gestión, mediación e intermediación en el mercado de trabajo. Además, gracias al diseño del programa, todos los titulados pueden ejercer como graduados sociales en cualquier parte del territorio, previa colegiación en el colegio profesional correspondiente.

*El grado de relaciones laborales es una titulación oficial, homologada por el Ministerio de Educación, Cultura y Deporte y adaptada al espacio europeo de educación superior (EEES). Más información en http:// estudios.uoc.edu/es/grados/relaciones-laborales-ocupacion/presentacion 


\section{OTIONOMICS \\ Revista de economía, empresa y sociedad}

NUEVOS DESAFÍOS

\section{Dirigir personas para transformar las organizaciones en tiempos de incertidumbre}

\section{Pilar Ficapal-Gusí}

Directora del Máster Universitario en Dirección y Gestión de Recursos Humanos (UOC)

El entorno laboral contemporáneo está experimentando cambios vertiginosos. Estas importantes transformaciones en el trabajo se han ido trasladando a las organizaciones a diferente ritmo, de forma que, hoy en día, nos encontramos en un período de transición, desde empresas que todavía mantienen características de una estructura organizativa tradicional y clásica hasta aquellas que han adoptado modelos organizativos novedosos propios de la economía global del conocimiento, que permiten adaptar mejor su actividad a entornos inciertos y complejos.

Desde el ámbito de los recursos humanos, recientemente se ha utilizado el acrónimo VUCA (Volatility, Uncertainly, Complexity, Ambiguity) para describir este contexto que requiere emprender proyectos de transformación en las organizaciones. La capacidad de respuesta y adaptación de las empresas a los cambios del entorno es determinante para ser competitivo en un contexto en que los empresarios, líderes y directivos se enfrentan a situaciones que, a diferencia otros tiempos, se alejan de la estabilidad y la previsibilidad. Así lo corrobora la literatura sobre el management que enfatiza la necesidad de establecer cambios sustanciales en la estrategia, en la forma de dirigir las organizaciones y de gestionar el talento, y de implementar nuevas prácticas de la organización del trabajo y de recursos humanos que permitan una mayor eficiencia a la hora de tomar decisiones en función del entorno. No obstante, la investigación académica también ha evidenciado que debe garantizarse el bienestar y la calidad de las condiciones de trabajo de los empleados para que haya beneficios mutuos, tanto para la organización como para los trabajadores. 
Un aspecto nuclear de las transformaciones en el mundo del trabajo se encuentra en los procesos de digitalización y tecnologización. Estos procesos aportan beneficios sustanciales en términos de competitividad y productividad cuando se asientan. No obstante, si no existe la capacidad de crear trabajo con mayor calidad y gestionar el cambio a través de la capacitación en su uso, las tecnologías también pueden comportar riesgos, tales como pérdidas de puestos de trabajo, exclusión de empleo por el sesgo de habilidades, disminución de la calidad del trabajo o aumentos de la desigualdad. Por todo ello, es necesario disponer de herramientas para evaluar la gestión de personas y el impacto de sus intervenciones a nivel individual, grupal y organizativo.

Este monográfico pretende integrar todos estos aspectos y proporcionar diferentes perspectivas de los retos a que se enfrentan los profesionales de la dirección de personas desde diferentes dimensiones: empresarial y económica, psicosocial y legislativa.

Abre el monográfico el artículo «El objetivo de dirigir empresas es crear justicia». Natàlia Cugueró y Josep Maria Rosanas consideran necesario el logro de este objetivo para que la empresa tenga sentido para todos los grupos de interés y sea sostenible. Según los autores, para tomar decisiones justas, es necesario incorporar la sabiduría práctica propuesta por Aristóteles, y entender cuáles deben ser los valores (virtudes) que alimenten las decisiones. De esta forma, la empresa puede generar su objetivo social que es la eudaimonia (felicidad).

Francisco Fermín Mallén y Emilio Domínguez, en el artículo «Del yo al nosotros: nuevas formas de liderar», nos presentan las características de los liderazgos emergentes o contemporáneos. El artículo explica cómo emerge, en el ámbito organizativo, esta nueva corriente de estilos de liderazgo, que tiene como denominador común la relevancia de los valores humanos y la preocupación por los demás.

Eva Rimbau estrecha la brecha entre el mundo académico y la práctica profesional a través de su artículo «Dirección de personas basada en evidencias. ¿Qué es, por qué importa, cómo implementarla?». Explica el proceso para la aplicación de la gestión basada en evidencias y ofrece sugerencias prácticas para su implementación. Así mismo, señala las razones por las que conviene adoptar este enfoque para la toma de decisiones y comenta también sus principales objeciones.

La adaptación del mercado de trabajo al entorno económico ha hecho aflorar la necesidad de proporcionar flexibilidad laboral a las empresas. Sin embargo, la manera de proporcionar esa flexibilidad y al mismo tiempo garantizar la seguridad de los trabajadores se ha convertido en una de las cuestiones que ha suscitado más interés y controversia en el ámbito de las relaciones laborales contemporáneas. Purificación Baldoví, en su artículo «Flexiseguridad o del paradigma del welfare al workfare en el actual contexto poscrisis español», se adentra en esta controversia 
y nos plantea diferentes propuestas para hacer converger ambos conceptos, así como la necesidad de establecer un debate entre las diferentes sensibilidades sociales y políticas.

Helena Thomas nos interpela sobre si «¿Hay empreses saludables?» y nos propone diferentes maneras de responder a esta cuestión. En su artículo se analizan los efectos de la puesta en práctica de diferentes programas y se presentan diferentes modelos válidos y testeados de empresas saludables para que los responsables de personas elijan el modelo más útli y evalúen la empresa en función de su organización y sus prácticas de gestión de personas.

El monográfico profundiza en la temática de la salud ocupacional a través de la investigación «Pasión y adicción al trabajo». Con el fin de determinar si son conceptos diferentes, María José Serrano analiza ambos constructos y determina la capacidad predictiva de diferentes variables, como la personalidad, el engagement, la autoeficacia, la obsesión, la satisfacción por la vida y el estilo de vida.

Desde una perspectiva muy vinculada al ámbito profesional, Verònica Platas, en su artículo «Digitalización de la gestión de personas», realiza un recorrido sobre la evolución y funcionalidades de determinadas herramientas digitales, cómo han transformado estas las prácticas de recursos humanos, por ejemplo el reclutamiento de personas, y cuál es el estado actual de su implantación.

Cierra el monográfico Joan Torrent con «El trabajo en la nueva ola digital: ¿robots humanos o recursos humanos?». En este artículo se analizan las implicaciones futuras (o no tan futuras) para el trabajo de la nueva robótica y centra su atención en las repercusiones que ello tiene para la dirección y gestión de recursos humanos. Analiza las posturas positivas, así como las más contrarias a los efectos de la tecnologización, y pone de relieve los miedos y la preocupación por el futuro del trabajo propios de cualquier proceso de cambio disruptivo en la tecnología. Asimismo, incide sobre las nuevas formas de trabajo contingente.

Palabras clave del monográfico como justicia, liderazgo, valores, toma de decisiones, empoderamiento, flexibilidad y seguridad, empresa saludable y riesgos psicosociales, desarrollo de personas, digitalitzación, robótica, inteligencia artificial y trabajo contingente nos acercan a los desafíos que afronta la dirección de personas para la transformación de las organizaciones. La dirección de personas tiene un largo y retador camino por delante. 


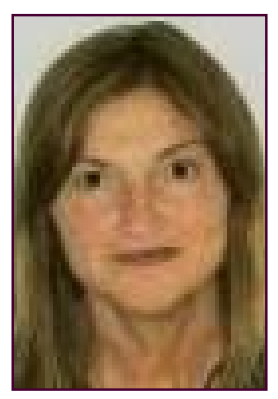

\section{Pilar Ficapal-Gusí pficapal@uoc.edu \\ Profesora de los Estudios de Economía y Empresa (UOC)}

Doctora en Sociedad de la Información y el Conocimiento (UOC). Licenciada en Psicología por la Universidad Autónoma de Barcelona y DEA en Recursos Humanos y Organizaciones por la Universidad de Barcelona. Directora del Máster universitario en Dirección y Gestión de Recursos Humanos de la UOC. Es miembro del grupo de investigación I2TIC y autora de varios libros y artículos en revistas indexadas en el ámbito de los recursos humanos, centrados en la organización, la productividad y la calidad de vida en el trabajo. Web personal: http://i2tic.net/es/equipo/pilar-ficapal/

Los textos publicados en esta revista están sujetas -salvo que se indique el contrario- a una licencia de Reconocimiento 3.0 España de Creative Commons. Podéis copiarlos, distribuirlos, comunicarlos públicamente y hacer obras derivadas siempre que reconozcáis los créditos de las obras (autoría, nombre de la revista, institución editora) de la manera especificada por los autores o por la revista. La licencia completa se puede consultar en http://creativecommons.org/licenses/by/3.0/es/deed.ca.

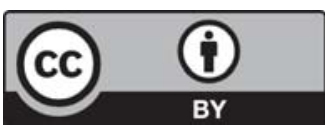




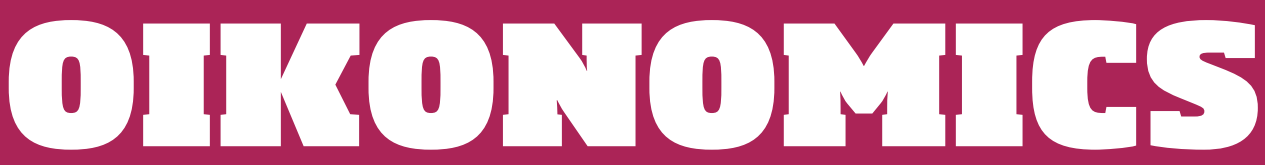

Revista de economía, empresa y sociedad

\section{Dossier: uDirigit personas para transformar las organitaciones en tiempos de incertidumbren coordinado por Pllar Hicapal-Gusí}




\title{
DOSSTHR OLKONONIHS
}

\author{
N. ${ }^{\circ} 1$, mayo 2014 \\ "r-learning en la economía y la empresa"
}

coordinado por Josep-Maria Batalla-Busquets

N. ${ }^{\circ} 2$, noviembre 2014

"Riedes sociales, economia y empresa"

coordinado por Oriol Miralbell Izard

N. ${ }^{\circ} 3$, mayo 2015

"Realidades y desafíos de la Unión Ruropean

coordinado por Albert Puig Gómez

N. ${ }^{\circ} 4$, noviembre 2015

"Prevención de riesgos laborales:

tendencias en tiempo de crisis»

coordinado por Xavier Baraza Sánchez y Mar Sabadell i Bosch

\author{
N. ${ }^{\circ}$ 5, mayo 2016 \\ "Repensando la enseñanra \\ de la economía en la universidadn
}

coordinado por Carolina Hintzmann

N. ${ }^{\circ}$ 6, noviembre de 2016

"Fconomía social y solidaria: experiencias y retos"

coordinado por August Corrons

N. ${ }^{\circ} 7$, mayo de 2017

"Hlaves para entender el turismo de hoy"

coordinado por Francesc González y Soledad Morales 


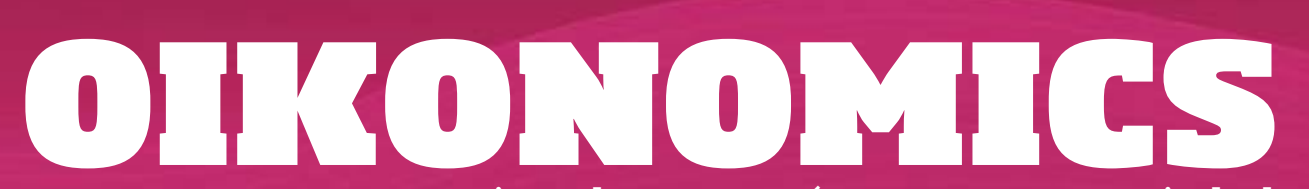

Revista de economía, empresa y sociedad

INCORPORACIÓN DE VALORES

\section{HI objetivo de dirigir empresas es crear justicia}

\section{Natàlia Gugueró-Escofet}

Profesora de los Estudios de Economia y Empresa (UOC)

\section{Josep Maria Rosanas}

Profesor emérito de Contabilidad y Control (IESE)

RESUMEN La justicia siempre se ha considerado un concepto alejado de la dirección de empresas y solo se ha considerado legítimo como objetivo social. La teoría económica no ha elaborado nunca nada que sea específico para organizaciones. En concreto, uno de los padres de la economía, Adam Smith, quería ver lo qué era bueno para el mundo, que se puede equiparar a la eudaimonia que proponía Aristóteles. Pero en una visión simplista de la economía, la «mano invisible» implica que las empresas tienen que maximizar los beneficios y que al hacerlo ya contribuyen a esta eudaimonia social. Este es su rol. Pero si repensamos este objetivo propuesto por Smith, veremos que esta eudaimonia solo se puede conseguir si, cuando se considera a las empresas y su toma de decisiones, se incorporan valores y virtudes, y que esto significa ver qué objetivos tiene que proponerse la toma de decisiones y considerar los beneficios como resultados que solo llegarán si se toman las decisiones correctas, es decir, con la presencia de dichos valores. Aquí queremos exponer el hecho de que generar justicia tiene que ser uno de los objetivos básicos a la hora de dirigir una empresa, pues si no se incorpora este elemento en la toma de decisiones, la posibilidad de incorporar injusticias en las decisones que se adopten puede acabar con la misma organización. En las empresas, pues, la toma de decisiones tiene que generar justicia, y por lo tanto no se puede dirigir de cualquier manera. La justicia se tiene que aplicar con sabiduría práctica 
aristotélica, es decir, caso a caso y situación a situación. De esta manera, se podrán llegar a generar unos beneficios, que nunca se sabrá si son máximos, pero sí satisfactorios, y por lo tanto conseguir el último objetivo, que es la eudaimonia. Así coincidiría lo que decía Aristóteles con lo que proponía Adam Smith.

PALABRAS CLAVE dirección; liderazgo; gobernanza; justicia; sabiduría práctica; shareholder-value

\section{The objective of managing organizations is to generate justice}

ABSTRACT Justice has always been considered a concept that is very separate from business management and has only been considered legitimate as a social objective. Economic theory has never produced anything that is specific to organizations. In particular, one of the fathers of economics, Adam Smith, wanted to show what was good for the world, which can be paralleled with the concept of eudaimonia (happiness) proposed by Aristotle. In a simplistic view of economics, the 'invisible hand' implies that companies must maximize profits and that doing so would already contribute to this social eudaimonia. That is their role. Rethinking this objective proposed by Smith, we can see that eudaimonia can only be achieved if, when companies are analysed, their decision-making incorporates values and virtues. This requires them to decide the goals they have to set and consider the benefits as results that will only be realised by making the right decisions or, in other words, with the inclusion of these values. In this essay, our aim is to show that generating justice must be one of the basic objectives when running a company because, if this objective is not incorporated within the decision-making process, the decisions made incorporating injustices can result in the same organizational structure. For companies, therefore, decision-making must generate justice and, as such, it cannot be directed in any way. This justice must be applied with Aristotelian logic or, in other words, on a case to case basis that judges each situation on its individual merits. This is how you can generate profits, which you will never be able to ascertain whether or not they have been maximized, but which are satisfactory, thereby achieving the ultimate goal of eudaimonia. This would align what Aristotle said with what Adam Smith proposed.

KEYWORDS management; leadership; governance; justice; practical wisdom shareholder-value 


\section{Introducción}

La justicia siempre ha sido contemplada como un concepto alejado de la dirección de empresas y solo se ha considerado legítima como objetivo social. De hecho, si nos fijamos en la teoría económica, muy influyente a la hora de alimentar las teorías organizativas, y en concreto en lo que proponía Adam Smith, estaba más interesado en estudiar qué era bueno para el mundo, para llegar a la idea de cómo conseguir aquello que se podría equiparar a la eudaimonia que proponía Aristóteles. Pero la manera de trasladarlo a las empresas se ha simplificado mucho y, en realidad, la teoría económica les ha asignado el rol de generadoras de beneficios, cuantos más mejor, es decir, maximizarlos.

Pero si repensamos el objetivo que propuso Adam Smith, podemos ver que la eudaimonia que proponía solo se puede conseguir si incorporamos valores, si nos fijamos en los objetivos de cada decisión, y no solo en un potencial resultado macro del conjunto de decisiones. La eudaimonia solo se puede conseguir si somos conscientes, en el proceso de toma de decisiones, de cuáles deben ser los objetivos de las decisiones y qué conocimiento es necesario para incorporar tales objetivos. Esto hace necesario entender que deben ser los valores y las virtudes los que alimenten las decisiones y los criterios para decidir, es decir, valorar en cada situación y en cada caso particular qué conocimiento es necesario para tomar una decisión, con qué objetivo y entender el beneficio como un resultado que llegará, y de manera sostenida, si se cumplen unos determinados objetivos. Aquí mostraremos que la economía no puede ser aplicada de forma aislada a las empresas, puesto que no les proporciona un objetivo claro. Examinaremos cómo se ha aplicado y cuáles han sido sus limitaciones. A continuación, mostraremos que el foco debe estar puesto en el proceso de toma de decisiones, porque el objetivo de las empresas tiene que ser generar justicia, la única manera de conseguir que la empresa tenga sentido para todos los grupos de interés y sea sostenible a la vez que obtiene resultados económicos. También mostraremos que para tomar decisiones justas es necesario incorporar la sabiduría práctica propuesta por Aristóteles. Por lo tanto, cuando el proceso de toma de decisiones incorpora la justicia como objetivo y la sabiduría práctica como conocimiento, es cuando los beneficios que se generan son sostenibles, y la empresa puede generar el objetivo social último deseado de la eudaimonia. 


\section{Las empresas tienen un objetivo y no es el que la gente cree. La economía aplicada a la empresa y sus limitaciones}

La justicia es un concepto que en general se ha olvidado para quien diseña sociedades o sistemas sociales. Se ha considerado que las sociedades tienen que ser justas, y en esta dirección se han ido desgranando diferentes conceptos sobre qué quiere decir que sean justas. Algunos conceptos de justicia social se han considerado más adecuados que otros y, en general, cada cual ha ido exponiendo las bondades de las diferentes opciones propuestas. La más influyente en dirección de empresas ha sido la de Rawls, contrapuesta a la de Senn (Rawls, 1971, 2003; Sen, 1992). No es el objetivo de este artículo decidir cuál es el mejor concepto, pero todos estaríamos de acuerdo en que cualquier sociedad tiene que garantizar unos mínimos de justicia. Una sociedad tiene que generar justicia para sus ciudadanos, pero no como última finalidad, sino porque cada cual se pueda desarrollar y pueda llegar a un estado personal de eudaimonia.

Este concepto, la eudaimonia (Aristóteles, 2009, Book I), que se suele traducir como felicidad, pero que es más amplio, lo proponen desde Aristóteles, de manera explícita, hasta Adam Smith, de manera menos explícita. Para llegar a conseguirlo, es necesario que se tomen en consideración los valores. No es posible conseguirlo sin que entren en juego los valores, que en términos aristotélicos toman el nombre de virtudes, y fundamentalmente sin que se garanticen unos ciertos niveles de justicia (Aristóteles, 2009, Book V).

Pero entonces, si para adquirir eudaimonia es necesario que se garanticen unos niveles de justicia social, es importante examinar dónde quedan las empresas en la generación de esta justicia. Y podemos observar que, de manera general, han quedado al margen, sobre todo en las visiones de la teoría económica clásica aplicadas a la empresa. Las empresas y su manera de funcionar han sido simplificadas por las teorías más influyentes, especialmente las económicas, que son las que queremos desgranar de manera especial aquí. El problema de cómo se aplica la teoría económica es que no tiene objetivo, y menos para las empresas, puesto que solo les atribuye la función de generar los máximos beneficios posibles sin concretar de qué manera y para qué.

Desde este punto de vista, lo que deberían hacer las empresas es generar riqueza, y después ya serán los «mercados» y quizás los instrumentos de gobierno de la sociedad los que se encargarán de ver cómo esta riqueza puede acabar trasladándose a los ciudadanos. Por lo tanto, la función de las empresas se reduciría a generar riqueza, cuanta más mejor, primero para los accionistas y después para la sociedad. El hecho de decidir en qué proporción tienen que contribuir a la 
riqueza colectiva ya será un tema de modelo de sociedad y de concepto de justicia predominante.

Pero hay dos cuestiones que hacen que esta simplificación no funcione. La primera es la confusión entre objetivos y resultados. Claramente no son lo mismo, y la economía los confunde en muchas ocasiones, lo que nos ha llevado a situaciones realmente caóticas, como la crisis que se debe a aquellos sistemas de incentivos guiados para maximizar los resultados (Cugueró-Escofet y Rosanas, 2016). Los objetivos se plantean antes y los resultados vienen después como consecuencia de conseguir determinados objetivos y de una determinada manera particular.

Y la segunda cuestión es que la teoría económica señala que las empresas tienen que generar resultados, pero no dice nada sobre cuáles tienen que ser sus objetivos; por lo tanto, en este sentido, no ayuda a desarrollar una teoría realista de dirección de empresas que permita guiar la acción directiva a medio y largo plazo. Las empresas reales sí que tienen que tener objetivos. Ahora bien, para saber cuáles son y cómo desarrollarlos no nos podemos basar en lo que dice la economía. Y es precisamente esto lo que haremos a continuación, examinar por qué la economía, tal y como se aplica mayoritariamente, no es útil para ayudar a determinar cuáles son los objetivos de las empresas.

\subsection{Limitaciones de la teoría económica}

Se puede considerar que la influencia de la economía en la dirección de empresas empezó a verse en áreas como finanzas y contabilidad, pero ha continuado con la estrategia e incluso la dirección de personas.

Los modelos económicos tienen una manera de ver a las personas, puesto que asumen que estas tienen una racionalidad ilimitada, que en general solo se mueven por intereses personales y egoístas, y que no aprenden. Estos presupuestos no son en realidad nada realistas cuando se aplican a las empresas y sus modelos de decisión, sino que más bien son promotores de decisiones que acaban generando resultados contraproducentes a medio y largo plazo (Rosanas, 2011).

En primer lugar, asumir una racionalidad ilimitada es muy poco realista y, por lo tanto, totalmente inútil para crear modelos de decisión que puedan ser aplicables a la empresa. En general, las personas no pueden prever todas las posibilidades futuras en toda circunstancia, ni tampoco saber perfectamente cuáles son sus preferencias en todo momento o tener en la mente todas las alternativas posibles.

En segundo lugar, si se acepta que el objetivo social que deben tener las organizaciones es maximizar su valor para los accionistas, la empresa se reduce a un problema de agencia, en el que hay un principal (posiblemente los accionistas) y el resto de los elementos de interés quedarían agrupados en un único grupo 
de agentes. Los agentes son típicamente considerados egoístas, y su objetivo es maximizar su propia función de utilidad. Y aquí es cuando aparece el primer problema y limitación, puesto que considerar que los agentes son egoístas puede acabar conduciendo a que acaben siéndolo, aunque originalmente no fuera este el caso, la llamada profecía que se ha autocumplido (Ghoshal, 2005).

Finalmente, una tercera limitación es considerar que las personas no aprenden. En realidad, según Rosanas (2008), cuando dos personas interactúan pasan tres cosas. La primera son los resultados explícitos de la interacción, que pueden ser los esperados o no. En segundo lugar, se produce un aprendizaje personal de cada individuo, puesto que todos aprenden a ver si aquellos resultados esperados satisfarán mejor o no en el futuro las mismas expectativas respecto a cómo lo han hecho en el caso presente. Y finalmente, la satisfacción que se ha producido al interactuar con el otro, que hace que en el futuro tengamos más o menos deseos de repetir la interacción.

\section{La justicia como objetivo de dirigir empresas}

No obstante, la riqueza que generan las empresas no es un objetivo, es un resultado que llega cuando estas funcionan como deben hacerlo, es decir, con los objetivos correctos. Y para decidir cuáles son los objetivos correctos, debemos tener en cuenta que son aquellos que nos permitan satisfacer de manera sostenida a todos los grupos de interés, no solo a los accionistas y, por lo tanto, cambiar la «maximización de valor por los accionistas» para «satisfacer las necesidades de todos de manera equilibrada», es decir, justa. Y con este ánimo, tomando las decisiones adecuadas, una a una, de acuerdo con cada situación que se plantee, sin automatismos.

Aquí estamos interesados en mostrar que la justicia tiene que ser un objetivo también de las empresas. Generar riqueza en las empresas tendría que ser el resultado de hacer las cosas siguiendo unos criterios de justicia, porque solo así son sostenibles, y la riqueza que generan llega y lo hace no sólo a corto plazo sino también a medio y largo plazo. Y en segundo término entender que las empresas tienen que gestionar no sólo la generación de justicia a través de sistemas que en la toma de decisions la permitan, sino también las percepciones de las personas que interactúan con estas deciones.

\subsection{Justicia en la toma de decisiones}

Los principales sistemas en las organizaciones que ayudan a tomar decisiones y a diagnosticar los resultados de las empresas son los sistemas de control de ges- 
tión (Anthony y Govindarajan, 2003). En general, estos sistemas persiguen que las personas tomen las decisiones que les favorecen y, al mismo tiempo, favorezcan también a la empresa en su conjunto, es decir, generen congruencia de objetivos (goal congruence, en el término inglés más conocido) (Vancouver \& Schmitt, 1991). Esta congruencia de objetivos, junto con la fairness, serían aspectos básicos a la hora de examinar que un sistema de control sea eficaz (Vancil, 1973). Últimamente, la justicia, como variable con sus dos dimensiones, formal e informal (toma de decisiones), se ha considerado un requisito para garantizar el máximo nivel de congruencia de objetivos (Cugueró-Escofet y Rosanas, 2013), pero sobre todo para garantizar que los resultados percibidos sean justos (Cugueró-Escofet y Rosanas, 2015)

\subsection{Las percepciones de justicia}

Por lo que respecta a las políticas de recursos humanos, en algunas escuelas de pensamiento, las percepciones de justicia se han considerado básicas para evaluar el clima y para que las personas que trabajan en la empresa se sientan bien tratadas e integradas. Las teorías de justicia organizativa estudian las percepciones de justicia relacionadas con: los procesos formales (procedural justice), lo que reciben las personas (distributive justice), la manera en que se transmite la información (informational justice) y cómo se produce cada una de las interacciones (interpersonal justice), las cuatro dimensiones importantes a la hora de valorar si hay o no justicia en la manera como me tratan en una empresa (Cropanzano, Bowen y Gilliland, 2007; Greenberg, 1990). Aunque la justicia organizativa se fije en las percepciones, y estas no sean necesariamente elementos fieles para valorar si existe o no justicia, sí que es cierto que son importantes para saber si la justicia que se quiere generar realmente se percibe como tal o si, aunque creamos que los sistemas son justos, en realidad no lo están siendo (Cugueró-Escofet y Fortin, 2014). Por lo tanto, generar justicia mediante sistemas de control y comprobar que se percibe desde el punto de vista de los afectados sería la manera correcta de diagnosticar que los objetivos de crear justicia se consolidan y las decisiones se están tomando de manera correcta.

\section{Tomar decisiones justas incluye la sabiduría práctica aristotélica}

Para hacerlo hay que tomar decisiones justas por medio del conocimiento que nos proporciona la sabiduría práctica. Es importante entender que las decisiones toma- 
das afectan a las personas, implican actuar y generan consecuencias. A la hora de tomar una decisión, es importante intentar conocer todas las circunstancias que la rodean. Pero el conocimiento real total nunca es posible, por lo que se necesita el conocimiento práctico que implica poder predecir de forma individualizada las potenciales consecuencias de cada una de las decisiones que el directivo tiene que tomar. Es decir, evaluar las acciones antes de llevarlas a la práctica y hacerlo para cada persona a quien afectará esa decisión y esas acciones. Así pues, es necesario utilizar el conocimiento práctico para tomar decisiones que tengan como objetivo crear justicia para todo el mundo, en la medida en que esto sea posible.

Pero la realidad es que en dirección de empresas es muy frecuente que se busquen recetas, por lo que las propuestas que las propugnan y defienden tienen mucho éxito. Recetas «automáticas», que no requieren pensar y que un ordenador puede proporcionar. Es mucho más cómodo, e incluso se puede pensar que más eficaz. Y en algunas ocasiones puede serlo a corto plazo, en decisiones concretas, pero un desarrollo a largo plazo de una organización que tenga una ventaja competitiva sobre las otras requiere una sabiduría práctica, referida a las cosas concretas que tienen que ver con esa organización. Y precisamente porque es así, traerlo a la práctica necesitará virtudes, la primera de las cuales es la justicia.

\section{Conclusiones}

En este artículo hemos examinado y desgranado cómo se vincula la justicia social con la justicia en las empresas. En general, las dos se han desvinculado en economía. En el proceso de generación de justicia social, las empresas son consideradas como meros generadores de recursos, y son luego los mercados o los sistemas de gobierno los que se encargan de distribuirlos, y, en alguna medida, esta distribución, si sigue ciertos criterios de justicia, acabará generando la eudaimonia aristotélica. Pero la realidad es que esta explicación de la economía presenta limitaciones. En primer lugar, porque se confunden resultados con objetivos. Los resultados vienen tras plantearse unos objetivos que los generen. $Y$ en segundo lugar, porque la teoría económica no habla en ningún momento de cuáles deberían ser los objetivos de las empresas, y ya acabamos de comentar que ese objetivo último de generar resultados no guía las decisiones. Finalmente, hay otros análisis que también ponen limitaciones a las teorías económicas aplicadas a la toma de decisiones, dado que se basan en un modelo de agencia que no es realista y presenta tres limitaciones básicas. Las limitaciones serían considerar una racionalidad ilimitada que no es realista, además de considerar que los motivos de los agentes siempre son egoístas, y que estos no aprenden nunca. En estas tres limitaciones hacen que su teoría no sea aplicable a las empresas. Concluimos que una manera 
de superar estas limitaciones es considerar que la toma de decisiones tiene que tener como objetivo generar justicia. Proponemos que la justicia tiene que alimentar los sistemas formales de control de gestión, tiene que ser una virtud de los directivos y, a la vez, se tiene que procurar que las personas reciban aquello que perciben como justo. Y todo eso -incorporar la justicia como objetivo, como valor que guía las decisiones- debe complementarse con un conocimiento práctico aplicado a cada caso, que es la sabiduría práctica aristotélica.

\section{Referencias bibliográficas}

ANTHONY, R. N.; GOVINDARAJAN, V. (2003). Management Control Systems. 11. ${ }^{a}$ ed. Homewood, Illinois: Richard D. Irwin.

ARISTÓTELES (2009). The Nicomachean Ethics (W. D. Ross, revisado por Leslie Brown). Oxford:. Oxford University Press.

CROPANZANO, R.; BOWEN, D. E.; GILLILAND, S. W. (2007). «The Management of Organizational Justice». Academy of Management Perspectives. Vol. 21, n. ${ }^{\circ}$ 4, págs. 34-48.

CUGUERÓ-ESCOFET, N.; ROSANAS, J. M. (2013). «The just design and use of Management Control Systems as requirements for Goal Congruence». Management Accounting Research. Vol. 24, n. ${ }^{1}$, págs. 23-40.

CUGUERÓ-ESCOFET, N.; FORTIN, M. (2014). «One Justice or Two? A Model of Reconciliation of Normative Justice Theories and Empirical Research on Organizational Justice». Journal of Business Ethics [artículo en línea]. Vol. 124, n. ${ }^{\circ}$, págs. 435-451. <http://dx.doi.org/10.1007/s10551-013-1881-1>.

CUGUERÓ-ESCOFET, N.; ROSANAS, J. M. (2015). «Social dynamics of Justice: The Ex-ante and Ex-post Justice Interplay with Formal and Informal Elements of Management Control Systems». En: Dirk, D. S.; GILLILAND, S. W.; SKARLICKI, D. P. (eds.). Social dynamics of organizational justice. Charlotte, NC: Information Age Publishing.

CUGUERÓ-ESCOFET, N.; ROSANAS, J. M. (2016). «The Ethics of Metrics: Overcoming the Dysfunctional Effects of Performance Measurements Through Justice». Journal of Business Ethics [artículo en línea]. <http://dx.doi.org/10.1007/ s10551-016-3049-2>.

GHOSHAL, S. (2005). «Bad Management Theories are Destroying Good Management Practices». Academy of Management Learning and Education. Vol. 4, n. ${ }^{\circ}$ 1, págs. 75-91.

GREENBERG, J. (1990). «Organizational justice: Yesterday, today, and tomorrow». Journal of Management. Vol. 16, n. ${ }^{\circ}$ 2, págs. 399-432. 
RAWLS, J. (1971). A theory of justice. Cambridege, MA: The Belknap press of Harvard University Press.

RAWLS, J. (2003). Justice as Fairness: a restatement. Cambridege, MA: The Belknap press of Harvard University Press.

ROSANAS, J. M. (2008). «Beyond Economic Criteria: A Humanistic Approach to Organizational Survival». Journal of Business Ethics. Vol. 78, n. ${ }^{\circ} 3$, págs. 447 462.

ROSANAS, J. M. (2011). «A Humanistic Approach to Organizations and Organizational Decision-making». En: The Future of Leadership Development (págs. 143-176). Londres: Palgrave Macmillan.

SEN, A. (1992). Inequality Reexamined. Cambridge, MA: Harvard University Press. VANCIL, R. F. (1973). «What kind of management control do you need?». Harvard Business Review.

VANCOUVER, J. B.; SCHMITT, N. W. (1991). «An exploratory examination of person-organization fit: Organizational goal congruence». Personnel Psychology. Vol. 44, n. ${ }^{\circ}$ 2, págs. 333-352. 


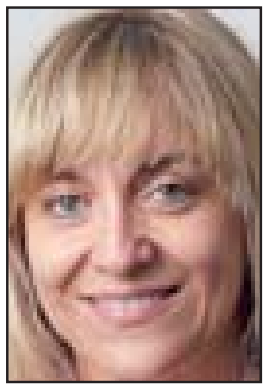

\section{Natàlia Gugueró-Fscofet ncuguero@uoc.edu Profesora de los Estudios de Economía y Empresa (UOC)}

Ph.D en Management Sciences por la IESE Business School, Universidad de Navarra, Licenciada en Derecho por la UOC e Ingeniera Industrial por la UPC. Ha publicado varios artículos tanto en revistas especializadas académicas cómo en revistas de divulgación.

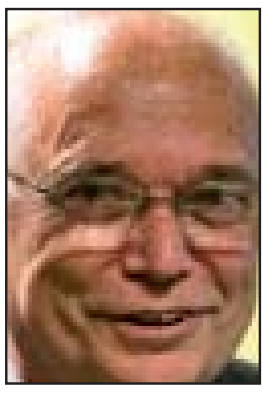

\section{Josep Maria Rosanas Martí} jrosanas@iese.edu Profesor emérito de Contabilidad y Control (IESE)

Doctor Ingeniero Industrial, MBA por el IESE y PhD en Management por la Northwestern University. Ha sido Catedrático de la Universitat Pompeu Fabra y formó parte del equipo fundador de esta Universidad. Ha publicado una veintena de libros y muchos artículos, tanto en revistas especializadas académicas cómo en revistas de divulgación y destinadas a un público profesional.

Los textos publicados en esta revista están sujetas -salvo que se indique el contrario- a una licencia de Reconocimiento 3.0 España de Creative Commons. Podéis copiarlos, distribuirlos, comunicarlos públicamente y hacer obras derivadas siempre que reconozcáis los créditos de las obras (autoría, nombre de la revista, institución editora) de la manera especificada por los autores o por la revista. La licencia completa se puede consultar en http://creativecommons.org/licenses/by/3.0/es/deed.ca.

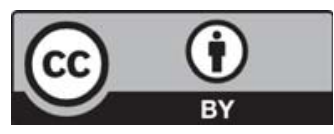




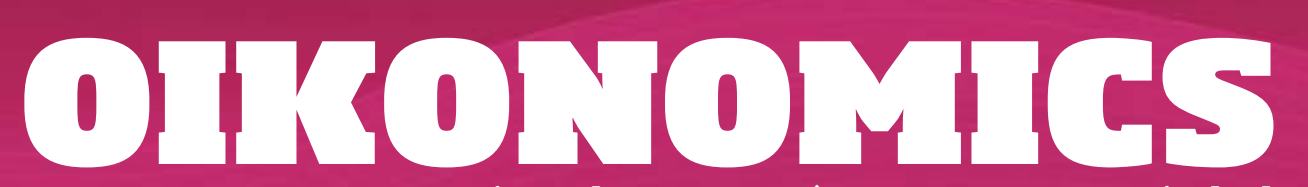

Revista de economía, empresa y sociedad

CAMBIO DE PARADIGMA

\section{Del yo al nosotros: nuevas formas de liderar}

\section{Francisco Fermín Mallén Broch}

Universidad Jaume I

\section{Fmilio Domínguez Escrig}

Universidad Jaume I

RESUMEN En los últimos años estamos asistiendo a un cambio de paradigma en las ciencias sociales y en las motivaciones que guían las relaciones entre las personas, desplazándonos desde lo que se ha acuñado como egosystem, donde lo prioritario es el bienestar de uno mismo, a lo que se ha venido a llamar ecosystem, un sistema que prioriza el bienestar de la comunidad. Centrados en el ámbito organizativo, las condiciones del entorno en el que se desenvuelven las empresas, así como acontecimientos recientes relacionados con comportamientos poco éticos y egoístas de sus líderes, están dando paso a un conjunto de estilos de liderazgo, contemporáneos o emergentes, donde los valores humanos adquieren especial relevancia. Numerosos trabajos analizan las consecuencias para el individuo, el grupo y la organización de esta nueva corriente de estilos de liderazgo, pero otros aconsejan el análisis de las consecuencias de comportamientos o conductas concretas de los líderes: comportamiento altruista, humildad, empoderamiento, capacidad de perdonar y orientación hacia la sostenibilidad, por citar algunos ejemplos. Se presentan algunas conclusiones y retos de esta nueva línea de trabajo.

PALABRAS CLAVE liderazgo; liderazgo servicial; liderazgo ético; altruismo; empoderamiento 


\title{
From me to us: new ways to lead
}

\begin{abstract}
In recent years, we have witnessed a paradigm shift in social sciences and the motivations that steer the relationships between people, moving from what has been described as an 'ego-system', in which priority is given to one's own wellbeing, to what could be referred to as an 'ecosystem', in which the wellbeing of the community is prioritized. Focusing on the organizational sphere, the conditions of the environment in which companies operate, as well as recent events related to the unethical and selfish conduct of their leaders, are paving the way for a new set of contemporary or emerging leadership styles in which human values are attributed particular significance. A number of studies analyse the consequences of this new trend of leadership styles for individuals, groups and organizations, but other studies recommend an analysis of the consequences of the specific behaviours or conducts of the leaders: altruism, humility, empowerment, capacity for forgiveness and focus on sustainability, to give just a few examples. Some conclusions are presented, as well as the challenges posed in this new line of work.
\end{abstract}

KEYWORDS leadership; servant leadership; ethical leadership; altruism; empowerment

\section{Introducción}

Al estudiar el rol que los líderes desempeñan en las organizaciones, no se pueden pasar por alto las condiciones del entorno en el que estas desarrollan su actividad, haciendo frente a cambios cada vez más frecuentes e inesperados. Las características del nuevo contexto competitivo están modificando la manera de trabajar en las empresas, lo que demanda nuevos estilos de dirección que se alejen de los clásicos estilos transaccionales (Zhu y otros, 2005), basados en premios y castigos para conseguir lo que se desea de los empleados. En una economía basada en el conocimiento, la competitividad de las empresas depende cada vez más de las personas y esta tendencia exige tener en cuenta sus necesidades más que nunca.

Además, algunos acontecimientos y noticias recientes han puesto en tela de juicio la conducta de algunos líderes y todo ello ha generado la necesidad de nuevos puntos de vista y formas de actuar por su parte. El abuso de poder, las emociones tóxicas, el aislamiento social en el puesto de trabajo y otras acciones limitan no solamente el bienestar psicológico de los empleados y su conciliación de la vida 
laboral y personal (De Cieri y otros, 2005), sino también el bienestar de la sociedad en general.

Este tipo de problemas está presente a nivel mundial, con casos tan conocidos como los que han llevado a la desaparición de Enron, WorldCom y Tyco en Estados Unidos, y casos más cercanos, algunos de ellos protagonizados por entidades financieras españolas, como los relacionados con las tarjetas black o la falta de transparencia en la emisión de preferentes. Todos estos ejemplos evidencian la influencia que algunas personas pueden tener sobre el bienestar social y es interesante conocer las razones por las que algunos individuos se centran en su éxito individual (egosystem), mientras que otros se preocupan por procurar el bienestar a largo plazo de sus negocios y las comunidades de personas que los integran (ecosystem).

Por egosystem se entiende un conjunto de motivaciones basadas en uno mismo, en asegurar la satisfacción de las necesidades y deseos propios, donde la preocupación por el bienestar de los demás es muy baja o inexistente, y si la hay, es porque se piensa que se le puede sacar partido. Frente a esta forma de entender las relaciones entre las personas, el concepto ecosystem reconoce la existencia de gente generosa, con empatía, que se preocupa por el bienestar de los demás y deja de lado el egoísmo implícito de la concepción anterior (Crocker y Canevello, 2012).

\section{Estilos de liderazgo emergentes o contemporáneos y sus consecuencias}

Este cambio tiene también su efecto en la forma de liderar. Según Sendjaya y otros (2008), no es ninguna sorpresa el auge que ha experimentado en los últimos años la investigación sobre estilos de liderazgo cargados de valores, bajo diferentes fórmulas o términos, como pueden ser el liderazgo auténtico, el liderazgo ético, el liderazgo espiritual o el liderazgo servicial, por citar solamente algunos de ellos. Entre los trabajos recientes, cabe destacar la propuesta de Anderson y Sun (2017), quienes examinan de forma conjunta y detallada diferentes estilos que están recibiendo especial atención por parte de la literatura académica: ideológico, pragmático, servicial, auténtico, ético, espiritual, integrador, compartido, además del carismático, transformacional y transaccional. Teniendo en cuenta el interés actual de estos estilos y su juventud relativa, se puede hablar de un conjunto de estilos de liderazgo emergentes o contemporáneos.

La figura 1 pone de relieve la creciente atención que han recibido algunos de estos estilos, con un incremento, en algunos casos exponencial, de las publicaciones relacionadas con los mismos. 
Figura 1. Evolución del número de artículos académicos relacionados con algunos estilos de liderazgo emergentes o contemporáneos

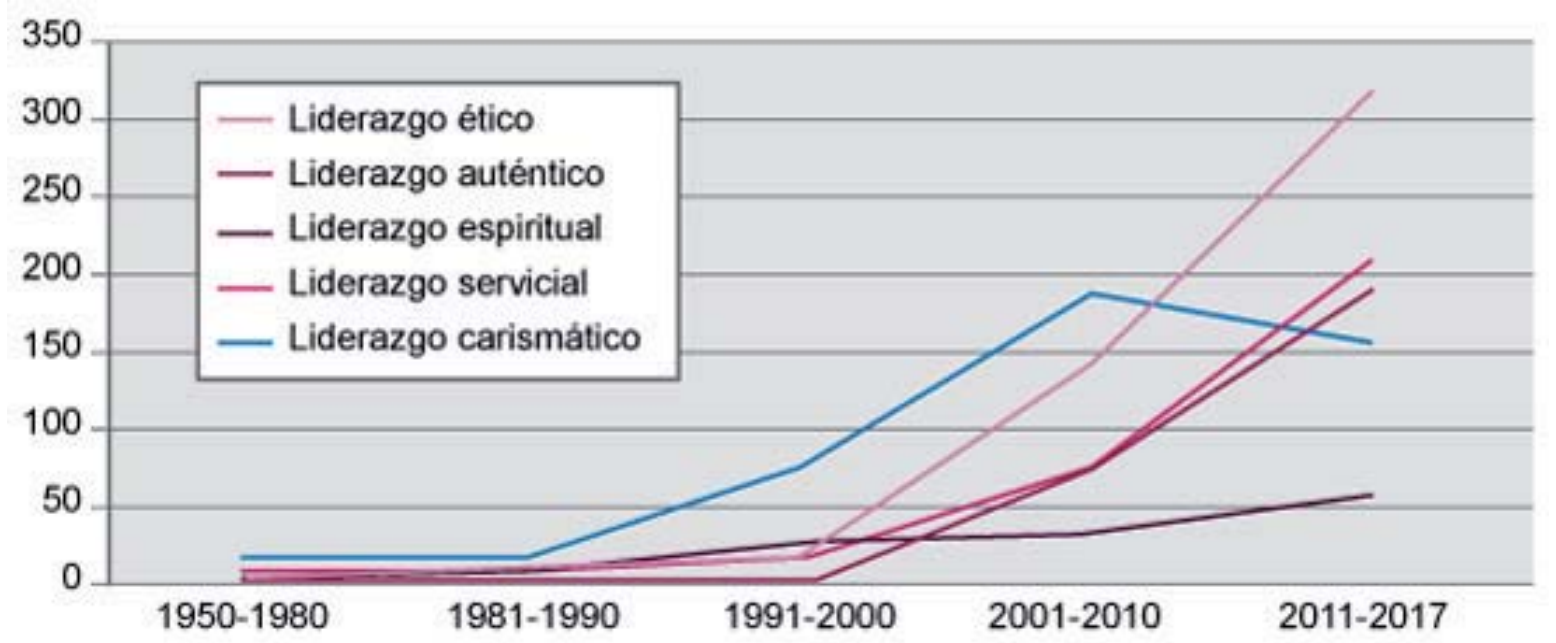

Fuente: elaboración propia a partir de Business Source Premier.

A continuación se introducen algunos estilos de liderazgo contemporáneos y se esbozan algunas de sus características y consecuencias.

El líder ético actúa de forma apropiada y promueve tal conducta en sus seguidores a través de la comunicación y la participación en la toma de decisiones (Brown y otros, 2005). En esencia, un líder ético es una persona justa, honesta y de confianza. Asimismo, actúa de acuerdo con lo que predica y es visto por los miembros de la organización como un ejemplo a seguir. Por último, utiliza la ética en su forma de dirigir y establece recompensas para que sus seguidores mantengan también una conducta ética.

Avolio y otros (2004) definen a los líderes auténticos como personas totalmente conscientes de su forma de pensar, que se comportan y son percibidas como conocedores de sus propios valores, conocimientos y fortalezas y también de las de los demás, y son reconocidas por su marcado carácter moral para actuar en beneficio del resto. Estas personas tienen confianza en sí mismas y son positivas, optimistas y flexibles. Shamir y Eilam (2005) consideran que los líderes auténticos tienen cuatro características: (1) son fieles a sí mismos, por lo que no intentan complacer a los demás sin más; (2) están motivados por convicciones personales, en lugar de estar centrados en alcanzar estatus, honores u otros beneficios personales; (3) son originales, no copian de otras personas y, por tanto, guían desde su propio punto de vista; (4) sus acciones están basadas en sus valores y convicciones personales.

El líder espiritual es definido por Fry (2003) como aquel que logra motivar e inspirar a los trabajadores a través de una visión transcendente y una cultura basada en valores altruistas para generar trabajadores motivados, comprometidos 
y productivos. El líder espiritual es aquel que muestra valores espirituales como la integridad, la honestidad, compasión, respeto y humilidad, y demuestra que se puede confiar en él o ella (Reave, 2005, pág. 663).

El líder servicial es aquel cuya prioridad es servir y satisfacer las necesidades de los demás (Greanleaf, 1970) y ayudar a las personas a desarrollarse, a esforzarse y a crecer. De acuerdo con Patterson (2003), el líder servicial es, entre otras cosas, altruista, humilde, de confianza, visionario y motivador. Estas personas también muestran una vocación altruista, son persuasivos y con coraje, demuestran capacidad de perdonar, son humildes y auténticos, se comportan de forma ética y con responsabilidad, y crean valor para la comunidad que les rodea (Anderson y Sun, 2017).

Los líderes carismáticos son capaces de transmitir la misión y la visión de la organización de forma convincente a los empleados, de forma que crean en un futuro mejor. A su vez, contribuyen a generar altos niveles de iniciativa y construir fuertes vínculos emocionales entre sus seguidores (Hugues y otros, 2009).

Numerosos trabajos demuestran consecuencias positivas de estos tipos de liderazgo, ya sea a nivel individual, grupal u organizativo. Por ejemplo, si observamos exclusivamente el liderazgo servicial, se ha demostrado la relación con mayores niveles de satisfacción de los empleados, mayor grado de apoyo percibido, menor intención de cambiar de compañía, menor nivel de estrés, mayor compromiso y confianza en la organización y sus supervisores, mayor efectividad en el desempeño de sus tareas, etc. (Van Dierendonck, 2011). Si nos referimos al liderazgo ético, se han encontrado relaciones positivas con la satisfacción de los empleados, su compromiso con la organización, mejora del desempeño, engagement e identificación con la organización (Bedi y otros, 2016), entre otros aspectos.

Todas estas variables resultan fundamentales para la supervivencia de muchas organizaciones y también lo son la creatividad y la capacidad para innovar. Estudios precedentes demuestran que estos estilos de liderazgo emergentes promueven estos aspectos en las empresas, lo que mejora su competitividad.

\section{Dificultades encontradas en su estudio y alternativas}

El estudio de estos estilos de liderazgo y sus consecuencias para la organización presenta algunas dificultades o problemas.

Como se ha explicado en líneas anteriores, estos estilos se miden mediante el uso de diferentes dimensiones: altruismo, humildad, conducta ética, etc. Se trata, por tanto, de estilos cuya amplia naturaleza lleva a que, en ocasiones, el análisis de sus consecuencias no resulte fácil. Por ejemplo, al encontrar que los líderes serviciales promueven la creatividad, innovación o mejoran el desempeño de los 
trabajadores, ¿qué variables son las que más influyen? ¿Se podrían compensar los efectos entre las mismas? Utilizar una taxonomía completa de liderazgo puede dificultar la interpretación de los resultados y, por tanto, llevar a decisiones erróneas.

Por otra parte, muchos de estos estilos presentan algún tipo de solapamiento o redundancia en su definición. Como se ha señalado, el altruismo está presente de forma explícita o implícita en la definición de estilos como el servicial, el espiritual o el ético. Y esto es algo que no solo pasa con esta dimensión, sino también con otras.

Para superar estas dificultades o problemas, algunos autores sugieren centrar el estudio del liderazgo en aspectos concretos del mismo, como, por ejemplo, el comportamiento o los rasgos del líder en contextos específos (Yukl, 2010). En los últimos años, algunos trabajos están siguiendo este enfoque. Por ejemplo, Sendjaya y Pekerti (2010) examinan diferentes dimensiones (por separado) del liderazgo servicial y su impacto sobre la confianza de los trabajadores en el líder. Otros trabajos empíricos más recientes se centran en el análisis de las consecuencias que tiene una de las dimensiones de estos estilos, concretamente el altruismo del líder, sobre el desempeño organizativo (Mallén y otros, 2015) o sobre la innovación (Domínguez-Escrig y otros, 2016).

Algunos de los comportamientos o actitudes específicas de los líderes sobre los que se podría profundizar son el altruismo, la capacidad de perdonar, la humildad, el empoderamiento, el comportamiento responsable o la orientación hacia la sostenibilidad del líder, entre otros. A continuación se explica brevemente en qué consisten estos comportamientos.

El comportamiento altruista de los líderes ha sido poco estudiado, a pesar de haber sido destacado como una interesante línea de investigación (Dinh y otros, 2014). Se trata de un tipo de comportamiento prosocial que busca ayudar a los demás sin estar pendiente de las consecuencias personales que pueda acarrear, aunque estas puedan ser negativas.

La capacidad para perdonar implica dejar pasar tanto los errores ajenos como los propios con la finalidad de aprender de los mismos (Caldwell y Dixon, 2010). Tener una orientación positiva hacia los errores, fallos y ofensas que se han cometido en el lugar de trabajo permitirá que, potencialmente, una situación de sufrimiento se convierta en una experiencia enriquecedora (Davidhizar y Laurent, 2000).

La humildad se podría definir como la disposición a intentar autoevaluarse de forma precisa y a ser conscientes del hecho de que nadie es perfecto (Templeton, 1997). Las personas humildes son vistas como comprensivas, dispuestas a admitir sus propios errores y a aprender de ellos. Owens y otros (2013), además de lo anterior, incluyen en la definición de humildad la consideración de las contribuciones y puntos fuertes de los demás, así como la apertura a nuevas ideas y el feedback. 
Aunque se considera que la humildad de los líderes es una de las claves para valorar su efectividad, los estudios empíricos sobre humildad en los líderes son todavía escasos.

El empoderamiento se define como el proceso por el que los líderes o directivos comparten el poder con sus empleados, los motivan para que realicen sus tareas sintiendo que son autónomos y eficaces. Estos líderes subrayan la importancia del trabajo realizado por los trabajadores, muestran confianza en las capacidades de los empleados, facilitan su participación en la toma de decisiones, promueven el autoliderazgo, comparten información, establecen objetivos significativos, inspiran y ofrecen una visión excitante del futuro, etc.

El comportamiento responsable se puede definir como la medida en que un individuo subordina voluntariamente sus intereses personales y piensa en el bienestar a largo plazo de sus subordinadoes y de la sociedad en general. Por otro lado, la orientación hacia la sostenibilidad es un concepto muy próximo al que se ha descrito para el comportamiento responsable, y se entiende como la preocupación por el bienestar de la sociedad y del medioambiente, para lo que se adopta una visión de largo plazo de tales cuestiones (Eisenbeiss, 2012). En este sentido, algunos autores (por ejemplo, Karns, 2011) enfatizan la necesidad de promover este tipo de comportamientos para fortalecer una economía que incorpore una visión más humana y sostenible para las generaciones futuras.

\section{Conclusiones}

Varios factores han contribuido en los últimos años a la aparición de nuevas formas de liderar las organizaciones y han adquirido cada vez mayor protagonismo estilos de liderazgo en los que predominan los valores humanos y la preocupación e interés por los demás. Estos nuevos estilos han recibido diferentes nombres y definiciones, pero en la mayoría de ellos se encuentran características comunes, como la humildad, el altruismo o la capacidad de perdonar.

Se ha estudiado qué efectos tienen estos estilos de liderazgo emergentes sobre variables como la innovación, la creatividad, el desempeño, la confianza o el compromiso de los empleados con la organización y sus supervisores, y los resultados son alentadores. Sin embargo, a la hora de trasladar a la empresa qué conductas se deben promover entre las personas que las lideran, parece razonable profundizar en el análisis del efecto de conductas o comportamientos concretos como los mencionados, ya que hasta la fecha la investigación es relativamente escasa. Un buen comienzo puede ser centrar la investigación en aquellas dimensiones o aspectos que se repiten en los estilos de liderazgo que están adquiriendo relevancia en la actualidad. 
Los resultados de estas investigaciones pueden suponer avances para la literatura académica, pero también para las empresas. Desde un punto de vista aplicado, las organizaciones pueden llevar a cabo procesos de selección de personal en los que se valoren comportamientos o conductas presentes en los estilos de liderazgo emergentes que se han presentado. Muchas de estas conductas pueden promoverse también a través de la formación a los empleados y serán más fáciles de transmitir si los nuevos líderes dan ejemplo y se comportan de igual modo. Aún se podría dar un paso más y tratar de inculcar estos comportamientos a estudiantes universitarios, como futuros líderes de nuestras empresas, a través de casos de estudio. A la vista del impacto de algunas de estas conductas o comportamientos sobre la innovación o el desempeño, las empresas también se podrían plantear valorarlas al evaluar a sus trabajadores y ser un factor más a tener en cuenta en sus sistemas retributivos o en sus políticas de promoción.

\section{Referencias bibliográficas}

ANDERSON, M. H.; SUN, P. I. (2017). «Reviewing leadership styles: Overlaps and the need for a new 'full-range' theory». International Journal of Management Reviews. Vol. 19, n. ${ }^{\circ}$, págs. 76-96.

AVOLIO, B. J.; GARDNER, W. L.; WALUMBWA, F. O.; LUTHANS, F.; MAY, D. R. (2004). «Unlocking the mask: A look at the process by which authentic leaders impact follower attitudes and behaviors». The Leadership Quarterly. Vol. 15, n. ${ }^{\circ}$ 6, págs. 801-823.

BEDI, A.; ALPASLAN, C. M.; GREEN, S. (2016). «A meta-analytic review of ethical leadership outcomes and moderators». Journal of Business Ethics. Vol. 139, n. ${ }^{\circ}$, págs. 517-536.

BROWN, M. I.; TREVIÑO, L. K.; HARRISON, D. A. (2005). «Ethical leadership: A social learning perspective for construct development and testing». Organizational behavior and human decision processes. Vol. 97, n. 2, págs. 117-134.

CALDWELL, C.; DIXON, R. D. (2010). «Love, forgiveness, and trust: Critical values of the modern leader». Journal of Business Ethics. Vol. 93, n. ${ }^{01}$, págs. 91-101. CROCKER, J.; CANEVELLO, A. (2012). «Egosystem and ecosystem: Motivational perspectives on caregiving». En: BROWN, S.; BROWN, M.; Penner, L. A. (eds.). Moving beyond self-interest: Perspectives from evolutionary biology, neuroscience, and the social sciences (págs. 211-223). Nueva York, NY: Oxford University Press.

DAVIDHIZAR, R. I.; LAURENT, C. R. (2000). «The art of forgiveness». Hospital materiel management quarterly. Vol. 21, n. ${ }^{\circ}$ 3, págs. 48. 
DE CIERI, H.; HOLMES, B.; ABBOTT, J.; PETTIT, T. (2005). «Achievements and challenges for work/life balanç strategies in Australian organizations». The International Journal of Human Resource Management. Vol. 16, n.¹, págs. 90-103. DINH, J. I.; LORD, R. G.; GARDNER, W. L.; MEUSER, J. D.; LIDEN, R. C.; HU, J. (2014). «Leadership theory and research in the new millennium: Current theoretical trends and changing perspectives». The Leadership Quarterly. Vol. 25, n. 1, págs. 36-62. DOMíNGUEZ-ESCRIG, I.; MALLÉN, F. F.; CHIVA, R.; LAPIEDRA, R. (2016). «How does altruistic leader behavior foster radical innovation? The mediating effect of organizational learning capability». Leadership \& Organization Development Journal. Vol. 37, n. ${ }^{\circ} 8$, págs. 1056-1082.

EISENBEISS, S. A. (2012). «Re-thinking ethical leadership: An interdisciplinary integrative approach». The Leadership Quarterly. Vol. 23, n. ${ }^{\circ}$ 5, págs. 791-808.

FRY, L. W. (2003). «Toward a theory of spiritual leadership». The Leadership Quarterly. Vol. 14, n. 6 , págs. 693-727.

GREENLEAF, R. (1970). The servant as leader. Indianapolis, IN: Robert K. Greenleaf Center.

HUGHES, R. L.; GINNETT, R. C.; CURPHY, G. J. (2009). Leadership: Enhancing the lessons of experience (6. ${ }^{a}$ ed.). Nueva York, NY: McGraw-Hill/Irwin.

KARNS, G. L. (2011). "Stewardship: a new vision for the purpose of business». Corporate Governance: The International Journal of Business Insociety. Vol. 11, n. ${ }^{\circ}$, págs. 337-347.

MALLÉN, F.; CHIVA, R.; ALEGRE, J.; GUINOT, J. (2015). «Are altruistic leaders worthy? The role of organizational learning capability». International Journal of Manpower. Vol. 36, n. ${ }^{\circ}$ 3, págs. 271-295.

OWENS, B. P.; JOHNSON, M. D.; MITCHELL, T. R. (2013). «Expressed humility in organizations: Implications for performance, teams, and leadership». Organization Science. Vol. 24, n. ${ }^{\circ}$, págs. 1517-1538.

PATTERSON, K. A. (2003). Servant leadership: A theoretical model. Virginia Beach, VA: Regent University.

REAVE, L. (2005). "Spiritual values and practices related to leadership effectiveness». The Leadership Quarterly. Vol. 16, n. ${ }^{\circ}$ 5, págs. 655-687.

SENDJAYA, S.; CARRALLS, J. C.; SANTORA, J. C. (2008). «Defining and measuring servant leadership behaviour inorganizations». Journal of Management Studies. Vol. 45, n. ${ }^{\circ}$ 2, págs. 402-424.

SENDJAYA, S.; PEKERTI, A. (2010). «Servant leadership as antecedent of trust inorganizations». Leadership \& Organization Development Journal. Vol. 31, n. ${ }^{\circ}$ 7, págs. 643-663.

SHAMIR, B.; EILAM, G. (2005). “"What's your story?” A life-stories approach to authentic leadership development». The Leadership Quarterly. Vol. 16, n. ${ }^{\circ}$, págs. 395-417. 
TEMPLETON, J. M. (1997). Worldwide Laws of Life. Philadelphia: Templeton Foundation Press.

VAN DIERENDONCK, D. (2011). "Servant leadership: A review and synthesis». Journal of Management. Vol. 37, n. 4, págs. 1228-1261.

Yukl, G. (2010). Leadership in organizations (7. ${ }^{a}$ ed. internacional). Londres: Prentice Hall.

ZHU, W.; CHEW, I. K.; SPANGLER, W. D. (2005). «CEO transformational leadership and organizational outcomes: The mediating role of human-capital-enhancing human resource management». The Leadership Quarterly. Vol. 16, n. 1, págs. 39-52.

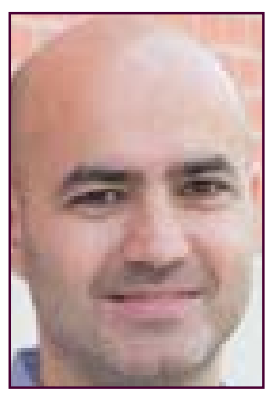

\section{Francisco Fermín Mallén Broch fmallen@uji.es Universitat Jaume I}

Doctor en Gestión Empresarial por la Universitat Jaume I (UJI), máster universitario en Psicología del Trabajo, de las Organizaciones y en Recursos Humanos (UJI), máster en Investigación de Mercados y Sistemas de Información (UNED), licenciado en Ciencias y Técnicas Estadísticas (Universidad de Valencia) y licenciado en Administración y Dirección de Empresas (UJI). Actualmente, es profesor en el Departamento de Administración de Empresas y Marketing de la Universitat Jaume I (Castellón), donde ha impartido asignaturas relacionadas con dirección de recursos humanos, sistemas de información y dirección estratégica, entre otras. Algunos de sus trabajos han sido publicados en revistas como Journal of Business Ethics, International Journal of Manpower o Leaderhip and Organizational Development Journal. Su área de investigación está relacionada con el liderazgo, la innovación y el aprendizaje organizativo. 


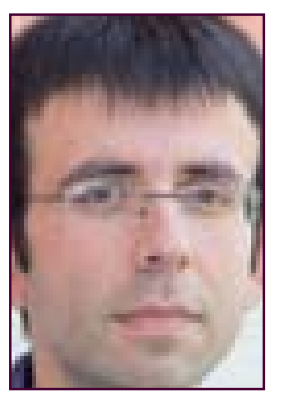

\section{Emilio Dominguez Fscrig edomingu@uji.es Universitat Jaume I}

Máster en Marketing e Investigación de Mercados (UJ) y licenciado en Publicidad y Relaciones Públicas (UJI). Ha sido professor asociado del Departamento de Administración de Empresas y Marketing de la Universitat Jaume I (Castellón), donde ha impartido asignaturas relacionadas con la dirección de recursos humanos.

Actualmente, es investigador en formación en esta misma universidad y elabora una tesis doctoral que analiza los antecedentes de la innovación radical en las organizaciones. Su investigación aborda temas como el empoderamiento, la capacidad para perdonar, el altruismo o el aprendizaje. Ha publicado en revistas como Leadership and Organizational Development Journal.

Los textos publicados en esta revista están sujetas -salvo que se indique el contrario- a una licencia de Reconocimiento 3.0 España de Creative Commons. Podéis copiarlos, distribuirlos, comunicarlos públicamente y hacer obras derivadas siempre que reconozcáis los créditos de las obras (autoría, nombre de la revista, institución editora) de la manera especificada por los autores o por la revista. La licencia completa se puede consultar en http://creativecommons.org/licenses/by/3.0/es/deed.ca.

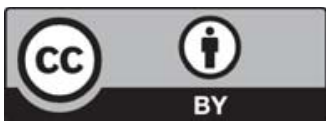




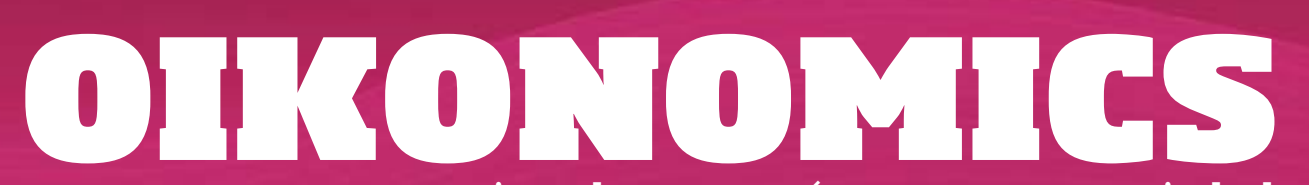

Revista de economía, empresa y sociedad

PENSAMIENTO CRÍTICO

\section{Dirección de personas basada en evidencias. ¿Qué es, por qué importa, cómo implementarla?}

\section{Eva Rimbau-Gilabert}

Profesora de los Estudios de Economía y Empresa (UOC)

RESUMEN La dirección de personas basada en evidencias es una aproximación a la profesión y la práctica de la dirección de personas que se centra en aumentar el uso del pensamiento crítico y el uso de las mejores evidencias disponibles para tomar decisiones. Este artículo sugiere varias razones por las que los profesionales de la dirección de personas no adoptan un enfoque más basado en las evidencias y señala la utilidad que este enfoque puede tener para las organizaciones. Se presenta un proceso en siete etapas para tomar decisiones que hagan un mejor uso de las evidencias: identificar, preguntar, obtener, valorar, agregar, aplicar y evaluar. Existen cuatro fuentes de evidencias que pueden mejorar la calidad de las decisiones en dirección de personas: evidencia científica, datos de la organización, experiencia profesional y aportaciones de los stakeholders. Finalmente, se ofrecen sugerencias prácticas para la implementación de este enfoque en las organizaciones y se comentan las principales objeciones al mismo que suelen presentar los directivos.

PALABRAS CLAVE gestión basada en evidencias; recursos humanos; dirección de personas; pensamiento crítico; brecha investigación-práctica 


\title{
Evidence-based people management: what is it, why does it matter and how can it be implemented?
}

\begin{abstract}
Evidence-based people management is an approach to the profession and practice of people management that focuses on increasing the use of critical thinking and the best evidence available for decisionmaking. This article puts forward several reasons why people management practitioners do not adopt a more evidence-based approach and argues how useful this approach can be for organizations. A seven-stage process is presented for making decisions that make better use of evidence: identifying, asking, acquiring, appraising, aggregating, applying and assessing. There are four sources of evidence that can improve the quality of decisions in people management: scientific evidence, organizational data, professional experience and stakeholder input. Finally, practical suggestions are offered for implementing this approach in organizations, as well as the main objections presented by managers are outlined.
\end{abstract}

KEYWORDS Evidence-based management; human resources; people management; critical thinking; research-practice gap

\section{Introducción}

Por favor, indique para cada una de las siguientes afirmaciones si considera que es «cierta» o «falsa»:

1. La selección de nuevos empleados que tengan éxito en la organización es óptima cuando combina la valoración de los directivos con los resultados de tests validados.

2. Las personas incompetentes se benefician más del feedback que las personas muy competentes.

3. Ser inteligente es una desventaja para realizar trabajos poco cualificados.

4. Los tests de integridad no sirven porque la gente miente al responderlos.

¿Le sorprende saber que todas estas afirmaciones son falsas? Cada una de ellas ha sido refutada por una gran cantidad de estudios, pero eso no ha sido suficiente para que esta información llegue a la mayor parte de los directivos. En la práctica, muchos directivos -sin saberlo y con la mejor intención- actúan al gestionar 
personas en contra de las evidencias científicas y de los intereses de su propia empresa.

Hace tiempo que sabemos que esto ocurre. Un estudio realizado en Estados Unidos en 2002 identificó 35 hallazgos bien documentados en la investigación sobre recursos humanos y decidió comprobar el conocimiento de esa función entre 959 directivos (Rynes, Colbert y Brown, 2002). Estos directivos tenían que indicar si las afirmaciones propuestas sobre los hallazgos de la investigación eran correctas o no. Los resultados fueron chocantes: en promedio, los participantes solamente eligieron la respuesta correcta en un $57 \%$ de las ocasiones. Y en una réplica realizada en los Países Bajos (Sanders, Van Riemsdijk y Groen, 2008) la cosa no fue mucho mejor: solamente un 62 \% de las respuestas fueron correctas. Reconozcámoslo: estos resultados son solo algo mejores que los que obtendríamos al decidir a cara o cruz. La comunidad de la dirección de personas parece estar, en general, pobremente informada sobre qué nos dicen las evidencias científicas en áreas fundamentales como la selección, la formación, el feedback y las estrategias de recursos humanos.

De estas investigaciones surgió otro dato relevante: los directivos que obtenían mejores resultados eran los que tenían un mayor nivel educativo, leían más sobre dirección de personas y tenían una actitud más positiva hacia los hallazgos de la investigación académica. Es decir, que no se basaban solamente en su instinto o su experiencia para tomar decisiones, sino que añadían otra información que les ayudaba a decidir de forma menos sesgada. Estos directivos eran los avanzados de una tendencia en gestión de empresas de la que se habla en otros países desde hace unos años y que por fin está llegando a nuestro país: la gestión basada en evidencias.

En este artículo se presentan las ideas básicas de la gestión basada en evidencias y cómo se aplica al contexto de la dirección de personas. Se explica qué es, por qué preocuparnos por ella, a qué nos referimos por «evidencias» y cómo implantarla en nuestra organización. Por cierto, si le interesa conocer la respuesta al test con que comienza el artículo, puede encontrarlas en el anexo final.

\section{Qué es la dirección de personas basada en evidencias y por qué importa}

La expresión «basado en evidencias» se acuñó en la década de los años setenta en el campo de la medicina (aunque su uso no se extendió hasta los noventa), pero sus principios se aplican hoy en disciplinas tan variadas como la educación, la criminología, las políticas públicas, el trabajo social y -recientemente- la gestión. En cualquiera de estas áreas, la práctica basada en evidencias se centra en lo mismo: 
tomar mejores decisiones utilizando el pensamiento crítico y las mejores evidencias empíricas disponibles. La gestión basada en evidencias es una aproximación a la toma de decisiones y al trabajo diario de los directivos que les ayuda a evaluar en qué grado pueden confiar en las evidencias que tienen a mano, y que les ayuda a identificar, encontrar y evaluar evidencias adicionales relevantes para sus decisiones (Barends, Rousseau y Briner, 2014, pág. 4). En el campo de la dirección de personas, este enfoque se concreta en los «recursos humanos basados en evidencias» (evidence-based human resources, EBHR) o «dirección de personas basada en evidencias», que se centra en utilizar el pensamiento crítico y las mejores evidencias disponibles para tomar decisiones relacionadas con la profesión y la práctica de la dirección de personas.

Aunque todos los directivos utilizan evidencias en sus decisiones, muchos apenas prestan atención a la calidad de dichas evidencias (Barends, Rousseau y Briner, 2014). Es decir, a menudo toman malas decisiones que se basan en creencias con poco o ningún fundamento, modas e ideas popularizadas por gurús de la gestión. En el campo de la dirección de personas, esto se traduce en una amplia variedad de situaciones poco deseables. Por ejemplo, no seleccionar a los mejores candidatos, dificultar que los empleados mejoren su rendimiento por no proporcionarles el feedback necesario, no detectar potenciales problemas de integridad personal, tener elevadas tasas de rotación de personal o de ausentismo, etc. Además, se dedican grandes importes a programas novedosos que, en el mejor de los casos, no producirán un retorno o que, en el peor caso, pueden llegar a ser dañinos para las organizaciones, sus empleados y sus clientes. A todo esto se añade el problema de que resultará imposible explicar por qué las cosas no han salido cómo se esperaba, con lo que la mejora será improbable.

Las razones por las que esto ocurre son múltiples, y tanto los profesionales como los académicos deben reconocer su parte de responsabilidad. En primer lugar, como Jeffrey Pfeffer (citado en Jacobs, 2015) señala, a menudo los departamentos de recursos humanos se centran más en sus «programas» que en pensar de forma crítica. Muchas empresas ponen programas en marcha porque otras empresas lo están haciendo o porque una consultoría se lo sugiere, pero no preguntan antes «¿seguro que tenemos un problema?» y, en caso afirmativo, «¿qué evidencia tenemos de que este programa puede ser una solución?».

En segundo lugar, el conocimiento científico no llega a los profesionales. Para empezar, los académicos suelen escribir en revistas destinadas a otros académicos, en un lenguaje poco accesible para los profesionales. Además, en algunas áreas no existe consenso académico sobre qué es lo que «funciona»-ya que se describen correlaciones, pero no causalidades-, lo que hace desconfiar a los profesionales. Son necesarias más publicaciones divulgadoras de buena calidad, que estén a medio camino entre la academia y la práctica -como Oikonomics-, que 
realmente den apoyo a los profesionales y les expliquen lo que necesitan saber sobre las conclusiones de la investigación en términos comprensibles.

Finalmente, también es necesario reconocer que los profesionales no reciben formación sobre cómo desarrollar una práctica basada en evidencias. En el siguiente apartado explicamos un proceso para tomar mejores decisiones con base en las evidencias disponibles.

\section{El proceso de la gestión basada en las evidencias}

El Center for Evidence-Based Management (CEBMa, 2014, pág. 4) sugiere seguir un proceso en seis etapas (las seis «A» en inglés) para tomar mejores decisiones, al que añadimos una etapa inicial de identificación:

1. Identificar: detectar un problema que necesita solución o una oportunidad que puede reportar beneficios.

2. Preguntar («Asking»): traducir esa cuestión práctica o problema en una pregunta que sea posible responder.

3. Obtener («Acquiring»): buscar y recopilar las evidencias sistemáticamente.

4. Valorar («Appraising»): valorar críticamente el nivel de confianza que merecen las evidencias y su relevancia.

5. Agregar («Aggregating»): ponderar y combinar las evidencias.

6. Aplicar («Applying»): incorporar las evidencias al proceso de toma de decisiones.

7. Evaluar («Assessing»): evaluar el resultado de la decisión tomada.

\subsection{Identificar}

Una de las críticas más frecuentes a la dirección de personas no basada en evidencias es que se centra en implementar soluciones para problemas que no han sido verificados, que quizá ni siquiera existen. Es el llamado solution-eering: una solución (quizá promovida por consultorías externas) en busca de un lugar donde implantarse, incluso aunque no haya ningún problema que solucionar.

Una práctica basada en evidencias debe verificar que existe un problema que genera ineficiencias o una oportunidad que puede aportar beneficios. Por ejemplo, la sensación de que el ausentismo es elevado no es suficiente para implementar un nuevo programa que intente mejorarlo. Antes de iniciar cualquier acción, deberíamos recopilar evidencias que muestren: a) que los niveles de ausentismo son altos o han aumentado, b) que hay posibilidad de mejora en los niveles de ausentismo 
sin incurrir en costes excesivos, por medio de identificar las áreas de la empresa en que esta mejora es más factible, y c) que existen intervenciones que podemos implementar y que han mostrado su eficacia para reducir el ausentismo. Hablaremos de cómo podemos obtener estas evidencias más adelante.

\subsection{Preguntar}

Una vez identificado el problema que debemos resolver, es necesario comenzar con una pregunta concreta basada en un problema práctico. Una pregunta como «¿Funcionan los programas de incentivos?» resulta interesante pero es demasiado amplia. Es necesario tener en cuenta en qué tipo de organización estamos y los tipos de resultados que interesa obtener para concretar la pregunta. Así, la pregunta anterior podría reformularse en «Los programas de incentivos ¿mejoran la motivación de los trabajadores?» o «¿mejoran la productividad?» o «¿reducen el absentismo?», según cuál sea el problema que la empresa necesita resolver. Una pregunta bien formulada es un problema medio resuelto, dado que canaliza los esfuerzos en la dirección que con mayor probabilidad puede ofrecer resultados significativos.

\subsection{Obtener}

Un elemento fundamental de la dirección de personas basada en evidencias es, precisamente, obtener evidencias que nos ayuden a responder la pregunta formulada. Habitualmente, los directivos recurren a su propia experiencia profesional o a la de otros directivos, o bien al consejo de consultores externos. No obstante, estas evidencias no son las únicas disponibles, hay que contar también con la evidencia científica, los datos provenientes de la propia organización, y las opiniones de los stakeholders.

Supongamos que hemos detectado un problema de ausentismo en nuestra empresa. La pregunta que nos planteamos es ¿cómo se puede reducir el ausentismo en esta empresa? Veamos qué puede aportar cada fuente de evidencias.

\section{Evidencia científica}

Los resultados de investigaciones científicas empíricas publicados en revistas académicas pueden indicar cuáles son las principales causas del ausentismo y qué intervenciones pueden ser eficaces. También pueden proporcionar las ratios de ausentismo registradas para mi sector y mi localización, lo que me ayuda a determinar si mi tasa actual es realmente elevada o no. 
Para acceder a la literatura científica, se puede contactar con expertos en el tema (a menudo, profesores universitarios) que puedan indicar directamente las referencias bibliográficas más relevantes. Si esto no es posible, se puede buscar en alguna de las múltiples bases de datos que recopilan el texto completo de revistas científicas, a las que se puede tener acceso mediante acuerdos con las bibliotecas universitarias o a través de las propias compañías propietarias de las bases de datos. Por ejemplo, ABI/Inform es una buena referencia donde buscar activando la opción «Evaluado por expertos». Una opción alternativa, gratuita pero que filtra menos la información y ofrece peor acceso a los artículos, es Google Scholar.

\section{Evidencia organizativa}

Llevar un registro en la propia organización permitirá saber cuál es realmente la tasa de ausentismo, qué tipo de ausencias (largas o cortas) tenemos y dónde se producen, podremos compararlas con la media del sector y ver si se dibuja una tendencia. También facilitará elegir en qué áreas de la empresa interesa más intervenir y permitirá calcular los posibles costes y beneficios de una intervención.

No se trata de acumular grandes cantidades de informes y registros internos, ni de adquirir un sofisticado sistema de people analytics, sino de detectar un problema y ver qué datos serán necesarios para tomar una decisión bien fundamentada. Hay áreas en la función de recursos humanos que se prestan especialmente bien a su gestión basada en evidencias, como las de selección y reclutamiento.

\section{Evidencia experiencial}

La experiencia y el criterio de los profesionales es importante, puesto que con los años acumulan un conocimiento tácito sobre lo que funciona en su organización, que es valioso incorporar en la toma de decisiones. Esta experiencia puede responder a preguntas sobre qué ha funcionado en el pasado y por qué.

A pesar del valor otorgado a la experiencia, el hecho de que una intervención haya funcionado en una organización no garantiza que funcione en otra. Esto significa que no es recomendable basarse en el benchmarking y las llamadas «mejores prácticas» para tomar decisiones. Barends y otros (2014, pág. 6) destacan que «los profesionales a veces copian lo que hacen otras organizaciones sin evaluar críticamente si dichas prácticas son realmente eficaces y, en caso de serlo, si es probable que también funcionen en un contexto diferente. El benchmarking puede mostrar formas alternativas de hacer las cosas, pero no es necesariamente un buen indicador de lo que funcionaría en otro lugar». La necesidad de evaluar críticamente las evidencias se pone aquí de manifiesto con mayor intensidad, si cabe, que con otras fuentes de evidencias. 


\section{Evidencia de los stakeholders}

En cualquier decisión, es necesario incorporar los valores y preocupaciones de las personas y organizaciones que se verán afectadas por la misma. Ante el problema de ausentismo, habría que averiguar qué piensan los empleados y los directivos sobre las intervenciones propuestas para reducirlo, si creen que pueden tener inconvenientes o consecuencias negativas inesperadas. Esta fuente de evidencias incorpora un criterio ético imprescindible que genera intervenciones aceptables y consideradas legítimas entre los afectados, pero también un criterio práctico, que destaca qué es factible teniendo en cuenta a los que van a implementar o recibir los efectos de la decisión.

\subsection{Valorar las evidencias críticamente}

Las evidencias de cualquiera de las anteriores fuentes nunca son perfectas. En todos los casos, es necesario evaluar cómo de fiable y de relevante es la información obtenida y escrutar posibles sesgos. Por ejemplo: un estudio puede ofrecer conclusiones atractivas pero estar basado en una muestra pequeña de un sector muy diferente al nuestro; la opinión de un colega sobre la eficacia de una intervención puede estar basada en una anécdota; la forma de hacer las cosas hasta el momento en nuestra organización puede no haber sido evaluada nunca para ver si funciona realmente o no.

La clave es valorar críticamente toda fuente de evidencias mediante preguntas como: ¿dónde y cómo se obtuvieron estas evidencias?, ¿son las mejores evidencias disponibles?, ¿tenemos suficientes evidencias como para alcanzar una conclusión?, ¿hay razones para pensar que estas evidencias pueden estar sesgadas en una dirección en particular? En el caso de las publicaciones científicas, existe una clara escala que jerarquiza los distintos tipos de estudios según su fiabilidad. Puede aprenderse más sobre ello en CIPD (2016).

Para algunas decisiones, puede ser que no exista literatura científica sobre el tema y que no haya datos organizativos de ningún tipo. Entonces no habrá más opción que basar la decisión en la experiencia profesional del equipo decisor o hacer una prueba piloto de diferentes opciones y ver qué funciona mejor. Para aprender a realizar experimentos en la propia organización, véase Gray (2004) y Davenport (2009). En cualquier caso, utilizar estas evidencias de calidad limitada puede llevar a mejores decisiones que utilizar solamente la intuición, siempre y cuando al utilizarlas seamos conscientes de sus limitaciones. 


\subsection{Agregar}

Cuando se han recopilado las mejores evidencias posibles, es necesario analizarlas en su conjunto y deducir en qué sentido nos orienta cada una, sin olvidar de hacer explícitas las posibles contradicciones entre ellas y los límites a su fiabilidad o su aplicabilidad a nuestro caso concreto. Una visión integrada ponderará las evidencias obtenidas de los estudios científicos, la propia experiencia y el contexto para llegar a conclusiones sobre la pregunta planteada y recomendar la actuación más adecuada ante el problema concreto de la organización.

\subsection{Aplicar a la decisión}

Tener evidencias no es lo mismo que tener respuestas. Los directivos aún necesitan interpretar las evidencias disponibles a la luz de la situación en que se encuentran. Como destacan Rousseau y Gunia (2016), esto puede ser particularmente complejo cuando las evidencias existentes no provienen del mismo sector, campo o disciplina, o no responden exactamente a las preguntas planteadas. Por ejemplo, es posible tener evidencias obtenidas en el sector hospitalario pero que nuestra empresa sea hotelera; o bien que haya conclusiones relativas a la calidad del producto cuando nuestra pregunta se refería al coste. También puede ser que la evidencia científica sobre intervenciones posibles no sea lo suficientemente detallada como para guiar su implantación práctica, o que no sea posible trasladar directamente los experimentos realizados en un contexto controlado como el de la investigación científica al contexto real de una organización. En situaciones así, aplicar esas evidencias a la decisión que nos ocupa puede ser complejo, y requerirá un esfuerzo de adaptación relevante.

\subsection{Valorar los resultados}

Evaluar los resultados de las decisiones tomadas es inherente a una práctica basada en las evidencias. Es necesario recopilar información sobre el impacto de las intervenciones realizadas, conversar y reflexionar sobre ellas para alcanzar conclusiones sobre cómo proceder en el futuro, tanto respecto al problema que suscitó la decisión como sobre el propio proceso de utilizar las evidencias y mejorar la práctica. 


\section{Consejos para llevarlo a la práctica}

Cambiar el modo en que se toman decisiones en una organización no es algo sencillo. Los profesionales de cualquier nivel pueden sentirse incómodos o incluso amenazados cuando se cuestionan los supuestos que siempre se han dado por sentados, o cuando se les piden evidencias que apoyen sus propuestas. A continuación comentaremos algunas sugerencias prácticas para ir introduciendo el enfoque basado en evidencias en la propia organización, así como respuestas a las principales objeciones de los directivos a este enfoque.

David D'Souza (2017) propone los siguientes consejos para la persona que intenta implantar el uso de evidencias para la toma de decisiones en su organización:

1. Hacer sentir a la gente que se está perdiendo algo: hay que destacar organizaciones que utilizan un enfoque más basado en evidencias y mostrar los excelentes resultados y el reconocimiento que están obteniendo. Así se genera la sensación de que si no se hace lo mismo nos estaremos quedando atrás. Google es un ejemplo bien conocido en este sentido.

2. Destacar la posibilidad de elegir: a nadie, y en particular a los directivos, le gusta pensar que no tiene elección. Por eso es recomendable ofrecer varias opciones razonables y pedir que se elija una. Lo importante no es llevarse el mérito de una decisión, sino lograr que las acciones que se emprendan sean lo más acertadas posible.

3. Realizar una prueba de bajo coste: para facilitar que se acepte una propuesta, es mejor minimizar las inversiones necesarias en tiempo y dinero. Por ejemplo, pedir «solo una hora» para experimentar con una nueva forma de evaluar críticamente una decisión y revisar las evidencias disponibles.

4. Centrarse en un fracaso o problema reconocido pero no sensible: lo más molesto que puede hacerse es apuntar al último gran fracaso de la organización, ya que todavía habrá egos dañados a los que no les gustará escuchar que «mi enfoque lo habría evitado». Es recomendable elegir temas lo suficientemente antiguos como para que haya una distancia emocional y sobre los que haya un consenso en que se adoptó un enfoque equivocado, o bien atacar problemas organizativos reconocidos (del tipo «falta tiempo, faltan recursos, falta eficiencia») y proponer una solución. Se trata de señalar cómo podría evitarse o mejorarse la situación en el futuro, más que destacar las razones del fracaso reciente.

5. Seleccionar los aliados con gran cuidado: es necesario ir ganando aliados o defensores del enfoque y crear una corriente de aprobación. Se puede hablar con otras personas antes de las reuniones para explicar de qué trata la propuesta y pedir apoyo, de modo que al proponer una forma de actuar ya haya un coro de voces que dicen «ya hemos hablado de ello y estamos de acuerdo». 
Por otra parte, es habitual que los directivos crean que un enfoque basado en evidencias presenta inconvenientes que lo hacen inaplicable:

1. Tiempo. Es frecuente que los directivos crean que la búsqueda y evaluación de evidencias les tomará un tiempo excesivo del que no disponen. No obstante, no todas las decisiones (de hecho muy pocas) de dirección se toman de un día para el otro, sino que siguen un proceso de maduración que permite la incorporación crítica de evidencias.

2. Datos. Los datos organizativos necesarios para una decisión pueden ser difíciles de conseguir, o bien los datos disponibles pueden ser de baja calidad, con lo que se reduce la capacidad de incorporar la información interna como fuente de evidencias. La respuesta a esta objeción es ir planteando una mejora progresiva en la calidad de los datos recabados, no rechazar de plano el enfoque basado en evidencias.

3. Capacidad de análisis cuantitativo. Relacionado con lo anterior, los profesionales de recursos humanos a menudo no han desarrollado la capacidad analítica necesaria para interpretar los datos y alcanzar conclusiones útiles para la organización. Dado que cada vez hay más organizaciones orientándose hacia una gestión basada en la evidencia, es recomendable que los profesionales desarrollen la capacidad de analizar datos y realizar inferencias a partir de ellos, lo que les puede favorecer en su trabajo actual o en el próximo.

\section{Conclusión}

La dirección de personas basada en evidencias no es un punto de llegada, sino un medio de transporte que nos lleva más directamente al destino que elijamos. Es un cambio de mentalidad en el modo cómo se decide sobre las políticas y prácticas de recursos humanos en una organización, que permite distinguir el grano de la paja entre los numerosísimos programas que podemos elegir. Facilita la implementación de los programas seleccionados y mejora los resultados que obtenemos de ellos.

Para lograrlo, es necesario que las organizaciones utilicen sistemáticamente el pensamiento crítico y se abran al aprendizaje. Además, requiere un acercamiento entre el mundo profesional y el académico, con esfuerzo por ambas partes. Los profesionales de la dirección de personas deben buscar la objetividad en sus decisiones y estar dispuestos a cambiar su forma de pensar y actuar cuando las evidencias sugieran que esta era inadecuada. Por su lado, los académicos deben ser capaces de trasladar sus hallazgos a la práctica profesional, para lo que necesitan comprender las condiciones en que esta se desarrolla. 


\section{Anexo: solución al test}

El cuestionario inicial se ha obtenido de Rousseau y Barends (2011). Aquí anotamos lo que la evidencia científica indica respecto a cada afirmación. Para saber más de cada uno de estos aspectos -y otros muchos-, recomendamos consultar Locke (2011).

1. «La selección de nuevos empleados que tengan éxito en la organización es óptima cuando se combinan la valoración de los directivos con los resultados de tests validados». Evidencia: añadir la valoración de los directivos a las decisiones de selección de hecho lleva a peores decisiones de selección que usar únicamente tests e indicadores de selección validados.

2. "Las personas incompetentes se benefician más del feedback que las personas muy competentes». Evidencia: las personas incompetentes tienen una gran dificultad para entender el feedback y tienden a utilizarlo de modo menos eficaz que sus compañeros/as más inteligentes.

3. "Ser inteligente es una desventaja para realizar trabajos poco cualificados». Evidencia: los trabajadores más inteligentes suelen tener un mejor desempeño en general, con independencia de si el trabajo es diseñar un hotel o limpiar sus habitaciones.

4. "Los tests de integridad no funcionan porque la gente miente al responderlos». Evidencia: aunque la gente ciertamente distorsiona sus respuestas, los tests de integridad siguen siendo muy buenos predictores de comportamientos laborales disfuncionales como el robo.

\section{Referencias bibliográfícas}

BARENDS, E.; ROUSSEAU, D. M.; BRINER, R. B. (2014). Evidence-Based Management. The Basic Principles. Amsterdam: Center for Evidence-Based Management [artículo en línea]. [Fecha de consulta: 1 de marzo de 2017]. <http:// www.cebma.org/wp-content/uploads/evidence-based-practice-the-basicprinciples.pdf>

CIPD (2016). «In search of the best available evidences». Positioning paper [artículo en línea]. Londres: Chartered Institute of Personnel and Development. [Fecha de consulta: 10 de junio de 2017]. <https://www.cipd.co.uk/Images/in-searchof-the-best-available-evidence_tcm18-16904.pdf>

DAVENPORT, T. H. (2009) «How to design smart business experiments». Harvard Business Review. Febrero, págs. 69-76 [artículo en línea]. [Fecha de consulta: 
10 de junio de 2017]. <https://hbr.org/2009/02/how-to-design-smart-business-experiments>

D'SOUZA, D. (2017, 27 de enero). "Sell the sizzle, not the evidence-based sausage». Future Work Centre [artículo en línea]. [Fecha de consulta: 1 de marzo de 2017]. <http://www.futureworkcentre.com/2017/01/sell-the-sizzle-not-theevidence-based-sausage/>

GRAY, D. E. (2004). «Experimental and quasi-experimental reseach design». En: Doing research in the real world (cap. 4, págs. 67-97). Londres: Sage Publications.

JACOBS, K. (2015). «Under the microscope». HR Magazine. Enero, págs. 24-31.

LOCKE, E. (ed.) (2011). Handbook of principles of organizational behavior: indispensable knowledge for evidence-based management. Nueva York: John Wiley \& Sons.

PFEFFER, J.; SUTTON, R. I. (2006). Hard facts, dangerous half-truths, and total nonsense: profiting from evidence-based management. Cambridge, MA: Harvard Business Press.

ROUSSEAU, D. M. (2006). «Is there such a thing as 'evidence-based management'?». Academy of Management Review. Vol. 31, n. ${ }^{\circ}$ 2, págs. 256-269.

ROUSSEAU, D. M.; BARENDS, E. G. (2011). «Becoming an evidence-based HR practitioner». Human Resource Management Journal. Vol. 21, n. ${ }^{\circ}$ 3, págs. 221 235.

ROUSSEAU, D. M.; GUNIA, B. C. (2016). «Evidence-based practice: the psychology of EBP implementation». Annual Review of Psychology. Núm. 67, págs. 667-692.

RYNES, S. L.; COLBERT, A. E.; BROWN, K. G. (2002). «HR professionals' beliefs about effective human resource practices: correspondence between research and practice». Human Resource Management. N. ${ }^{\circ} 41$, págs. 149-174.

SANDERS, K.; VAN RIEMSDIJK, M.; GROEN, B. (2008). «The gap between research and practice: a replication study on the HR professionals' beliefs about effective human resource practices». The International Journal of Human Resource Management. Vol. 19, n. 10, págs. 1976-1988. 


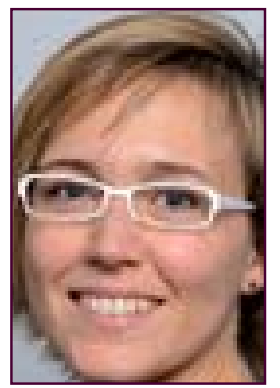

\section{Fva Rimbau-Gilabert erimbau@uoc.edu Profesora de los Estudios de Economía y Empresa (UOC)}

Doctora en Administración y Dirección de Empresas por la Universidad de Barcelona. Es profesora de la UOC desde el año 2004, donde enseña en los ámbitos de la dirección de personas, la gestión del cambio y la responsabilidad social corporativa. Desde 2014, además, es miembro de la Comisión Académica del Programa de Doctorado en Información y Sociedad del Conocimiento. Anteriormente, ejerció como directora académica de diversos programas: la Licenciatura en Ciencias del Trabajo, el Máster en Prevención de Riesgos Laborales y el Área de Posgrado de los Estudios de Economía y Empresa.

En cuanto a la investigación, sus líneas de interés son las siguientes: organización flexible del trabajo, específicamente el teletrabajo y los contratos contingentes; las relaciones entre la digitalización, la dirección de personas y el bienestar de los empleados; el comportamiento organizacional y el aprendizaje en línea, en particular, el aprendizaje en línea de competencias interpersonales, los equipos virtuales en la educación en línea, y el liderazgo y el bienestar de los empleados en las universidades en línea.

Eva es miembro del Digital Business Research Group (DigiBiz), que ha sido reconocido como Grupo de Investigación Consolidado de la Generalitat de Cataluña. Difunde su investigación en revistas indexadas, congresos internacionales y capítulos de libro de editoriales de prestigio. Ha participado en proyectos de investigación tanto de ámbito local como nacional e internacional, y actúa regularmente como revisora externa para revistas internacionales en sus áreas de especialización. Está acreditada como profesora lectora de la Agencia de Calidad Universitaria catalana (AQU).

Los textos publicados en esta revista están sujetas -salvo que se indique el contrario- a una licencia de Reconocimiento 3.0 España de Creative Commons. Podéis copiarlos, distribuirlos, comunicarlos públicamente y hacer obras derivadas siempre que reconozcáis los créditos de las obras (autoría, nombre de la revista, institución editora) de la manera especificada por los autores o por la revista. La licencia completa se puede consultar en http://creativecommons.org/licenses/by/3.0/es/deed.ca.

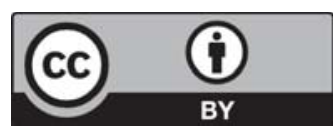




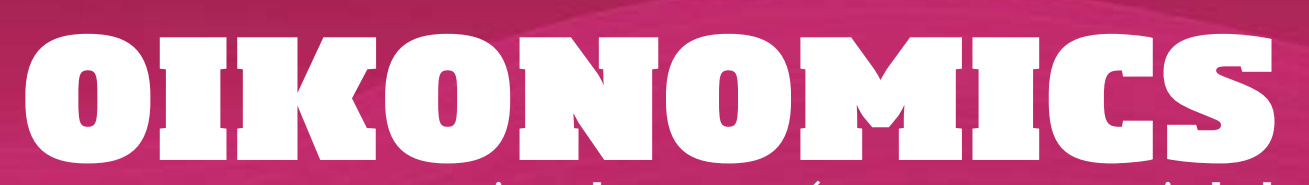

Revista de economía, empresa y sociedad

ESTRATEGIAS PARA REDUCIR LA DESIGUALDAD

\section{Flexiseguridad o del paradigma del welfare al workfare en el actual contexto poscrisis español}

\section{Purificación Baldoví}

Profesora colaboradora de los Estudios de Economía y Empresa (UOC) Vocal independiente experta en innovación (CES, Comunidad Valenciana)

RESUMEN Actualmente, la economía española es más productiva y, sin embargo, no ha recuperado las tasas de empleo antes de la crisis, por lo que el principal reto es reducir el desempleo y el empleo temporal, crear empleos de calidad, estables y productivos, que ayuden a reducir la desigualdad y reanudar el camino de convergencia con las economías más avanzadas. El modelo de flexiseguridad define como una estrategia de modernización del mercado de trabajo a través de dos vías convergentes: flexibilidad (tanto empresarial como laboral, para responder a las necesidades de ambos) y seguridad (para los trabajadores, que deben poder desarrollar su carrera, sus habilidades y recibir apoyo de los sistemas de seguridad social durante períodos de inactividad). Sin embargo, este modelo de flexiguridad danesa no puede aplicarse directamente a cada Estado miembro o región de la Unión Europea, sino adaptarse a cada contexto con una combinación adecuada de instrumentos que respondan, en nuestra región, al debate entre diferentes sensibilidades sociales y políticas. Se busca la especialización flexible y no la flexibilidad precarizante.

PALABRAS CLAVE seguridad; flexibilidad; flexiseguridad; VUCA; economía colaborativa; digitalización; productividad; sostenibilidad; glocal 


\title{
Flexicurity or the paradigm of welfare to workfare in the current Spanish post-recession period
}

\begin{abstract}
The Spanish economy is more productive but employment rates have not returned to levels prior to the recession. Therefore, the main challenge is reducing unemployment and temporary employment, creating quality, stable and productive jobs that help reduce inequality, as well as resuming the path of convergence with more advanced economies. The model of flexicurity is defined as a strategy to modernize the labour market through two paths that converge: flexibility (for both business and workers, to respond to the needs of both) and safety (for workers who must be able to develop their careers, expand their skills and receive support from social security systems during periods of inactivity). However, this model of Danish flexicurity cannot be implemented directly to each Member State or region of the European Union, but rather it must be adapted to each context with an adequate combination of instruments that respond in our region to the debate between different social and political sensitivities. The goal is not increasing precariousness through flexibility, but rather flexible specialization.
\end{abstract}

KEYWORDS security; flexibility; flexicurity; VUCA; collaborative economy; digitalization; productivity; sustainability; glocal

\section{Introducción}

En un contexto VUCA (acrónimo que significa volatilidad, incertidumbre, complejidad y ambigüedad), las transformaciones que está experimentando el mundo del trabajo son estructurales y afectan al núcleo de las condiciones de producción y reproducción de la sociedad, definiendo nuevos horizontes para el empleo, y para todas las instituciones sociales principales: familia, escuela y gobierno.

En el contexto actual de España, tras destruir un 17,1 \% de la afiliación a la Seguridad Social (desde julio de 2007 a febrero de 2013), se ha recuperado ya el 68,3 \% del empleo destruido (junio 2017), es decir, que desde 2013 se ha producido un intenso proceso de creación de empleo, aunque la temporalidad sigue siendo elevada.

En definitiva, la economía española es más productiva pero no ha recuperado las tasas de empleo anteriores a la crisis por lo que el principal reto es reducir la tasa de paro y la temporalidad, creando empleo de calidad, estable y productivo, 
que ayude a reducir la desigualdad y a retomar la senda de convergencia con las economías más avanzadas.

Los interrogantes abiertos en esta nueva época están relacionados ahora con el ascenso de la «economía» colaborativa, el impacto de la digitalización en el trabajo y el tipo de demografía empresarial:

- En la llamada «economía colaborativa», existen nuevas vías de coordinación y de inclusión económica y financiera, y han emergido en sectores tradicionales como el alojamiento y el transporte (Airbnb, BlaBlaCar...).

- La digitalización supone una transformación disruptiva que genera un paradigma económico y laboral que aún no sabemos gestionar eficientemente. La digitalización transforma los puestos de trabajo, potencia la externalización y las deslocalizaciones (tareas, procesos y empresas), e incrementa la polarización y la exclusión de trabajadores con falta de competencias para abordar este nuevo escenario laboral, en el que las principales esferas del cambio tecnológico son la robotización, las máquinas inteligentes, el Big Data, la nube, la geolocalización, las plataformas digitales y el internet de las cosas.

- Por todo lo anterior, la demografía empresarial en el sector TIC aumenta, se consolida proyecta la aparición de nuevos productos y servicios, y provoca la mutación de las formas de organizar el trabajo y la producción.

Las cuestiones que subyacen en la reflexión sobre el mercado de trabajo actual giran en torno a sobre si está cambiando el concepto de «empleo», ya que las transformaciones anteriormente citadas suscitan interrogantes:

- ¿Se mantiene el concepto de empresario/a?

- ¿Está cambiando el tiempo de trabajo? ¿Hay un incremento del porcentaje de freelance/autoempleo o del multiempleo (empleos/tareas)?

- ¿Hay más autonomía, menos jerarquía en las organizaciones? ¿Es diferente la mentalidad de los jóvenes (millennials)?

- ¿Son escasos los datos de trabajadores en la economía colaborativa (1 \%)?

- ¿Es la medición de la productividad mucho más sofisticada (privacidad)?

- ¿Continúa la externalización (outsourcing/offshoring) pero también la tendencia inversa?

- ¿Existe una competición global del talento?

- ¿Hay nuevas maneras de formarse, más informal, más a medida (MOOC)? 
Figura 1. Nuevo paradigma del mercado de trabajo

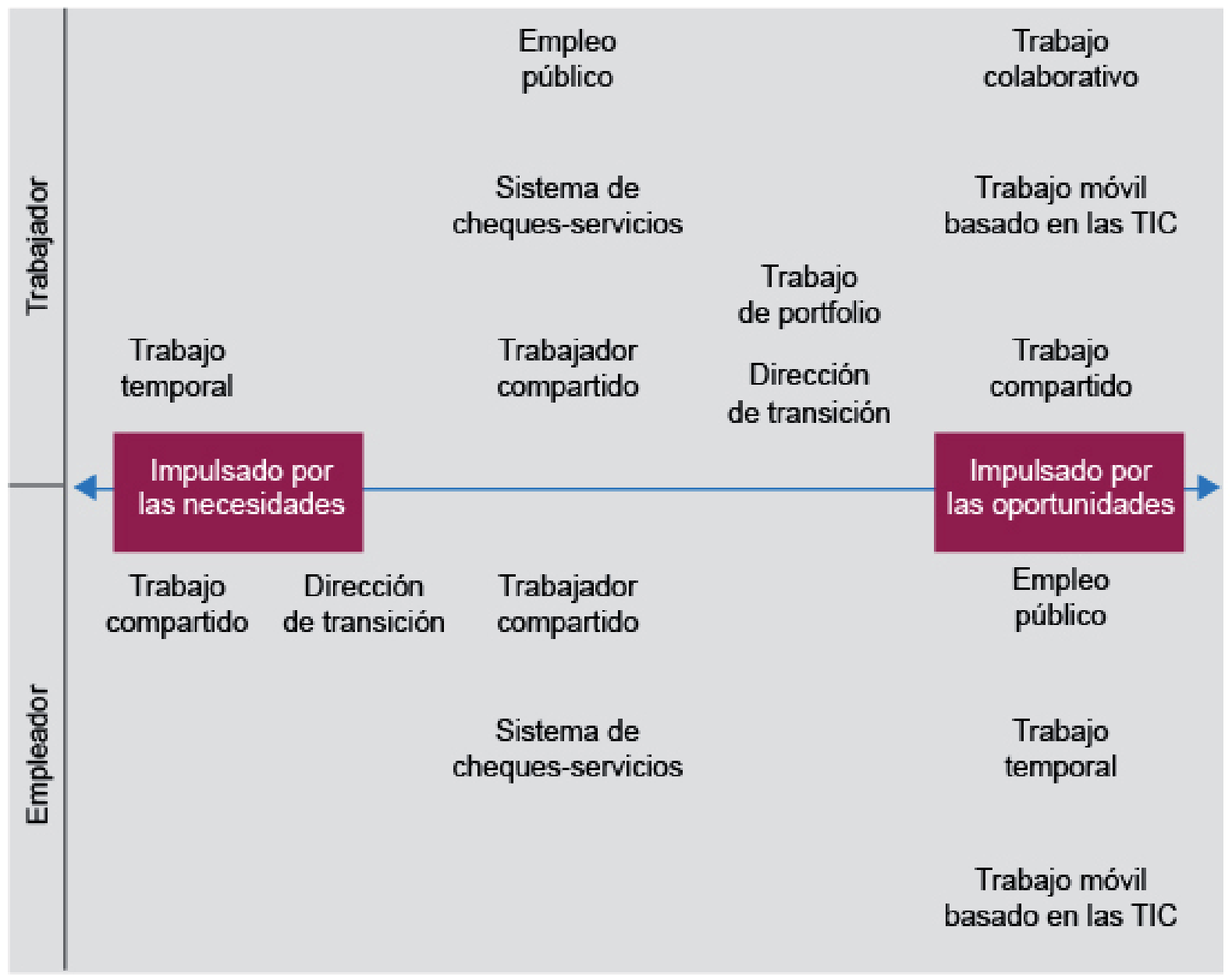

La respuesta al entorno es la de la flexiseguridad del mercado laboral, concepto que hace referencia al incremento de la flexibilidad (obtenido mediante facilidades en la contratación y en el despido) y un nivel alto de protección social (seguridad) a través de generosas prestaciones por desempleo, sujetas a la búsqueda proactiva de empleo y de formación continua.

\section{El modelo de flexiseguridad}

El modelo se define como una estrategia para modernizar el mercado laboral mediante dos vías que confluyen:

1. La flexibilidad, tanto empresarial como de los trabajadores, para responder a las necesidades de ambos. 
2. La seguridad para los trabajadores, que deben poder desarrollar sus carreras profesionales, ampliar sus competencias y recibir apoyo de los sistemas de seguridad social durante los períodos de inactividad.

La génesis de este modelo está asociada al modelo danés, que lo operativizó con éxito al combinar elevados subsidios por desempleo con bajos niveles de protección al despido, y suavizó así el desencuentro de la flexibilidad y la seguridad mediante un entorno suficientemente seguro con herramientas de protección y la compensación de la flexibilidad de los despidos con la seguridad de los trabajadores, que de este modo no entran en una espiral de paro y desfase formativo.

El énfasis en la protección o seguridad (con sus valores asociados: solidaridad, responsabilidad colectiva, derechos...) o en la activación o flexibilidad (o lo que es lo mismo: competencia, responsabilidad individual, exigencias...) pretenden confluir en una línea de encuentro entre las dos formas de entender la política laboral.

Sin embargo, este modelo de flexiseguridad danesa no puede ser implementado directamente en cada Estado miembro o región de la Unión Europea, sino que se ha de adaptar a cada contexto, con una adecuada combinación de instrumentos que den respuesta, en nuestra región, al debate entre distintas sensibilidades sociales y políticas.

No se busca la flexibilidad precarizadora, sino la especialización flexible.

\section{El equilibrio de intereses entre empresas y trabajadores}

El equilibrio de intereses entre empresas y trabajadores puede ser determinado mediante el diálogo social y las negociaciones con el Gobierno, de modo que existan garantías de seguridad para que trabajadores y empleadores inviertan en mejoras de la productividad (muy necesarias, especialmente en España) y la flexibilidad les permita adaptarse a la evolución del mercado y de la tecnología.

Esta transformación en la norma social de empleo ha de tender hacia la «flexibilidad sostenible» (Carnoy y Castells, 1997), de modo que se evite la «surafricanización» (Gorz, 1995) o de la «sudización del Norte» (Gallino, 2002) para que las características del llamado Tercer Mundo (trabajo precario, discontinuo e informal) no irrumpan en nuestra sociedad. 
Figura 2. Modelos de economía y sociedades capitalistas

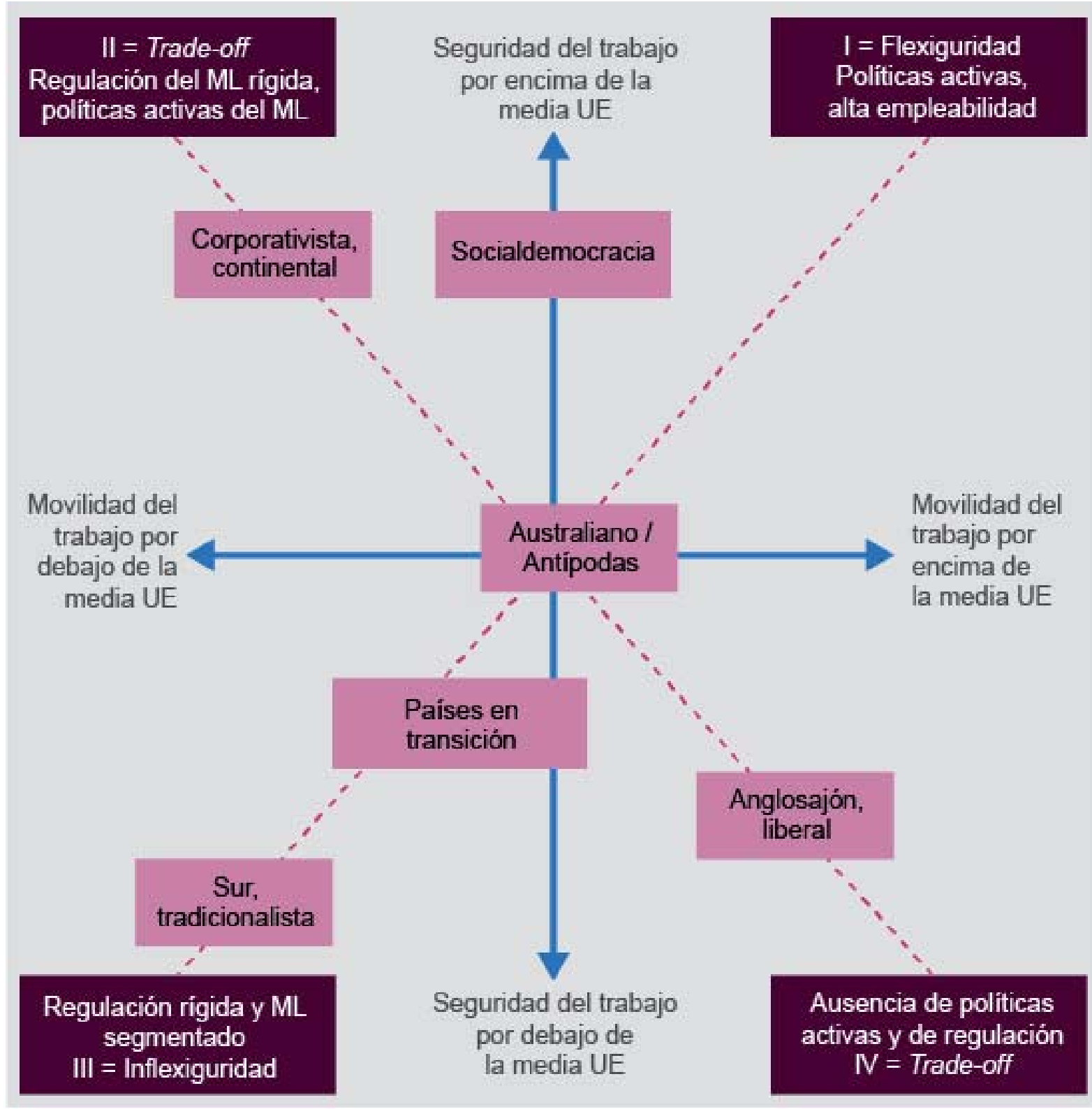

Fuente: Muffels y Wilthagen (2016).

Nota: Según Bruno Amable (2005), hay cinco capitalismos, cinco modelos de economías y de sociedades capitalistas: el modelo liberal (Australia, Canadá, Estados Unidos, Reino Unido), el modelo europeo continental (Alemania, Austria, Bélgica, Francia, Países Bajos, Irlanda, Noruega, Suiza), el modelo asiático (Corea del Sur, Japón), el modelo mediterráneo (España, Grecia, Italia, Portugal) y el modelo socialdemócrata (Dinamarca, Finlandia, Suecia). 


\section{Contexto español: baja productividad}

La baja productividad es un obstáculo para el crecimiento económico en nuestro país, lo cual es un freno para el desarrollo económico.

Según Emilio Ontiveros (2015), catedrático de Economía de la Empresa de la Universidad Autónoma de Madrid y fundador y presidente de Analistas Financieros Internacionales, las razones de la menor productividad española son:

1. La producción está concentrada mayormente en sectores manufactureros tradicionales.

2. Inferior crecimiento de la participación en la economía de las empresas del sector servicios en los que aumenta la productividad.

3. Menor contribución de las industrias productoras de TIC y de las empresas usuarias de las mismas al conjunto de la economía.

4. Reducidos incentivos empresariales para la asunción de riesgos.

5. Escasa complicidad del sistema educativo con la capacidad para emprender.

6. Reducida (o insuficiente) inversión en I+D.

\section{Orientaciones para avanzar en las soluciones}

Es imprescindible que la sociedad (sector publico, empresas y trabajadores) se prepare y gobierne el cambio de manera activa, con un amplio conjunto de políticas que garanticen la igualdad de oportunidades, potencien a largo plazo los efectos positivos de un progreso técnico y digital inclusivo, que ponga al alcance de todos las oportunidades de esta nueva era y reduzcan los costes de la transición a corto y medio plazo. Los principales retos de la economía española son:

- Facilitar un mercado de trabajo más eficiente y equitativo, con un crecimiento económico más inclusivo para reducir la desigualdad.

- Generar una mayor calidad institucional y apostar por la sostenibilidad y la eficiencia del sector público.

- Incentivar el aumento del tamaño de las empresas y potenciar una mayor internacionalización y competitividad.

- Promover la innovación, la adquisición y uso del capital tecnológico que promueva el incremento de la productividad y la competitividad de nuestra economía. 
En definitiva, eficiencia, equidad, sostenibilidad y competitividad global para mantener un sistema flexible ante las necesidades de un contexto "glocal» y VUCA, y justo para promover el estado del bienestar.

Algunas de las propuestas que pretenden dar respuesta al contexto actual podrían ser:

- Garantizar una renta mínima universal.

- Ordenar y regular las actividades en la economía colaborativa.

- Fiscalizar sobre las máquinas.

- Anticipar necesidades concretas de cualificaciones, por país, sector, región, e identificar los casos en los que una cooperación entre el sector educativo y el mundo empresarial han generado valor a la sociedad.

- Potenciar la formación a lo largo de la vida.

- Realizar análisis más rigurosos de la evolución y el desarrollo de las nuevas formas de trabajo.

- Ofrecer apoyo público más eficiente en las transiciones de un empleo a otro.

- Recomendar el diálogo social y las relaciones laborales.

- Reforzar el valor de las organizaciones empresariales y sindicales de manera que ofrezcan más servicios a sus afiliados.

- Promover una normativa laboral más predecible en Europa (seguridad jurídica), que contenga nuevos riesgos (responsabilidad de diferentes actores).

- Analizar la aparición de nuevas formas de agrupación colectiva y promover la defensa de los derechos de las empresas y las personas consumidoras que participan en estas nuevas formas de oferta y consumo colaborativo.

\section{Conclusiones}

En el último decenio se constata una tendencia generalizada del estado del bienestar (welfare) hacia un modelo caracterizado por ideas como la empleabilidad y la activación del mercado laboral (workfare). Este deslizamiento hacia el paradigma del workfare se acompaña de un cambio profundo en la perspectiva sobre la pobreza, abordada como «pobreza descalificadora» (Paugam, 2007), y también de un reforzamiento del discurso sobre la responsabilidad individual o «internalizada» (Schmidtz y Goodin, 2000).

En cualquier caso, lo que todas estas transformaciones socioeconómicas ponen de manifiesto es un desplazamiento desde el modelo de política social institucional redistributiva hacia un modelo de política social basado en el logro personal / resultado laboral, que apunta a un modelo residual de política social del bienestar. En este sentido, depende de los actores económicos que la transición de un mo- 
delo a otro, en un marco de adaptación a la complejidad del entorno, se realice de modo sostenible, justo e inclusivo.

\section{Referencias bibliográficas}

CARNOY, M.; CASTELLS, M. (1997). Sustainable flexibility: A prospective study on work, family and society in the information age. París: OECD.

DOMÉNECH, R. (2007). «Perspectivas macroeconómicas y retos del mercado de trabajo». Universidad Internacional Menéndez Pelayo (UIMP). Santander, 10 de julio.

EUROFOUND (2015). «New forms of employment». Luxemburgo: Publications Office of the European Union.

GALLINO, L. (2002). «La informalización del trabajo en los países desarrollados: cómo y por qué las condiciones de trabajo en el Norte se están aproximando a las del Sur». Sociología del Trabajo. N. ${ }^{\circ} 45$, págs. 7-24.

GORZ, A. (1995). Metamorfosis del trabajo. Crítica de la razón económica. Madrid: Sistema.

GUTIÉRREZ, R. (2017). «Viejas y nuevas ocupaciones». Encuentro CES «El futuro del trabajo». Universidad Complutense de Madrid, 17 de julio.

MUFFELS, T. J. A.; WILTHAGEN, T. (2006). "Conceptualization and Measurement of Flexicutiry in a Comparative Perspective». Seminar Flexicurity Network. Copenhague, 9 de junio.

OBSERVATORIO ADEI. «Notas técnicas». <http://observatorioadei.es/>

ONTIVEROS, I. (2015). «Digitalitzación industrial en España». El País Negocios, 20 de diciembre.

PAUGAM, S. (2007). Le salarié de la précarité: Les nouvelles formis de l'intégration professionnelle. Préface inédite de l'auteur. París: Presses universitaires de France.

SCHMIDTZ, D.; GOODIN, R. I. (2000). El bienestar social y la responsabilidad individual. Madrid: Ediciones Akal.

SUÁREZ, R. (2017). «Entendiendo el futuro del trabajo». Encuentro CES «El futuro del trabajo». Universidad Complutense de Madrid, 17 de julio. 


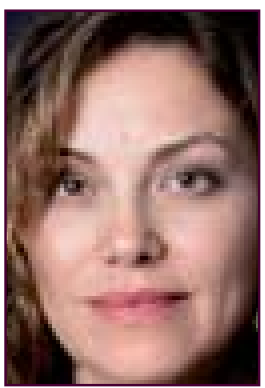

\section{Purificación Baldoví} baldoviborraspurificacion@gmail.com Profesora colaboradora de los Estudios de Economía y Empresa (UOC)

Economista por la Universidad de Valencia, licenciada en Ciencias del Trabajo por la UOC y máster en Recurso Humanos (ESIC), Innovación (UV) y Consejos de Dirección (UEV). Doctoranda en Innovación (UV). Vocal del Comité Económico y Social de la Comunidad Valenciana. En la actualidad, imparte talleres y ejerce como consultora en procesos de innovación empresariales, educativos y asociativos relacionados con el liderazgo, la negociación, la motivación y la gestión del equipo. Es también autora de contenidos docentes y profesora colaboradora de la UOC. En los últimos diez años ha sido la gerente de la Asociación Valenciana de Empresas Innovadoras en la Universidad Politécnica de Valencia y de la Fundación Globalis, dedicada a la innovación social dentro del contexto de la red nacional Innpulso.

Los textos publicados en esta revista están sujetas -salvo que se indique el contrario- a una licencia de Reconocimiento 3.0 España de Creative Commons. Podéis copiarlos, distribuirlos, comunicarlos públicamente y hacer obras derivadas siempre que reconozcáis los créditos de las obras (autoría, nombre de la revista, institución editora) de la manera especificada por los autores o por la revista. La licencia completa se puede consultar en http://creativecommons.org/licenses/by/3.0/es/deed.ca.

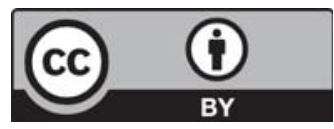




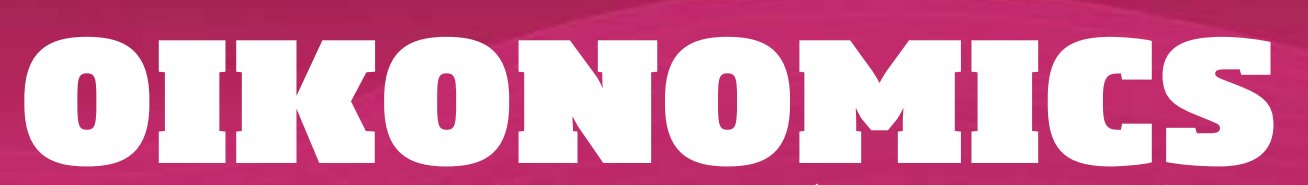

Revista de economía, empresa y sociedad

ANÁLISIS DE LOS DIFERENTES MODELOS

\section{¿Hay empresas saludables? Tres maneras de responder a esta pregunta}

\section{Helena Thomas Gurrás}

Profesora de Psicología Social (URJC). Profesora colaboradora de la UOC

RESUMEN La salud laboral es una cuestión importante en la vida de las personas. Tener empresas saludables que contribuyan a mantener y mejorar la salud de sus trabajadores y de su entorno tiene además efectos directos sobre el rendimiento, la productividad y los beneficios de las organizaciones. Se analizan los efectos de la puesta en práctica de diferentes programas de empresas saludables en los trabajadores. Se presentan tres modelos diferentes y complementarios para que los responsables de las personas en las organizaciones puedan elegir cuál es el modelo que más útil les puede ser para sus intereses. Los modelos son el propuesto por la ENWHP, creado bajo el auspicio de la Unión Europea; el modelo de empresas saludables propuesto por AENOR, que permite obtener un certificado de empresa saludable, y el modelo creado por el equipo WONT, de la Universitat Jaume I, con un claro enfoque psicosocial. Cumplir con las especificaciones de alguno de estos modelos permitirá dar una respuesta afirmativa a la pregunta planteada.

PALABRAS CLAVE organización saludable; prevención de riesgos laborales; riesgos psicosociales; salud laboral; vigilancia de la salud laboral 


\title{
Are organizations healthy? Three ways to answer this question
}

\begin{abstract}
Occupational health is an important issue in people's lives. Having healthy companies that contribute to maintaining and improving the health of their workers and their environment also has direct effects on the performance, productivity and benefits of organizations. The effects on workers of the implementation of different healthy company programmes are analysed. Three different and complementary models are presented so that professionals responsible for people in organizations can choose which model best suits their needs. The models of healthy companies are proposed by the ENWHP, created with the support of the European Union, by AENOR, through which a Healthy Company certificate can be obtained, and by the WONT team at the Universitat Jaume I, which has a clear psychosocial focus. Fulfilling the specifications of any of these models will allow an affirmative answer to the question posed.
\end{abstract}

KEYWORDS healthy organization; occupational health; occupational health surveillance; prevention of occupational hazards; psychosocial risks.

\section{Introducción}

La salud, y por tanto la calidad de vida, es actualmente una de las mayores preocupaciones de las personas. Es lógico que, dado que las personas adultas pueden pasar más de un tercio del día en el entorno laboral, este sea también uno de los aspectos por los que más se interesan los trabajadores y las empresas. Desde mediados del siglo pasado, se viene investigando y trabajando para crear empresas saludables, es decir, lugares donde no se ponga en riesgo la salud de las personas. Chris Argyris (1958) ya definió en su momento las organizaciones saludables como aquellas que permiten un óptimo funcionamiento humano.

Sin embargo, no se han conseguido alcanzar estos objetivos y, tanto a nivel particular -desde el ámbito privado- como desde el sector público, se sigue tratando de potenciar la implantación de estas organizaciones para que contribuyan al bienestar de las personas, al mantenimiento de su salud, y no solo en su aspecto laboral, sino que pueda servir también como apoyo a otras medidas de prevención y tratamiento de enfermedades. En este sentido, el Plan global de acción sobre la salud de los trabajadores (GPA, por sus siglas en inglés) para el período 2008-2017 
fue aprobado en mayo de 2007 por la Asamblea Mundial de la Salud de la OMS para incentivar que los países promovieran nuevas estrategias de actuación.

Por lo tanto, se busca lograr que se obtenga una adaptación fiel a la definición de salud de la OMS: es un estado de completo bienestar físico, mental y social, y no solamente la ausencia de afecciones o enfermedades (Organización Mundial de la Salud, 1946). Esta definición se recoge en el preámbulo de su Constitución y se mantiene vigente desde entonces.

Posteriormente, la OMS, junto con la Organización Internacional del Trabajo $(\mathrm{OIT})$, definió qué es un entorno de trabajo saludable y lo identificó como aquel en el que «los trabajadores y jefes colaboran en un proceso de mejora continua para promover y proteger la salud, la seguridad y el bienestar de los trabajadores, y la sostenibilidad del ambiente de trabajo en función de los siguientes indicadores (Burton, 2010, pág.4):

- «la salud y la seguridad que afectan al ambiente físico de trabajo;

- la salud, la seguridad y el bienestar concernientes a las relaciones psicosociales en el trabajo, que incluyen la organización del mismo y el espacio de trabajo, así como la cultura organizacional;

- los recursos de salud personales en el ambiente de trabajo, y

- las formas en que la comunidad busca mejorar la salud de los trabajadores, sus familias y de otros miembros de la comunidad».

Figura 1. Áreas de influencia de los programas de salud en el trabajo (OMS)

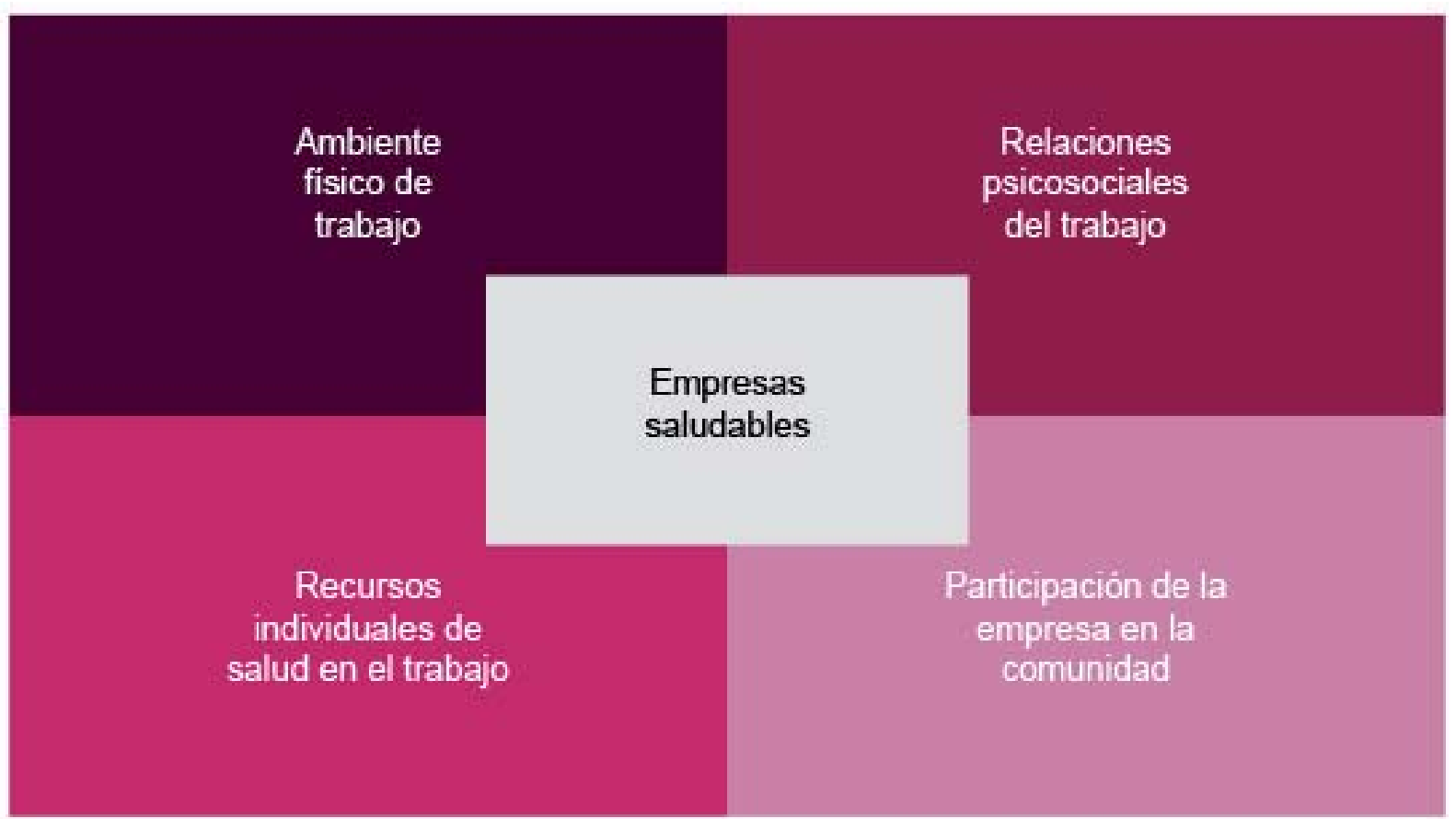


Tres elementos importantes destacan en esta definición:

1. En la definición de salud laboral del empleado se asume la definición de salud física, mental y social de la OMS.

2. En un sentido amplio, un entorno de trabajo saludable es sinónimo de una organización próspera, en su funcionamiento y en la consecución de sus objetivos. Así, la salud del empleado y la de la empresa están estrechamente vinculadas.

3. Un entorno de trabajo saludable debe incluir la protección y promoción de la salud.

\section{1. Áreas y programas de intervención en las empresas saludables}

La psicología de la salud ocupacional se ha destacado como una especialización de la psicología del trabajo y de las organizaciones que busca crear ambientes de trabajo seguros y saludables, y que promueve, a su vez, la creación de empresas, equipos y personas saludables (Acosta, Cruz-Ortiz, Salanova y Llorens, 2015). Tres líneas de acción se consideran claves para lograr que las organizaciones sean seguras y saludables, y logren además un apoyo para que las personas trabajadoras cuiden su salud. La primera es la prevención de riesgos laborales, que no olvidemos que es una obligación empresarial proteger a los trabajadores de los daños derivados de las condiciones de trabajo. La segunda, la cultura de la organización con sus valores compartidos y la forma de interactuar las personas entre sí, tanto en la organización como fuera de ella. Y por último, las acciones voluntarias por parte de la empresa para crear no solo entornos seguros y exentos de riesgos de origen laboral, sino entornos que permitan y apoyen elecciones saludables y que aporten valor a la sociedad. Los diferentes programas sobre los que se ha trabajado para lograr empresas saludables se muestran en la tabla 1. Estas acciones tienen que ser voluntarias para los trabajadores, que no pueden ser obligados si no están interesados en ello. 
Tabla 1. Ámbitos de intervención

\begin{tabular}{|c|c|c|}
\hline Actuación sobre & $\begin{array}{c}\text { Programas de las } \\
\text { empresas }\end{array}$ & $\begin{array}{c}\text { Beneficios para el } \\
\text { trabajador }\end{array}$ \\
\hline $\begin{array}{l}\text { Organización del } \\
\text { trabajo }\end{array}$ & $\begin{array}{l}\text { Crear las estructuras, proce- } \\
\text { sos y cultura necesarios para } \\
\text { promocionar la salud en el } \\
\text { trabajo. }\end{array}$ & $\begin{array}{l}\text { Prevenir el estrés, la ansie- } \\
\text { dad. }\end{array}$ \\
\hline Descanso en el trabajo & $\begin{array}{l}\text { Establecer pausas de } \\
\text { descanso en el trabajo para } \\
\text { la recuperación de la fatiga } \\
\text { física y mental. }\end{array}$ & $\begin{array}{l}\text { Incrementar el rendimiento, } \\
\text { evitar trastornos músculo- } \\
\text { esqueléticos, oculares o } \\
\text { fatiga mental, entre otros. }\end{array}$ \\
\hline $\begin{array}{l}\text { Conciliación de la vida } \\
\text { laboral }\end{array}$ & $\begin{array}{l}\text { Facilitar la conciliación de la } \\
\text { vida personal y profesional, } \\
\text { mantener el equilibrio entre } \\
\text { las necesidades de la em- } \\
\text { presa y de la plantilla. }\end{array}$ & $\begin{array}{l}\text { Satisfacer las necesidades } \\
\text { de desarrollo personal y } \\
\text { laboral. }\end{array}$ \\
\hline $\begin{array}{l}\text { Vuelta al trabajo (Return } \\
\text { to work) }\end{array}$ & $\begin{array}{l}\text { Realizar intervenciones que } \\
\text { permitan facilitar el regreso } \\
\text { al trabajo tras un accidente o } \\
\text { una enfermedad, adaptar el } \\
\text { puesto de trabajo o facilitar } \\
\text { el cambio a otro. }\end{array}$ & $\begin{array}{l}\text { Prepararse para la incor- } \\
\text { poración o readaptación al } \\
\text { puesto de trabajo y evitar su } \\
\text { estigmatización. Aprender } \\
\text { nuevos métodos de trabajo } \\
\text { con equipos y herramientas. }\end{array}$ \\
\hline Salud mental & $\begin{array}{l}\text { Fortalecer los factores pro- } \\
\text { tectores y disminuir los de } \\
\text { riesgo para la salud mental } \\
\text { en la organización. }\end{array}$ & $\begin{array}{l}\text { Mejorar la salud mental y } \\
\text { evitar la aparición de tras- } \\
\text { tornos relacionados por los } \\
\text { riesgos psicosociales: estrés, } \\
\text { burnout, acoso o violencia. }\end{array}$ \\
\hline Alimentación saludable & $\begin{array}{l}\text { Promover hábitos para una } \\
\text { dieta saludable a través de la } \\
\text { elaboración de menús sanos } \\
\text { con productos naturales y } \\
\text { sin azúcar, grasas y bajos en } \\
\text { sodio. }\end{array}$ & $\begin{array}{l}\text { Aprender a alimentarse } \\
\text { según el tipo de trabajo o } \\
\text { esfuerzo requerido. Evitar la } \\
\text { obesidad o la malnutrición. }\end{array}$ \\
\hline Actividad física & $\begin{array}{l}\text { Facilitar lugares para la } \\
\text { práctica del ejercicio físico: } \\
\text { gimnasios, salas especiales, } \\
\text { actividades al aire libre. Se } \\
\text { recomienda una actividad } \\
\text { aeróbica de } 30 \text { a } 60 \text { minutos } \\
\text { diarios. }\end{array}$ & $\begin{array}{l}\text { Corregir los efectos del } \\
\text { sedentarismo en enferme- } \\
\text { dades crónicas, como las } \\
\text { cardiovasculares, respirato- } \\
\text { rias, diabetes u obesidad, } \\
\text { entre otras. }\end{array}$ \\
\hline
\end{tabular}




\begin{tabular}{|c|c|c|}
\hline Actuación sobre & $\begin{array}{l}\text { Programas de las } \\
\text { empresas }\end{array}$ & $\begin{array}{l}\text { Beneficios para el } \\
\text { trabajador }\end{array}$ \\
\hline Hábitos de sueño & $\begin{array}{l}\text { Estimular los programas de } \\
\text { recuperación del sueño y } \\
\text { descanso diario. }\end{array}$ & $\begin{array}{l}\text { Recuperar el sueño como } \\
\text { una actividad reparadora y } \\
\text { necesaria, con los ritmos y } \\
\text { horas adecuados. }\end{array}$ \\
\hline Embarazo y lactancia & $\begin{array}{l}\text { Apoyar la educación para la } \\
\text { salud y la creación de entor- } \\
\text { nos que eviten los riesgos } \\
\text { y ayuden a la mujer a hacer } \\
\text { frente a las posibles mo- } \\
\text { lestias que surgen durante } \\
\text { las diferentes etapas de su } \\
\text { maternidad. }\end{array}$ & $\begin{array}{l}\text { Adaptarse a los numerosos } \\
\text { cambios físicos, psicológicos } \\
\text { y sociales producidos por el } \\
\text { embarazo. }\end{array}$ \\
\hline Envejecimiento & $\begin{array}{l}\text { Adaptar los puestos y traba- } \\
\text { jos a las competencias, ne- } \\
\text { cesidades y características } \\
\text { de las personas mayores. }\end{array}$ & $\begin{array}{l}\text { Reforzar su compromiso } \\
\text { con la empresa y favorecer } \\
\text { una actitud positiva hacia el } \\
\text { mantenimiento del trabajo, } \\
\text { con una mejor salud, calidad } \\
\text { de vida y satisfacción en el } \\
\text { trabajo. }\end{array}$ \\
\hline $\begin{array}{l}\text { Tabaco, alcohol y otras } \\
\text { drogas }\end{array}$ & $\begin{array}{l}\text { Prevenir del consumo de } \\
\text { drogas en el ámbito laboral. }\end{array}$ & $\begin{array}{l}\text { Disminuir los riesgos de } \\
\text { enfermedades oncológicas y } \\
\text { cardiovasculares. }\end{array}$ \\
\hline Enfermedades crónicas & $\begin{array}{l}\text { Atender, facilitar y proporcio- } \\
\text { nar el acceso a los trata- } \\
\text { mientos de enfermedades } \\
\text { crónicas, que pueden evitar } \\
\text { el } 25 \% \text { de los accidentes } \\
\text { mortales de trabajo. }\end{array}$ & $\begin{array}{l}\text { Procurar la adherencia a los } \\
\text { tratamientos de las enferme- } \\
\text { dades crónicas. }\end{array}$ \\
\hline $\begin{array}{l}\text { Responsabilidad } \\
\text { social empresarial }\end{array}$ & $\begin{array}{l}\text { Promover acciones que } \\
\text { beneficien a la comunidad } \\
\text { en la que está instalada la } \\
\text { empresa. }\end{array}$ & $\begin{array}{l}\text { Incrementar el compromiso } \\
\text { y la satisfacción con la } \\
\text { empresa. }\end{array}$ \\
\hline
\end{tabular}

Fuente: elaboración propia a partir de Gil-Monte (2012); Jiménez (2014); Otero Dorrego y Gálvez Herrer (2014); Sirgo Granda (2016) y el Portal de Promoción de la Salud en el Trabajo.

A estas iniciativas pueden añadirse otras que sean de interés mutuo entre la empresa y los trabajadores, como por ejemplo, la práctica del mindfulness o yoga, deportes ligeros, etc. La aplicación de un conjunto de ellos será lo que confiera la 
calificación de empresa más saludable. Estos programas tienen que integrarse de forma permanente en la organización, en sus estrategias y en sus políticas, lo que exige el compromiso por ambas partes.

Se ha encontrado que promover y proteger la salud de los trabajadores crea algunas de las empresas más competitivas a largo plazo, con menores tasas de absentismo, mayor productividad y mayores índices de retención/atracción de empleados. El bienestar de los trabajadores está relacionado con su satisfacción.

\section{Modelos de empresas saludables}

En la actualidad, hay varios modelos que pueden utilizarse para evaluar si la organización es saludable: el modelo creado por The European Network for Workplace Health Promotion (ENWHP), el modelo de la Asociación Española de Normalización y Certificación (AENOR) y el modelo Healthy and Resilient Organizations (HERO). Cada uno de ellos presenta características propias y permitirán a cada organización valorarlos en función de sus intereses.

\subsection{Red Europea de Promoción de la Salud en el Trabajo}

The European Network for Workplace Health Promotion (ENWHP) (Sochert, Siebeneich y De Broeck, 2013) surge como iniciativa de la Comisión Europea y está formada por los institutos nacionales de seguridad y salud en el trabajo de los Estados miembros de la Unión Europea. Estos países firmaron la Declaración de Luxemburgo, en la que proponían «Aunar los esfuerzos de los empresarios, los trabajadores y la sociedad para mejorar la salud y el bienestar de las personas en el lugar de trabajo» (ENWHP, 1997, pág.1). En España, el organismo encargado por el Ministerio de Trabajo es el Instituto Nacional de Seguridad e Higiene en el Trabajo, que ha adaptado las herramientas para la evaluación.

\subsection{Modelo de empresa saludable}

AENOR, junto con Instituto Europeo de Salud y Bienestar Social y la Sociedad de Prevención de Fremap, ha desarrollado este modelo. Está inspirado en el de la OMS y es un modelo de gestión de la organización que pretende que la salud, la seguridad y el bienestar de los trabajadores sean protegidos y promovidos junto con la sostenibilidad del ambiente de trabajo. Para ello, desarrollan una metodología y unas buenas prácticas para las empresas que se centra en cuatro áreas: 
- Ambiente físico (agentes químicos, físicos, biológicos, ergonómicos, etc.).

- Ambiente psicosocial (cultura institucional, estilo de mando y control, conciliación, acoso, etc.).

- Recursos de salud (inactividad física, alimentación inadecuada, consumo de sustancias nocivas, salud mental, envejecimiento, etc.).

- Participación de la empresa en la comunidad (familias de los trabajadores, traslado de los conocimientos a la comunidad, aspectos ambientales, etc.).

Figura 2. Áreas de intervención del modelo AENOR

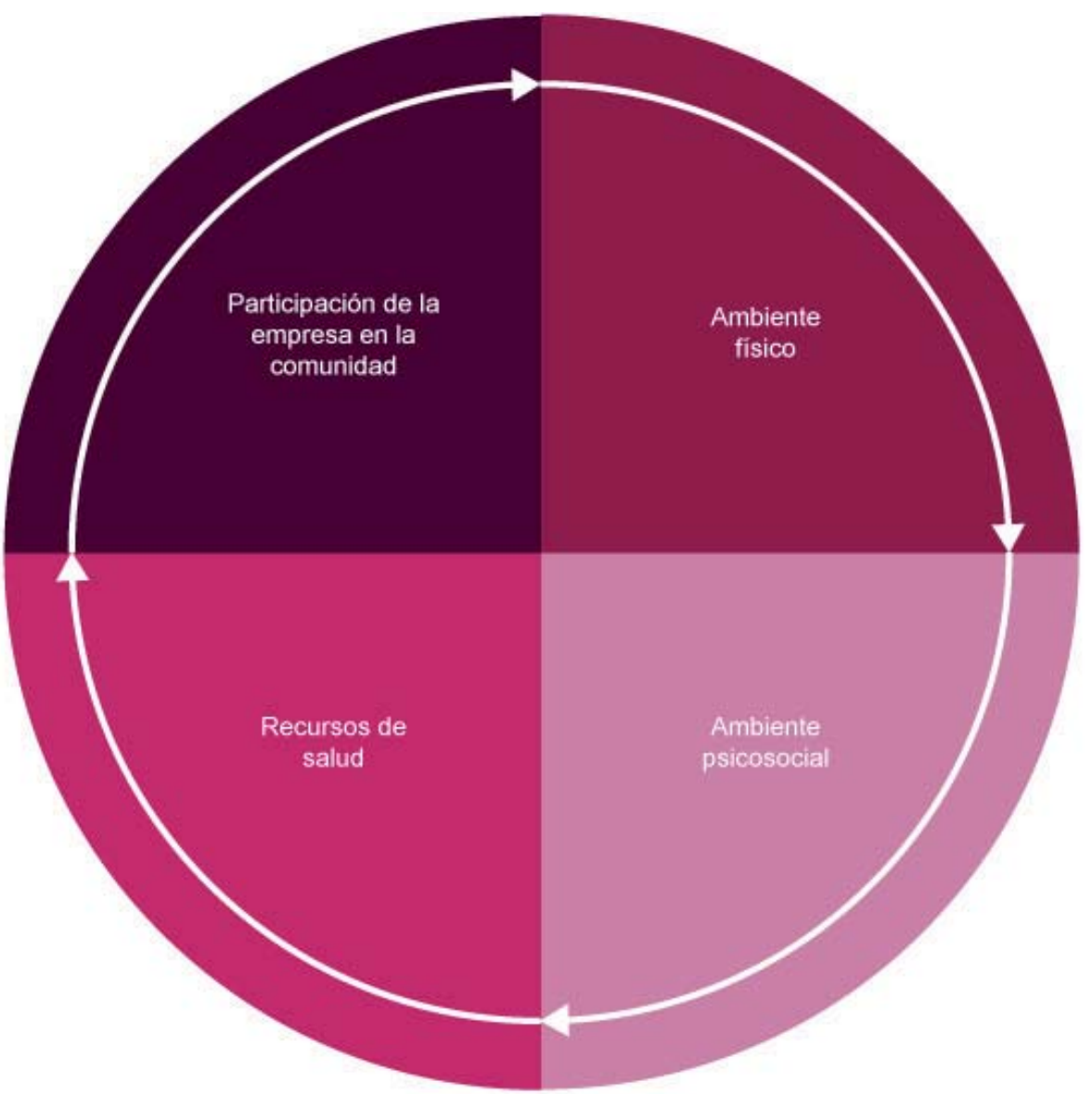

Se pretende identificar y evaluar los factores que influyen en las empresas saludables en cada una de estas áreas para controlarlos. Este modelo busca la aplicación de normas y buenas prácticas que posteriormente serán auditadas por AENOR con el fin de que la empresa consiga el certificado que la acredite como empresa saludable. 


\subsection{Modelo HERO}

Por último, desde una perspectiva psicosocial, el modelo Healthy and Resilient Organization (HERO) (Salanova, Llorens, Cifre y Martínez, 2012) da un paso más al considerar que una organización saludable no solo abarca la salud del trabajador en su ambiente de trabajo, sino que afecta a su comunidad. Este método ha sido investigado y desarrollado por el equipo WONT (Work and Organizational Network) de la Universitat Jaume I de Castellón. Los recursos y prácticas organizacionales en los que la organización invierte se convierten en un elemento fundamental para desarrollar el modelo HERO (Acosta y otros, 2015). El modelo se centra en tres áreas:

- Recursos y prácticas organizacionales saludables, por ejemplo la conciliación personal y profesional, la prevención de riesgos psicosociales o los programas de salud psicosocial.

- Empleados saludables, lo cual abarca campos como la comunicación, el liderazgo, el trabajo en equipo y las relaciones interpersonales. Cumplen la doble función de aumentar el bienestar psicosocial y disminuir el malestar psicosocial.

- Resultados organizacionales saludables, tanto intraorganizacionales para la producción y los resultados como los extraorganizacionales sobre la reputación empresarial.

Figura 3. Áreas de influencia del modelo HERO

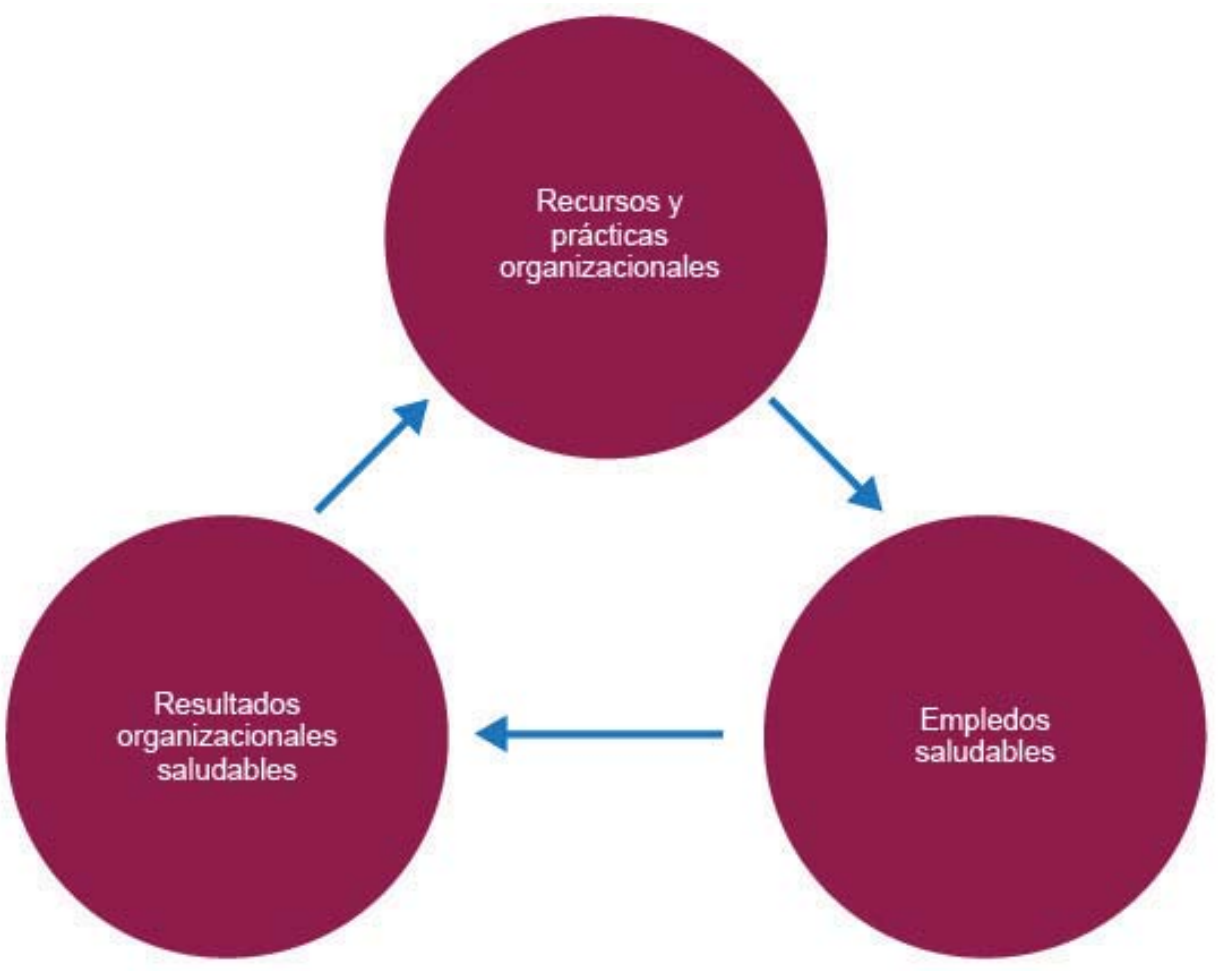


Basándose en este modelo teórico, han desarrollado también una metodología HERO validada científicamente para fomentar organizaciones positivas (Salanova, Llorens y Martínez Martínez, 2016; Salanova, Martínez y Llorens, 2014).

\section{Conclusiones}

Actualmente, se cuenta con instrumentos válidos y probados para poder evaluar si una organización y sus prácticas de gestión de personas se corresponden con una empresa saludable. Aplicados bajo un método Deming de mejora continua (PDCA: planificar, hacer, evaluar y rectificar), estos modelos permiten avanzar a las empresas. Entre las ventajas que supone tener empresas saludables, figuran la disminución de los accidentes, las enfermedades, el absentismo laboral, la rotación de personal, los costes sociales sanitarios y de seguridad social y de seguros, y la reducción de la contaminación. Además, mejora la salud, la motivación y la participación de los trabajadores, el clima laboral, la imagen corporativa (para los trabajadores, para las empresas y para la comunidad donde éestas se ubican), la calidad de vida de los ciudadanos y el medio ambiente. Y también aumenta la productividad empresarial. Lograr empresas saludables es necesario porque invertir en promoción de la salud laboral es lo correcto, supone una decisión inteligente para la empresa y se aplica la ley. Por lo tanto, debería darse una respuesta afirmativa: sí, debe haber empresas saludables.

\section{Referencias bibliográficas}

ACOSTA, H.; CRUZ-ORTIZ, V.; SALANOVA, M.; LLORENS, S. (2015). «Healthy organization: analysing its meaning based on the HERO Model / Organizaciones saludables: analizando su significado desde el Modelo HERO». Revista de Psicología Social [en línea]. Vol. 30, n. ${ }^{0}$ 2, págs. 323-350. <http://dx.doi.org/10 .1080/21711976.2015.1016751>.

ARGYRIS, C. (1958). «The orzanizacion: What makes it healthy?». Harvard Business Review. Vol. 36, n. ${ }^{\circ}$ 6, págs. 107-116.

BURTON, J. (2010). «Entornos laborales saludables: Fundamentos y modelo de la OMS. Contextualización, prácticas y literatura de apoyo. Ginebra (Suiza): Organización Mundial de la Salud» [en línea]. <http://www.who.int/occupational_health/evelyn_hwp_spanish.pdf>

ENWHP (1997). «Declaración de Luxemburgo» [en línea]. <http://www.insht.es/ PromocionSalud/Contenidos/Promocion Salud Trabajo/Documentos ENWHP/ Documentos estrategicos/Ficheros/22_1 Declaracion_ Luxemburgo.pdf $>$ 
GIL-MONTE, P. R. (2012). «Riesgos psicosociales en el trabajo y salud ocupacional». Revista Peruana de Medicina Experimental y Salud Publica. Vol. 29, n. ${ }^{\circ}$, págs. 237-241.

JIMÉNEZ, S. (2014). «Factores psicosociales y salud: de vida laboral a factor de riesgo». Revista Española de Comunicación en Salud. Vol. 5, n. 2, págs. 134148.

ORGANIZACIÓN MUNDIAL DE LA SALUD. (1946). "Constitución de la OMS: Principios» [en línea]. <www.who.int/about/mission/es/>

OTERO DORREGO, C.; GÁLVEZ HERRER, M. (2014). «Plan de retorno al trabajo tras baja laboral por motivos de salud mental». Medicina y Seguridad del Trabajo [en línea]. Vol. 60, n. 235, págs. 392-405. <http://dx.doi.org/10.4321/ S0465-546X2014000200011>

SALANOVA, M.; LLORENS, S.; CIFRE, E.; MARTÍNEZ, I. M. (2012). «We Need a Hero! Toward a Validation of the Healthy and Resilient Organization (HERO) Model». Group \& Organization Management [en línea]. Vol. 37, n. 6, págs. 785822. <http://dx.doi.org/10.1177/1059601112470405>

SALANOVA, M.; LLORENS, S.; MARTÍNEZ MARTíNEZ, I. M. (2016). «Aportaciones desde la psicología organizacional positiva para desarrollar organizaciones saludables y resilientes». Papeles del Psicólogo. Vol. 37, n. 3, págs. 177-184.

SALANOVA, M.; MARTÍNEZ, I. M.; LLORENS, S. (2014). "Una mirada mas "positiva" a la salud ocupacional desde la psicología organizacional positiva en tiempos de crisis: aportaciones desde el equipo de investigación WoNT». Papeles del Psicólogo. Vol. 35, n. ${ }^{0} 1$, págs. 22-30.

SIRGO GRANDA, P. (2016). «Nuevas perspectivas para la salud laboral en un marco público y privado». Medicina y Seguridad del Trabajo. Vol. 62, n. 244, págs. 178-187.

SOCHERT, R.; SIEBENEICH, A.; DE BROECK, V. (2013). «European Network for Workplace Health Promotion» [en línea]. Lovaina (Bélgica). <http://www.enwhp. org/fileadmin/user_upload/pdf/ENWHP-image_brochure-final.pdf> 


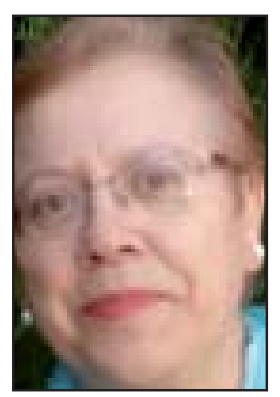

\section{Helena Thomas Gurrás \\ helena.thomas@urjc.es Profesora de Psicología Social}

Doctora en Psicología en el programa de Comportamiento Social y Organizacional. Profesora de grados y masters en la Universidad Rey Juan Carlos de Madrid. Profesora colaboradora de la UOC. Miembro fundador del Grupo de Salud Laboral del Colegio Oficial de Psicólogos de Madrid. Investigadora en el ámbito de la salud laboral.

Los textos publicados en esta revista están sujetas -salvo que se indique el contrario- a una licencia de Reconocimiento 3.0 España de Creative Commons. Podéis copiarlos, distribuirlos, comunicarlos públicamente y hacer obras derivadas siempre que reconozcáis los créditos de las obras (autoría, nombre de la revista, institución editora) de la manera especificada por los autores o por la revista. La licencia completa se puede consultar en http://creativecommons.org/licenses/by/3.0/es/deed.ca.

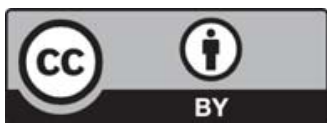




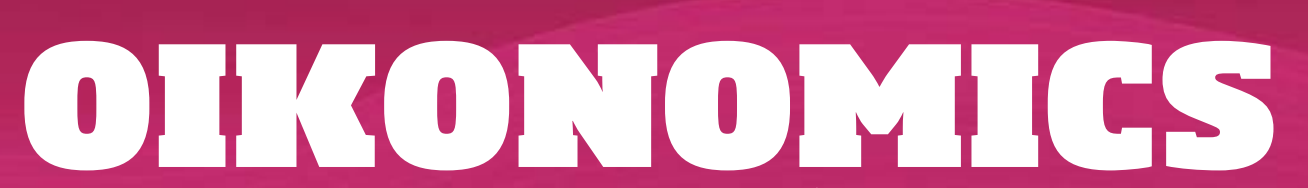

Revista de economía, empresa y sociedad

¿CONCEPTOS DIFERENTES?

\section{Pasión y adicción al trabajo}

\section{María José Serrano Fernández}

Profesora colaboradora de los Estudios de Psicología y Ciencias

de la Educación (UOC)

RESUMEN La adicción y la pasión por el trabajo tienen una gran influencia en la salud de los trabajadores. En este estudio, analizamos estos conceptos con la finalidad de averiguar si son el mismo o conceptos diferentes, además de analizar la capacidad predictiva de algunas variables. Los participantes de la investigación han sido 513 trabajadores (48,1\% hombres, 51,9 \% mujeres), obtenidos mediante un muestreo no probabilístico. La prueba de Fisher demuestra que la «adicción al trabajo» y la "pasión por el trabajo» son constructos diferentes. Se determina la capacidad predictiva de variables como personalidad, engagement, autoeficacia, ICO, satisfacción por la vida y estilo de vida sobre la adicción al trabajo y la pasión por el trabajo. En conclusión, la adicción al trabajo y la pasión por el trabajo son conceptos diferentes, que pueden predecirse mediante determinadas variables (personalidad, engagement, autoeficacia, ICO, satisfacción por la vida y estilo de vida).

PALABRAS CLAVE salud laboral; adicción al trabajo; pasión por el trabajo; estilo de vida; personalidad; escalas.

\section{Addiction and Passion for Work}

ABSTRACT Addiction and passion for work have a great influence on workers' occupational health and, in this study, we analyse these concepts in order to ascertain whether they are the same or different concepts. Moreover, we evaluate the predictive capacity of variable criteria on addiction and 
passion for work. The research participants were 513 workers $448.1 \%$ men, 51.9\% women), obtained through non-probabilistic sampling. Fisher's Test shows that work addiction and passion for work are different constructs. The predictive capacity is determined by variables such as personality, engagement, self-efficacy, ICO, life satisfaction and lifestyle with respect to workaholism and passion at work. In conclusion, workaholism and passion at work are different constructs, which can be predicted by the abovementioned variables.

KEYWORDS occupational health; workaholism; passion at work; lifestyle; personality; scales

\section{Introducción}

Los profesionales de la salud cada vez más nos encontramos con personas que dedican demasiado tiempo al trabajo y se olvidan de la familia, las relaciones sociales e incluso descuidan a veces su propia salud. Estas personas realizan demandas sobre su sintomatología (física, emocional y social), sin ser, la mayoría de veces, conscientes de la relación anormal que están manteniendo con su trabajo y cómo esta relación está afectando a sus vidas. Hablamos de adictos al trabajo. Se ha observado que algunas de estas personas adoran su trabajo y esto nos lleva a pensar en la posibilidad de que aquello que apasiona a una persona pueda acabar convirtiéndola en un adicto.

Esta investigación se situó en este contexto, en el que fueron analizadas la relación entre adicción y pasión por el trabajo, con la finalidad de determinar si son conceptos diferentes. Además, analizamos la capacidad que tienen algunas variables para predecir la pasión y la adicción al trabajo, entre ellas la personalidad, el engagement, la autoeficacia, la obsesión (ICO), la satisfacción por la vida y el estilo de vida sobre las distintas escalas de adicción al trabajo (WorkBAT y Duwas) y la pasión por el trabajo. Los participantes de la investigación han sido 513 trabajadores (48,1 \% hombres, 51,9 \% mujeres), obtenidos mediante un muestreo no probabilístico.

\section{Pasión por el trabajo}

La pasión hacia las cosas había recibido poca atención por parte de la psicología hasta que Vallerand y otros (2003) nos propusieron un nuevo enfoque de la pasión: 
la definieron como una fuerte inclinación o deseo hacia una actividad que gusta a las personas, que es importante en sus vidas y en la que invierten tiempo y energía.

Vallerand y sus colaboradores proponen dos tipos de pasión: la pasión armoniosa, que se produce cuando las personas aceptan libremente realizar una actividad que para ellas es importante, sin que se le atribuya ningún tipo de contingencias, y aunque se sienten obligados a realizarla, pueden decidir libremente hacerla o no, por lo que, aunque les ocupe un tiempo, esta dedicación se encuentra en armonía con otros aspectos de su vida. Por otro lado, la pasión obsesiva se origina por una presión intrapersonal y/o interpersonal, ya sea por ganancias resultantes de la actividad, sentimientos de aceptación social, autoestima, o porque la sensación de emoción por su realización se vuelve incontrolable. Es decir, aunque es una actividad que les gusta, se sienten obligados a realizarla, lo que provoca que no dejen de participar en ella porque esta les controla y acaba ocupando un espacio muy grande en sus vidas, lo que, a su vez, conlleva conflictos con otras áreas de la misma.

La pasión, tanto armoniosa como obsesiva, predice positivamente la práctica de la actividad. $Y$ hay una asociación positiva entre pasión armoniosa y bienestar subjetivo (Vallerand y otros, 2007).

\section{Adicción al trabajo}

El constructo científico workaholism (adicción al trabajo) fue definido por Oates (1968) como una necesidad incontrolable y constante de trabajar que puede tener una persona y que afecta a sus relaciones sociales, su felicidad y su salud. Posteriormente, Fassel (1990) nos lo define como una enfermedad progresiva y fatal en la que una persona es adicta al proceso de trabajo.

Scott, Moore y Miceli (1997) describen tres dimensiones que caracterizan a los adictos al trabajo: (1) la tendencia a pasar tiempo en el trabajo sacrificando la vida familiar y social; (2) la tendencia a tener pensamientos obsesivos sobre el trabajo aun cuando no se esté en él, y (3) la tendencia a trabajar largas horas más allá de las requeridas y de las necesidades financieras. Estos autores, identificaron tres tipos de adictos al trabajo: (1) los adictos al trabajo que no pueden controlar su deseo de trabajar y que sufren síntomas de abstinencia cuando no están trabajando (dependientes compulsivos); (2) los adictos al trabajo orientados a logros (trabajan muchas horas motivados por la competencia y la consecución de objetivos a largo plazo), y (3) los adictos al trabajo perfeccionistas (trabajan muchas horas por la necesidad controlar el trabajo y alcanzar la perfección).

La conceptualización más utilizada de la adicción al trabajo ha sido la propuesta por Spence y Robbins (1992), quienes sugieren que un adicto al trabajo es 
alguien que se siente impulsado o forzado a trabajar, no por la demanda ni el placer del trabajo, sino por causas internas que le presionan haciendo que se sienta culpable sino está trabajando.

\section{Personalidad}

La personas con pasión armoniosa se caracterizan por un cierto grado de responsabilidad, extraversión, amabilidad y apertura a la experiencia, mientras que las personas con pasión obsesiva tienen un bajo nivel de amabilidad (Balon, Lecoq y Rimé, 2013). Vallerand y Houlfort (2003) encontraron que los empleados apasionados hacen que las empresas tengan más beneficios debido a que tienen mayor capacidad para atraer y retener a los clientes.

Hameed, Amjad y Hameed (2013) realizaron un estudio para determinar si la personalidad podía predecir la adicción al trabajo, y demostraron que sí está relacionada con la adicción al trabajo y que esta última puede ser considerada como un factor estable de la personalidad. Se encontraron relaciones positivas de la participación en el trabajo (Work Involvement) con todos los factores de la personalidad, excepto con el neuroticismo (Aziz y Tronzo, 2011). También se han encontrado relaciones positivas del impulso a trabajar (Driven) con todos los factores de la personalidad, excepto con el de apertura a la experiencia (Burke, Matthiesen y Pallesen, 2006). Y disfrutar en el trabajo (Work Enjoyment) se relaciona positivamente con todos los factores de la personalidad (Abou-Deif y otros, 2013).

Las personas con rasgos obsesivo-compulsivos son las más propensas a convertirse en adictos al trabajo (Seybold y Salomone, 1994). También se ha encontrado que la relación entre trabajo, autoeficacia y adicción al trabajo es positiva, por lo que unos altos niveles de autoeficacia podrían estar relacionados con altos niveles de adicción al trabajo (Ng, Sorensen y Feldman, 2007).

\section{Engagement}

El compromiso (engagement) se define como una relación positiva, satisfactoria, relacionada con el trabajo, que se caracteriza por el vigor, la dedicación y la absorción. Se trata de un sentimiento de significación, entusiasmo, inspiración, orgullo, dedicación y desafío, donde las personas se sienten felizmente absortos en su trabajo.

El engagement está vinculado positivamente con la pasión armoniosa y ambos hacen que se incremente el rendimiento laboral. La relación entre engagement, afecto positivo y las emociones en el trabajo produce una mayor atención y una 
mayor capacidad para desarrollar recursos, y además predice una buena salud mental y física, lo que aumenta el rendimiento de los empleados.

La pasión armoniosa predice positivamente el engagement y permite que los empleados realicen su trabajo de una manera flexible, lo que los conduce a conseguir resultados positivos. En cambio, la pasión obsesiva no está relacionada con el engagement. Esto se debe a que los empleados con más pasión obsesiva, aunque trabajan más, no disfrutan de su trabajo (Balon y otros, 2013).

Según Hernández-Pozo (2010), la pasión es una de las dos posibles motivaciones que impulsan a la adicción al trabajo; la otra es la obsesión. Las características compartidas entre los adictos al trabajo y la pasión obsesiva son que trabajan duro, que son reacios a retirarse del trabajo y que piensan de manera persistente y con frecuencia en trabajo incluso fuera del mismo. Trabajan más de lo que se espera de ellos para satisfacer las necesidades de la organización o las económicas (Gorgievski, Moriano y Bakker, 2014).

\section{Burnout}

Estar quemado por el trabajo (Burnout) es un síndrome psicológico de agotamiento emocional, despersonalización y reducida realización personal que puede ocurrir en personas que trabajan, de alguna manera, con personas (Maslach, 1993). Al igual que la adicción al trabajo, el burnout se relaciona con una serie de resultados negativos. La diferencia entre el adicto y las personas que sufren burnout es que estas últimas no se sienten obligadas a trabajar, sino que tienen una distancia mental hacia su trabajo (Schaufeli y Salanova, 2007).

La pasión por el trabajo es un factor importante que influye en el bienestar psicológico. Se han encontrado diferencias entre los dos tipos de pasión. La pasión armoniosa hace que se produzca menos agotamiento emocional e incrementa la satisfacción del trabajo, y por eso se asocia con la satisfacción laboral, las emociones positivas y los bajos niveles de problemas psicológicos, mientras que la pasión obsesiva se asocia con altos niveles de síntomas cognitivos y ansiedad (Houlfort y otros, 2010).

\section{Satisfacción por la vida}

La pasión obsesiva hace que la satisfacción por la vida dependa del éxito o el fracaso de la actividad laboral (Lafrenière y otros, 2012). De hecho, las personas en las que predomina una pasión armoniosa están menos a la defensiva y son más abiertas al resultado de la actividad. Esto nos permite afirmar que la pasión 
armoniosa hace que aumenten los niveles de satisfacción por la vida, mientras que la pasión obsesiva tiene una relación negativa (Philippe, Vallerand y Lavigne, 2009).

Las actividades sociales hacen que las personas se sientan bien, ya que cumplen con la necesidad psicológica de pertenencia. Pero los trabajadores adictos no parecen beneficiarse de las actividades sociales después del trabajo, un efecto que es independiente del nivel de adicción que tengan. Esto indica que la adicción al trabajo tiene un efecto negativo en el bienestar. Investigaciones anteriores ya mostraban que los adictos al trabajo están menos satisfechos con la vida en general (Schaufeli y otros, 2008).

\section{Salud}

Para sentirnos mejor, las personas realizamos actividades que nos gustan, por lo que algunas experiencias de pasión pueden fomentar la mejoría de la salud y hacer que tengamos un mayor afecto positivo, mejore el bienestar y de un mayor significado a nuestra vida (Rousseau y Vallerand, 2008).

Las personas con pasión armoniosa sienten más emociones positivas y se sienten mejor (Vallerand y otros, 2007), además de tener menos nivel de depresión (Sacco y Beck, 1995). Así pues, experimentar pasión armoniosa hacia una actividad podría ayudar en la recuperación de personas enfermas, favorecer el sentimiento de una sensación de control, sentir más energía y dar significado a sus vidas (Philippe, Vallerand y Lavigne, 2009).

Respecto a la pasión obsesiva, debido a que una persona experimenta un impulso incontrolable de participar en una actividad, pueden producirse efectos negativos y desadaptativos si no puede realizarla. De hecho, las personas con pasión obsesiva se asocian con mayores niveles de emociones negativas, conflictos y comportamientos peligrosos y contraproducentes (Vallerand y otros, 2007).

También ha sido ampliamente estudiada la manera en que el trabajo puede afectar a la salud de los trabajadores, tanto a nivel físico como psicológico. Una de las consecuencias más ampliamente reconocidas de la adicción al trabajo son los efectos negativos sobre la salud física y mental que estas personas pueden padecer (Poelmans y Masuda, 2009).

\section{Conclusiones}

Los resultados hallados en nuestra investigación aportan una información valiosa, relevante y original en el estudio de la pasión y la adicción al trabajo. Se ha podido 
comprobar que la adicción al trabajo y la pasión por el trabajo son constructos diferentes (Serrano-Fernández, 2014).

También se constata que diversas variables influyen en las diferentes dimensiones que afectan a la adicción al trabajo y a la pasión por el trabajo, por lo que, en función de la actividad que se realice, se podrían fomentar aquellos aspectos que pueden hacer que los empleados se sientan mejor en el trabajo y también fuera de él.

A continuación se exponen aquellos aspectos que influyen tanto positiva como negativamente y que pueden conducir a realizar predicciones: las variables que hacen que las personas sientan más presión para trabajar (Driven) son el perfeccionismo, la absorción, el crecimiento y las relaciones interpersonales, y tener valores bajos en satisfacción por la vida, amabilidad, nutrición y dedicación. Si hablamos de disfrute por el trabajo (Work Enjoyment), lo predicen la absorción, la responsabilidad hacia la salud, el crecimiento y las relaciones interpersonales, y la dedicación (Serrano-Fernández y otros, 2016).

En lo que respecta al trabajo excesivo, lo predicen positivamente variables como absorción, perfeccionismo, autoeficacia y responsabilidad hacia la salud. Y trabajarán menos aquellas personas que sientan satisfacción por la vida, realicen actividad física, tengan más estabilidad emocional y cuiden su nutrición. Respecto al trabajo compulsivo, lo realizarán más aquellas personas con valores altos en perfeccionismo, absorción, autoeficacia y crecimiento, y menos aquellas personas que se sientan satisfechas con la vida, tengan más estabilidad emocional, más dedicación y cuiden su nutrición (Serrano-Fernández y otros, 2016).

La pasión armoniosa se predice de forma directa con las variables dedicación, crecimiento, actividad física, satisfacción por la vida y responsabilidad excesiva, y de manera inversa con el vigor. Por su parte, la pasión obsesiva se predice positivamente por la absorción y la responsabilidad excesiva, y negativamente por la satisfacción por la vida, la apertura a la experiencia y la amabilidad.

Estos datos nos proporcionan importantes implicaciones con respecto a la pasión y a la adicción al trabajo que pueden ser consideradas para una adecuada gestión de los recursos humanos dentro de las organizaciones, y fomentar aquellos aspectos que produzcan en los empleados un mayor grado de bienestar, que puede traducirse en mayores beneficios para las empresas.

\section{Referencias bibliográficas}

ABOU-DEIF, M. H. y otros (2013). "Characterization of Twenty Wheat Varieties by ISSR Markers». Middle-East Journal of Scientific Research. Vol. 15, págs. 168175. 
AZIZ, S.; TRONZO, L. C. (2011). «Exploring the Relationship between Workaholism Facets and Personality Traits: A Replication in American Workers». The Psychological Record. Vol. 61, págs. 269-286.

BAKKER, A. B.; LEITER, M. P. (eds.) (2010). Work engagement: A handbook of essential theory and research ed. Nueva York: Psychology Press.

BALON, S.; LECOQ, J.; RIMÉ, B. (2013). «Passion and personality: Is passionate behaviour a function of personality?». Revue Européenne de Psychologie Appliquée / European Review of Applied Psychology. Vol. 63, págs.59-65.

BURKE, R. J.; MATTHIESEN, S. B.; PALLESEN, S. (2006). «Personality correlates of workaholism». Personality and Individual differences. Vol. 40, págs. 12231233.

FASSEL, D. (1990). Working ourselves to death: The hight cost of Workaholism, the rewards or recovery. San Francisco, CA: Harper Collins Publishers.

GORGIEVSKI, M. J.; MORIANO, J. A.; BAKKER, A. B. (2014). «Relating Work Engagement and Workaholism to Entrepreneurial Performance». Journal of Managerial Psychology. Vol. 29, págs. 1-29.

HAMEED, F.; AMJAD, S.; HAMEED, A. (2013). «The Relationship Between Workaholism and Personality». Middle-East Journal of Scientific Research. Vol. 17, págs. 898-907.

HERNÁNDEZ-POZO, M. R. (2010). «Workaholism: Contingential radiography of an addiction». Revista Mexicana de Análisis de la Conducta. Vol. 36, págs. 117135.

HOULFORT, N. y otros (2010). «On the role of passion for work in psychological well-being». Artículo presentado para su publicación.

LAFRENIĖRE, M. K. y otros (2012). «On the relation between performance and life satisfaction: The moderating role of passion». Self and Identity. Vol. 11, págs. 516-530.

MASLACH, C. (1993). «Burnout: A multi-dimensional perspective». En: Schaufeli, W. B.; Maslach, C.; Marek, T. (eds.). Professional burnout: Recent developments in theory and research. Washington, D.C.: Taylor and Francis, págs. 1932.

NG, T. W. H.; SORENSEN, K. L.; FELDMAN, D. C. (2007). «Dimensions, antecedents, and consequences of workaholism: A conceptual integration and extension». Journal of Organizational Behavior. Vol. 28, págs. 111-136.

OATES, W. E. (1968). «On being a "workaholic" (a serious jest)». Pastoral Psychology. Vol. 19, págs. 16-20.

PHILIPPE, F. L.; VALLERAND, R. J.; LAVIGNE, G. L. (2009). «Passion does make a difference in people's lives: A look at well-being in passionate and non-passionate individuals». Applied Psychology: Health and Well-Being. Vol. 1, págs. 3-22. 
POELMANS, S. Y.; MASUDA, A. D. (2009). «Work Addiction. In Workplace Psychological Health: Current Research and Practice». En: BROUGH, P.; O’DRISCOLL, M.; KALLIATH, T.; COOPER, C. L.; POELMANS, S. Y. (eds.). Workplace Psychological Health: Current Research and Practice. Cheltenham, UK: Edward Elgar Publishing, págs. 87-97.

ROUSSEAU, F. L.; VALLERAND, R. J. (2008). "An examination of the relationship between passion and subjective well-being in older adults». International Journal of Aging and Human Development. Vol. 66, págs. 195-211.

SACCO, W. P.; BECK, A. T. (1995). «Cognitive theory and therapy». En: BECKHAM, E.; LEBER, W. R. (eds.). Handbook of Depression. Nueva York: Guilford Press, págs. 329-351.

SCHAUFELI, W. B.; SALANOVA, M. (2007). «Efficacy or inefficacy, that's the question: Burnout and work engagement, and their relationship with efficacy beliefS». Anxiety, Stress \& Coping. Vol. 20, págs. 177-196.

SCOTT, K. S., MOORE, K. S.; MICELI, M. P. (1997). «An exploration of the meaning and consequences of workaholism». Human Relations. Vol. 50, págs. 287-314. SERRANO-FERNÁNDEZ, M. J. (2014). Pasión y adicción al trabajo: Una investigación psicométrica y predictiva. Tesis doctoral (dir. J. Boada-Grau). Universitat Rovira i Virgili, Tarragona.

SERRANO-FERNÁNDEZ, M. J. y otros (2016). "A predictive study of antecedent variables of workaholism». Psicothema. Vol. 28, n. ${ }^{\circ}$ 4, págs. 401-406.

SEYBOLD, K. C.; SALOMONE, P. R. (1994). «Understanding workaholism: A review of causes and counseling approaches». Journal of Counseling and Development. Vol. 73, págs. 4-9.

SPENCE, J. T.; ROBBINS, A. S. (1992). «Workaholism: Definition, measurement, and preliminary results». Journal of Personality Assessment. Vol. 58, págs. 160178.

VALLERAND, R. J. y otros (2003). «Les passions de l'âme: on obsessive and harmonious passion». Journal of Personality and Social Psychology. Vol. 85, págs. 756-767.

VALLERAND, R. J. y otros (2006). "Passion in sport: A look at determinants and outcomes». Journal of Sport \& Exercise Psychology. Vol. 28, págs. 454-478.

VALLERAND, R. J. y otros (2007). «On the role of passion in performance». Journal of Personality. Vol. 75, págs. 505-533. 


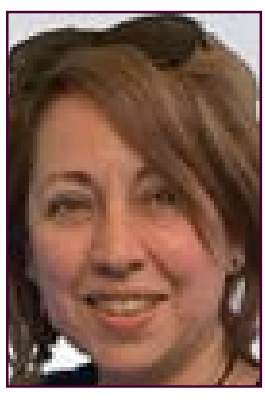

\section{María José Serrano Fernández} mserranofe@uoc.edu Profesora colaboradora de los Estudios de Psicología y Ciencias de la Educación (UOC). Directora de Alba Psicología

Doctora en Psicología por la Universitat Rovira i Virgili de Tarragona, profesora colaboradora en el Departamento de Psicología y Educación de la Universitat Oberta de Catalunya (UOC) y pertenece al Centro de Investigación en Evaluación y Medida de la Conducta de la Universitat Rovira i Virgili (URV). Sus líneas de investigación se centran en las adicciones tecnológicas y en la pasión y la adicción por el trabajo.

Los textos publicados en esta revista están sujetas -salvo que se indique el contrario- a una licencia de Reconocimiento 3.0 España de Creative Commons. Podéis copiarlos, distribuirlos, comunicarlos públicamente y hacer obras derivadas siempre que reconozcáis los créditos de las obras (autoría, nombre de la revista, institución editora) de la manera especificada por los autores o por la revista. La licencia completa se puede consultar en http://creativecommons.org/licenses/by/3.0/es/deed.ca.

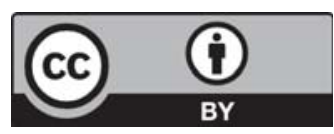




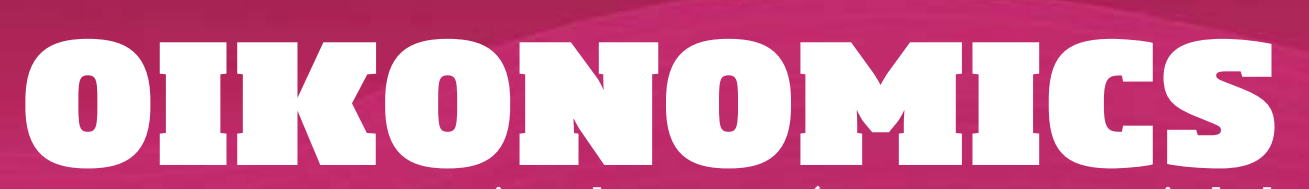

Revista de economía, empresa y sociedad

UNA DIMENSIÓN TRANSVERSAL

\section{Digitalización de la gestión de personas}

\section{Verònica Platas Ruiz}

Profesora colaboradora de los Estudios de Economía y Empresa (UOC)

RESUMEN LOS cambios en pleno siglo XXI son constantes, $y$ en el contexto VUCA (volatilidad, incertidumbre, complejidad y ambigüedad) en que nos encontramos, la digitalización en todas las áreas de las organizaciones va tomando una dimensión transversal que no excluye a la gestión de personas. En este artículo haremos un recorrido por elementos clave que debemos tener en cuenta en lo relativo a la gestión de personas y la digitalización, y cuál es el estado de situación actual en la implementación de herramientas para la mejora de nuestras funciones en ámbitos de desarrollo de personas.

PALABRAS CLAVE gestión del talento; tecnología; digitalización; gestión de personas; desarrollo; recursos humanos

\section{The digitization of people management}

ABSTRACT The changes in the $21^{\text {st }}$ Century are constant and, within the framework of VUCA Nolatility, Uncertainty, Complexity, Ambiguity) that we face, digitization in all the areas of organizations has an increasingly mainstream dimension, which also has an impact on people management. In this article, we review the key elements that must be considered in relation to people management and digitization, as well as the current state of the art in terms of the implementation of tools for improving our functions in the field of personal development.

KEYWORDS talent management; technology; digitization; people management; development; human resources 


\section{Introducción}

Las funciones y el encaje de la gestión de personas en las empresas no siempre han sido las mismas, sino que han ido evolucionando en función del contexto de la organización y de la visión en este ámbito, hasta el extremo de la desaparición del esquema clásico de los recursos humanos en algunas organizaciones.

En los años setenta se utilizó el término administración de personal, en los años ochenta se incorporaron nuevas áreas administrativas, la compensación o la contratación, y ya en los años noventa, se consiguió evaluar el desempeño y fomentar el desarrollo de los empleados, tendencia que continuó en los primeros años de este siglo, haciendo hincapié en su desarrollo, así como en su motivación y fidelización. De esta manera, el enfoque de nuestra labor en gestión de personas ha evolucionado y ha pasado del clásico «departamento de personal», ejecutor de determinadas tareas vinculadas sobre todo con la gestión laboral, a una «área de gestión estratégica de recursos humanos", donde recae sobre nosotros la importancia de establecer políticas para desarrollar el talento de nuestra organización. Encontramos también otro estadio, en que el departamento de gestión de recursos humanos se transforma en una «unidad de consultoría interna de apoyo al negocio». Todo el conocimiento que tenemos se traslada a un enfoque más de consultor que de ejecutor. Seremos un facilitador, un agente de cambio que acompaña procesos y estrategias. Esta evolución también impacta en la situación de la gestión de personas en el organigrama. Si observamos las empresas que componen el IBEX 35, veremos que la proporción de los departamentos de recursos humanos que dependen de la dirección general ha pasado a ser de una relación de 25 a 10, mientras que los que dependen del director financiero han pasado de 5 a 20.

Junto con estos cambios, también vemos que los profesionales del sector van evolucionando: de tener principalmente directores de recursos humanos ingenieros o economistas a los psicólogos en los años noventa o a un retorno más técni$\mathrm{co}$, con equipos multidisciplinares que enriquecen las diferentes funciones dentro de los departamentos de recursos humanos en el siglo XXI. Los profesionales de recursos humanos han variado hacia perfiles más científicos. En 1995, un 5 \% de los profesionales de los recursos humanos provenía de las ingenierías, mientras que en 2014 eran ya un $12 \%$. Y si bien actualmente los perfiles que ocupan funciones relacionadas con la gestión de recursos humanos está encabezada por profesionales del derecho (33\%), le siguen los perfiles provenientes de las ciencias sociales y del comportamiento (26 \%) (ESADE, 2014).

Más allá de estos cambios propios de la evolución del management y de nuevas formas de entender la organización empresarial, la función de los recursos humanos ha visto modificar sus procesos y su impacto, fundamentalmente gracias a la tecnología y a la incorporación de la misma en su día a día. 


\section{Del fax al Analytics}

Desde los años ochenta, los departamentos de recursos humanos están evolucionando, y de forma muy rápida, hacia la incorporación de tecnologías que permitan desarrollar la función de "gestión de personas» de manera eficiente. Dentro de los profundos cambios que la revolución tecnológica del último tercio del siglo xx y los primeros años del siglo xxı han provocado en las organizaciones, el ámbito de los recursos humanos ha sido uno de los que han experimentado efectos más importantes. No tan solo por la adaptación en la gestión de la empresa, sino porque una de las transformaciones más destacadas y radicales se produce, precisamente, en el ámbito de las personas. La aparición progresiva de los trabajadores del conocimiento a partir de la década de los ochenta del siglo pasado provoca una revolución en los mercados de trabajo y la gestión del talento y las capacidades, de la que en realidad estamos todavía en sus primeras fases. En paralelo, la tecnología sigue avanzando, principalmente en los ámbitos de la informática, las comunicaciones y las telecomunicaciones, en un proceso que todavía es muy incipiente, y que comportará cambios aún más profundos. Mientras, los departamentos y responsables de personas dentro de la empresa ven como su rol cambia a un ritmo vertiginoso y se convierten en una función cada vez más poliédrica y compleja, alejada de los tradicionales roles más administrativos para situarse en posiciones mucho más estratégicas para la organización.

Ya no nos acordamos en qué fecha nació el primer portal de búsqueda de empleo por Internet (fue en el año 1999), porque en definitiva, las tecnologías y herramientas que nos ayudan a desarrollar nuestro trabajo y que tienen un proceso de implementación rápido suelen normalizarse rápidamente. $Y$ hoy en día ya nadie recuerda tampoco cómo era recibir currículums por fax o por correo ordinario. Hasta nuestro contexto actual, donde hablar de Business Intelligence y cómo aplicarlo a la gestión de personas se ha convertido en uno de los principales retos para convertir los datos en información, y esta en conocimiento, con el objetivo último de optimizar el proceso de toma de decisiones en las organizaciones. Poder aportar datos tangibles, y no percepciones u opiniones, permitirá medir realmente el rendimiento y el ROI (retorno de la inversión) en la gestión del talento.

Un ejemplo claro donde la digitalización y la incorporación de la tecnología han significado un cambio de enfoque y de optimización de los recursos ha sido el área de reclutamiento y selección. En menos de veinte años, hemos pasado de trabajar un reclutamiento 1.0 a un reclutamiento que hoy denominamos 4.0.

- Con el reclutamiento 1.0 se realizó la contratación tradicional, a través de hardware como el fax, publicidad impresa (correos, carteles, y a esperar...). Los reclutadores estaban más centrados en los procesos que en los resultados finales. 
- Con el reclutamiento 2.0 se vivió el traspaso a la tecnología en línea y a su uso con fines de reclutamiento. Aparecieron las bolsas de trabajo y las búsquedas de CV en línea. Mientras que la tecnología iba avanzando, la metodología tradicional 1.0 era aún frecuente, pero incluyendo los correos electrónicos y la que se conoció como la «lotería de reclutamiento».

Tanto el reclutamiento 1.0 como el 2.0 se centran fundamentalmente en los buscadores de trabajo activos. El $15 \%$ del mercado son candidatos activos.

- Con el reclutamiento 3.0 se da un gran salto. El corazón del 3.0 es el candidato no activo/pasivo y se enfoca hacia la atracción del mejor talento. Se parte de la idea de que cualquier persona es un candidato potencial. El 3.0. se apoya en la marca empleadora, el marketing y la comunicación bidireccional.

- Con el reclutamiento 4.0, se lleva el concepto de la comunidad a un nivel superior. La inversión en atracción del talento ya no se imputa al centro de costes, sino al centro de beneficio. Las empresas atraen talento y contratan a través de la nube, de referencias externas y crowdsourcing, por medio de aplicaciones móviles y gamificación.

Como decía Lou Adler, consejero delegado de The Adler Group, "contratar a la mejor persona disponible para cubrir una vacante, en vez de al mejor candidato que se ha presentado para el puesto, requiere un técnico de selección de personal diferente, así como un proceso de selección distinto». Y todo ello es posible gracias a la tecnología, que nos aporta poder realizar más con menos, en el sentido más estricto, y minimizar el margen de error aportando más valor a nuestro trabajo. Si queremos encontrar a los mejores, deberemos ir a buscarlos allí donde estén, y eso pasa por conocer dónde y cómo encontrarlos.

No es casualidad la revolución de las aplicaciones de oferta y demanda laboral y todos sus servicios complementarios. Según el Informe Global Adecco 2015, el $65 \%$ de los españoles busca empleo a través del móvil, dinámica que ha hecho que tanto desarrolladores como empresas se estén centrando en ofrecer soluciones que se ajusten a lo que demanda el mercado. Y una vez más, el mercado (candidatos) está haciendo que la empresa cambie sus maneras de proceder. Nos pasa lo mismo con los empleados. Los trabajadores ya tienen terminales móviles en muchos casos más potentes que los que te ofrece la empresa (ya no es habitual ver a una persona con dos teléfonos móviles). En estos terminales ya vienen por defecto instaladas aplicaciones que nos permiten compartir documentos, gestionar notas, comprimir archivos, disponer de aplicaciones de trabajo colaborativo y sistemas de mensajería que hacen obsoleta la intranet de una empresa. 


\section{Cambian los cómos, no los qués}

Si bien es claro que las organizaciones están sufriendo una evolución (algunas más rápida que otras), y que muchas están transformando su manera de producir, o como mínimo de relacionarse, hacia el 2.0, uno de los elementos más importantes dentro de nuestras responsabilidades va a ser gestionar y liderar personas que funcionan bajo esquemas tecnológicos y parámetros del siglo xxI. Eso es, responder a exigencias y maneras de proceder basados en la sociedad del conocimiento y en el capitalismo cultural frente al capitalismo industrial, y con organizaciones basadas en la visión de tolerancia al riesgo y al cambio (Schuschny, 2008) y no tanto en la planificación.

La función de la gestión de personas debe transformarse, ya que reproducir los esquemas tradicionales de gestión y dirección de personas del siglo xx bajo paradigmas tecnológicos propios del siglo xxı no tendría encaje. En la actualidad, las personas demandan organizaciones donde la innovación y la tecnologización son necesarias para un buen desarrollo empresarial y, en definitiva, para cumplir los objetivos clave del área de desarrollo de personas: «atraer, incorporar, motivar, desarrollar y retener a aquellos profesionales que nos permitirán conseguir los objetivos de la empresa tanto a corto como a medio y largo plazo, desde el enriquecimiento mutuo y desde un impacto social positivo» (Martín, 2010).

Si analizamos área por área, veremos que las maneras de proceder han cambiado sustancialmente al utilizar las nuevas herramientas tecnológicas. Algunos ejemplos de ello son:

- Atraer: desarrollar estrategias vinculadas con el Employer Branding y políticas de reclutamiento y selección a través de herramientas tecnológicas, como workplace, glassdor o bolsas de empleo corporativas, así como metodologías innovadoras, como la gamificación o los concursos de talento.

- Incorporar: establecer planes de acogida a través de plataformas de gamificación o plataformas de autoaprendizaje y de figuras como las de mentoring, manteniendo las políticas de Employer Branding de manera transversal a todas las fases.

- Motivar: definir estilos de liderazgo corporativos, sistemas de compensación y retribución por objetivos, generar elementos para el desarrollo de empresas saludables (retribución flexible, workplace, nuevas formas de organización del trabajo).

- Desarrollar y fidelizar: establecer planes de carrera, programas de desarrollo de liderazgo y planes de sucesión a través de programas de desarrollo, universidades corporativas, gamificación, programas de voluntariado... 
Una de las herramientas más utilizadas para conseguir el desarrollo y la fidelización del talento es la formación y el aprendizaje continuo de los equipos. La digitalización ya es clave para el diagnóstico de necesidades de formación, para establecer un plan formativo y medir su impacto en nuestros equipos, y para incorporar elementos innovadores como el EPA (entorno personal de aprendizaje) o PLE (Personal Learning Environment), los MOOC (Massive Open Online Courses), la gamificación o las nuevas metodologías en línea, que configuran un nuevo escenario lleno de retos y posibilidades para el campo del desarrollo de personas.

Para poder ejecutar esta transformación, debemos empezar por las herramientas de gestión y de trabajo. En un reciente estudio de la Fundació Factor Humà (2016) en el que se recogieron más de trescientas repuestas de directivos dedicados mayoritariamente a la gestión de personas, procedentes de medianas y grandes empresas de seis sectores diferentes, el correo electrónico, las hojas de cálculo y el software de recursos humanos eran las tres herramientas principales en el puesto de trabajo.

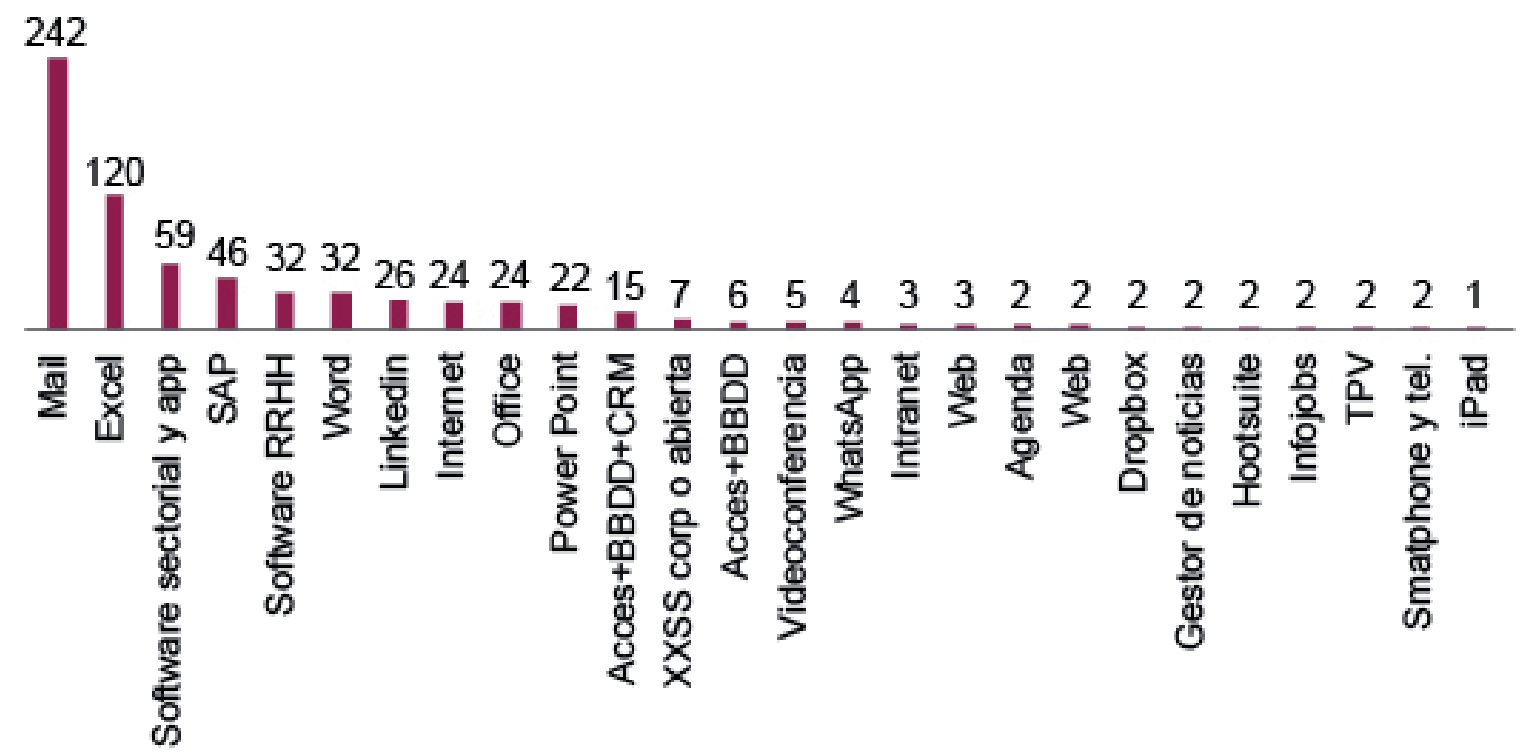

Fuente: Fundació Factor Humà (2016).

Pese a disponer de herramientas que mejoran nuestra productividad y nos hacen ser más efectivos, existen varios motivos por los cuales Estas no se están implementando en las organizaciones. Estos son:

a) Desconocimiento de otras herramientas.

b) Implementación de herramientas corporativas no útiles o no adaptadas a las necesidades.

c) Curvas de aprendizaje elevadas. 
d) Resistencias al cambio.

e) Generación de un hábito.

Como destaca el $2 .^{\circ}$ estudio en España sobre transformación digital en recursos humanos (Íncipy e Inesdi, 2017), el 60 \% de organizaciones están iniciando el proceso de transformación digital, mientras que solo el $19 \%$ se encuentran en una fase avanzada. Para un 7 \%, la cuestión no es prioritaria. Las acciones se orientan al uso de herramientas digitales de comunicación interna, al trabajo en red y a la implementación de software en línea de recursos humanos, así como a la presencia en redes sociales para la atracción y captación de talento. La investigación pone de relieve una utilización dual de las herramientas y aplicaciones digitales en el ámbito de los recursos humanos. Así, mientras que un $82 \%$ de las organizaciones utiliza las redes sociales para captar y seleccionar candidatos, un $74 \%$ tiene página en Linkedln y un $50 \%$ tiene una web corporativa de empleo, otros resultados son más discretos. Solo un $19 \%$ adaptan estos portales de empleo a las nuevas tendencias digitales, un $33 \%$ dispone de una estratètiga de Employer Branding en las redes sociales y un $15 \%$ ha creado perfiles corporativos específicos de recursos humnos en otras redes sociales que no sean Linkedln. En cuanto a la formación, los resultados también son más discretos cuando se trata de ir más allá del uso de las aplicaciones y redes sociales más básicas. Menos de la mitad de empresas proporciona formación digital a sus trabajadores (43 \%) y solo un 29 \% incorporan nuevos perfiles digitales en sus demandas de empleo.

Con este escenario, vemos que más allá de teorías, informes y artículos en torno a la digitalización en la empresa, existe aún mucho camino por recorrer, empezando por la formación en herramientas de gestión, por la generación de una cultura del cambio, con vocación de ahorrar costes, tiempo y conseguir mejores resultados.

\section{Conclusiones}

La irrupción de las tecnologías de la información y la comunicación (TIC) están transformando profundamente la economía y la sociedad. Estas tecnologías son aplicadas masivamente a la esfera económica, y son aplicadas a un gran número de usos sociales. De hecho, este fondo social de conocimiento ya ha impregnado toda nuestra actividad económica y social. La de gestión de personas no es ajena a esta transformación. Puede verse cómo se ha transformado tanto su gestión diaria con el uso del correo electrónico, de los canales directos de comunicación, de las videoconferencias, de las redes sociales corporativas..., como la gestión de las áreas funcionales a través de nuevas formas de organización, como el teletrabajo, 
y del establecimiento de procesos más rapidos y de mayor calidad. Aun así, existe mucho camino por recorrer: se requiere facilitar culturas de cambio y generar actitudes positivas hacia la digitalización.

\section{Referencias bibliográficas}

ADECCO (2015). Informe Global Adecco 2015: Búsqueda de empleo y reputación digital en la era 3.0. Madrid: Adecco.

ANDREW, P.; IP, J.; WORTHINGTON, J. (2014). Fast Forward 2030: The Future of Work and the Workplace. Los Ángeles: CB Richard Ellis Workplace Strategy.

BELLAMY, C. (2000). «Modelling electronic democracy: towards democratic discourses for an information age». En: HOFF, J.; HORROCKS, I.; TOPS, P. (eds.). Democratic Governance and New Technology. Londres: Routledge.

ESADE (2014). VII Informe Cranet ESADE: Gestión estratégica en recursos humanos. Barcelona: ESADE.

FUNDACIÓ FACTOR HUMÀ (2016). «Nuevo management... ¿Nuevo? ¡Urgente!». IV Espacio Factor Humà.

IBM INSTITUTE FOR BUSINESS VALUE (2014). "New expectations for a new era. $\mathrm{CHRO}$ insights from the Global C-suite Study». IBM Institute for Business Value. ÍNCIPY; INESDI (2017). 2. ${ }^{\circ}$ estudio en España sobre transformación digital en recursos humanos.

MARTIN, J. F. (2008). El nuevo rol de los RR. HH. Las personas como motor de la empresa.

PIN, J. R.; SUÁREZ, E.; GALLIFA, A. (2011). Desafíos de la dirección de personas en la cultura 2.0: impacto del mundo 2.0 sobre recursos humanos y aspectos legales-laborales. Pamplona: IESE Business School.

SCHUSCHNY, A. (2008). La red y el futuro de las organizaciones. Más conectados... ¿Más integrados? Buenos Aires: Kier.

SERRANO, J.; GARCÍA, S. (2013). El ocaso del empleo. Cómo sobrevivir en el futuro del trabajo. Barcelona: Libros de Cabecera. 


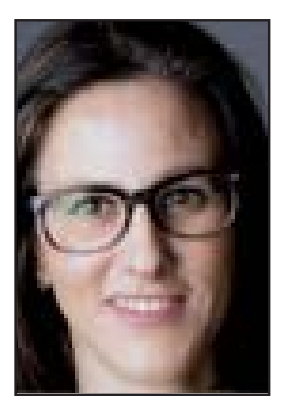

\section{Verònica Platas Ruiz} vplatas@uoc.edu

Profesora colaboradora de los Estudios de Economía y Empresa (UOC)

Licenciada en Pedagogía. Especialista en desarrollo de personas y organizaciones, recursos humanos 2.0, e-recruitment y orientación laboral. Con más de quince años de experiencia en recursos humanos, dirección y gestión empresarial y desarrollo de personas. Socia-directora del área de personas en Maurilia Knowledge y cofundadora de The Human Business.

Los textos publicados en esta revista están sujetas -salvo que se indique el contrario- a una licencia de Reconocimiento 3.0 España de Creative Commons. Podéis copiarlos, distribuirlos, comunicarlos públicamente y hacer obras derivadas siempre que reconozcáis los créditos de las obras (autoría, nombre de la revista, institución editora) de la manera especificada por los autores o por la revista. La licencia completa se puede consultar en http://creativecommons.org/licenses/by/3.0/es/deed.ca.

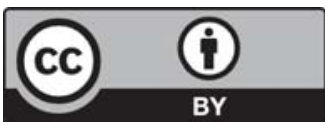




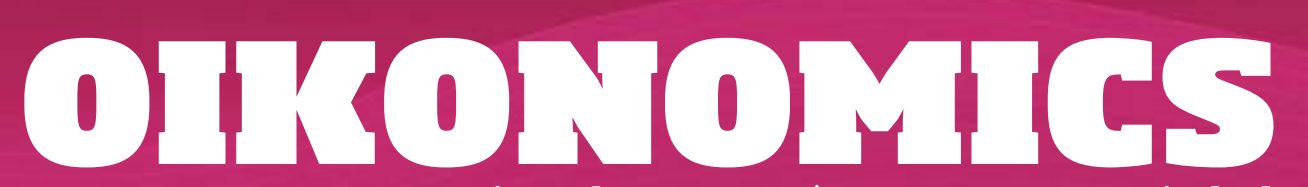

Revista de economía, empresa y sociedad

INTELIGENCIA ARTIFICIAL

\section{Fl empleo ante la nueva oleada digital: ¿robots humanos 0 recursos humanos?}

\section{Joan Torrent-Sellens}

Profesor de los Estudios de Economía y Empresa (UOC)

RESUMEN La preocupación por el futuro del trabajo es un tema recurrente cada vez que se evidencia un proceso de cambio disruptivo en la tecnología. El análisis económico ha señalado que la tecnología no destruye el trabajo, sino que sesga habilidades y destrezas, y desplaza tareas, empleos, ocupaciones y personas. En general, a largo plazo, las consecuencias de estas oleadas tecnológicas sobre el trabajo suelen ser positivas, porque se vinculan con incrementos de la productividad, nueva actividad económica, más ocupación y mejoras salariales para las personas que trabajan en las empresas o los sectores vinculados con la innovación tecnológica. Además, estos efectos positivos suelen compensar en el largo plazo los efectos de sustitución del empleo si las empresas, especialmente a través de sus políticas de recursos humanos, actúan en forma de políticas activas, que formen y recapaciten a las personas desplazadas. Esta forma general de interacción de la tecnología con el trabajo se ha puesto en entredicho con la reciente oleada digital, caracterizada, entre otras cosas, por la explosión de la robótica inteligente. Según algunos autores, el ritmo de sustitución del trabajo humano por parte de los robots será tan elevado que difícilmente se podrán compensar por la vía habitual de incrementos de demanda y productividad. Otros autores defienden justo lo contrario y enmarcan la dinámica actual en el contexto de las interacciones tradicionales entre tecnología y trabajo. Pero la robótica es trabajo no humano, tiene unas características muy particulares y dinámicas, ofrece un amplio abanico de posibilidades de utilización y, al mismo tiempo, también genera miedos. En este artículo, analizaremos las 
implicaciones para el empleo de la nueva robótica, con especial atención a las repercusiones para la dirección y la gestión de recursos humanos.

PALABRAS CLAVE robótica; inteligencia artificial; empleo; desigualdad; gestión de recursos humanos

\section{Employment in the new digital wave: human robots or human resources?}

ABSTRACT Concern for the future of employment is a recurring theme whenever a process of disruptive change in technology takes place. Economic analysis has shown that technology does not destroy work, but it skews skills and abilities, and displaces tasks, jobs, occupations and people. Generally, in the long term, the consequences of these technological waves on work tend to be positive because they are linked to increases in productivity, new economic activity, higher employment and salary improvements for people working in firms or sectors related to technological innovation. In addition, the effects of job substitution can be offset in the long term if firms' strategies and policies, especially in terms of human resource management, take the form of active employment policies that train and reskill displaced people. This general form of interaction of technology with work has been questioned with the recent digital wave characterized, among other factors, by the explosion of intelligent robotics. According to some authors, the rate of substitution of human labour by robots will be so fast that they can hardly be compensated by the usual route of increases in demand and productivity. Other authors argue just the opposite, and frame the current dynamics within the context of the traditional interactions between technology and work. However, robotics is non-human work, has very particular and dynamic characteristics, offers a wide range of possibilities of use and, at the same time, generates fears too. In this article, we will analyse the employment implications of new robotics, paying special attention to the human resources management.

KEYWORDS robotics; artificial intelligence (Al); employment; inequality; human resource management (HRM) 


\section{Introducción}

La consolidación de la economía global del conocimiento y la progresiva articulación de la empresa y los negocios en red han venido transformando muy profundamente, de manera estructural, el empleo. Poco a poco, el trabajo homogéneo y manual, la organización industrial del empleo (atomización, jerarquía y falta de autonomía en el puesto de trabajo), el trabajo estable para toda la vida en una misma empresa, los períodos separados de formación y empleo, la retribución únicamente fija y un marco de relaciones laborales, con un contrato social que intercambia horas homogéneas de trabajo y salarios fijos por productividad, se van agotando lentamente. En sustitución de las formas tradicionales de empleo, se consolida una nueva forma de trabajo en red. Se trata de la forma típica, en el sentido de fundamental, de estructurar el trabajo ante las nuevas condiciones de innovación, flexibilidad y bienestar que demanda la economía global del conocimiento. El trabajo en red, que amplifica el trabajo cognitivo no rutinario y sustituye al trabajo no cognitivo y cognitivo rutinario, se caracteriza por cinco elementos clave (Torrent-Sellens y Ficapal-Cusí, 2009):

- En primer lugar, por la intensidad de las competencias en el uso de las tecnologías de la información y la comunicación (TIC), o competencias digitales.

- En segundo lugar, por una estrategia competitiva de las empresas basada en la innovación como instrumento imprescindible para competir flexiblemente en la economía global del conocimiento.

- En tercer lugar, por una organización del trabajo flexible, lejos de los esquemas tayloristas y fordistas, con un trabajo autónomo por equipos y proyectos, una toma de decisiones autónoma y descentralizada y una supervisión basada en objetivos/resultados.

- En cuarto lugar, por unos trabajadores cualificados, polivalentes, comprometidos y con una división del trabajo basada en el conocimiento de todo tipo, no únicamente el científico y tecnológico.

- Y, en quinto lugar, por unas prácticas de gestión de los recursos humanos avanzadas, con unos mecanismos de selección y trabajo por competencias, formación y cualificación constante, formas de retribución variable y un marco de relaciones laborales flexible pero estable. En este contexto, aparece un nuevo contrato social que intercambia conocimiento, innovación, trabajo heterogéneo y compromiso por retribuciones, formales e informales, basadas en el cumplimiento de objetivos y con la incorporación de los trabajadores en la toma de decisiones. Este nuevo contrato social intercambia competitividad por gestión colaborativa. 
Pero sobre este proceso de consolidación del trabajo en red, durante los últimos años se está construyendo un nuevo escenario de cambio para el mundo laboral. Sobre las transformaciones vinculadas con la tercera revolución industrial, la de las TIC y de internet, se ha generado una nueva oleada de cambio tecnológico disruptivo, que algunos, quizá precipitadamente, ya han denominado cuarta revolución industrial, pero que empieza a generar también importantes transformaciones sobre los mercados de trabajo. Todo parece indicar que estamos a las puertas de una nueva oleada tecnológica de utilidad general, que refuerza y profundiza la oleada de las tecnologías digitales y la era de la información y el conocimiento (tercera revolución industrial). La robótica, la inteligencia artificial, el aprendizaje de las máquinas o aprendizaje profundo, la computación en la nube, los grandes datos, la impresión 3D, internet de la cosas, la nanotecnología y la biotecnología parece que se configurarán como una base tecnológica interconectada de un nuevo paradigma técnico-económico que se interrelacionará con cambios sociales y culturales de primera magnitud (Torrent-Sellens, 2015). Esta nueva oleada tecnológica, que se materializará con fuerza durante los próximos años, tiene implicaciones fundamentales en la explicación de la productividad y la estructura del empleo. A lo largo del artículo, revisaremos estas implicaciones y pondremos especial énfasis en los efectos sobre el trabajo de la robótica inteligente y sus implicaciones para las prácticas de recursos humanos. Para contestar a esta pregunta, lo primero que debemos establecer es ¿cómo está evolucionando la robótica y en qué dirección?

\section{Revolución cámbrica en la robótica}

Según la Federación Internacional de Robótica (IFR, 2017), un robot es un manipulador multipropósito, controlado automáticamente, reprogramable y que puede ser fijo o móvil. Durante los últimos años, los datos disponibles nos señalan una presencia claramente creciente y una amplia diversificación de utilidades de los robots industriales (utilizados en los procesos de automatización industrial). Según las previsiones de la IFR, en 2020 más de 2,5 millones de robots serán utilizados por la industria mundial, a un ritmo de crecimiento anual que superará el 10 \% y con un número de unidades que duplicará sobradamente el de los robots que había a principios de la década (poco más de un millón en 2010). A pesar de que más del $70 \%$ de los robots instalados en la actualidad se ubican principalmente en cuatro ramas de actividad industrial -automoción, electricidad y electrónica, metalurgia y química-, durante los próximos años se prevé una expansión hacia otras ramas, como resultado de cuatro tendencias detectadas: 
- En primer lugar, gracias a los avances en la compactación y usabilidad de los robots que determina la introducción de las nuevas aplicaciones en inteligencia artificial y programación.

- En segundo lugar, por la creciente colaboración entre humanos y robots, lo que permite la complementariedad de tareas y un trabajo conjunto mucho más eficiente que si se realiza por separado.

- En tercer lugar, la incorporación de las PYMES al mundo de la robótica, lo que permitirá un crecimiento muy amplio de su base de aplicación.

- Y, en cuarto lugar, las mejoras de eficiencia económica y ambiental que la robótica introduce y que la actividad industrial debería adoptar para desarrollar un sistema productivo más limpio y sostenible, además de eficiente.

La mayoría de investigadores coincide en que, en la actualidad, la robótica experimenta una explosión vinculada con un crecimiento exponencial de su diversificación y aplicabilidad. Algunos denominan a este período revolución cámbrica, en el sentido de que la robótica vive una situación similar a la que vivió la vida en la tierra hace unos 500 millones de años (Pratt, 2015). Esta revolución estaría vinculada con el hecho de que muchas de las tecnologías de base que se aplican sobre la robótica, en especial la informática (rendimiento informático; instrumentos de diseño electromecánico y fabricación controlada numéricamente), el almacenaje de energía y datos (poder computación global) y las comunicaciones (inalámbricas e internet), han crecido exponencialmente en potencia y capacidad durante los últimos años. Además, dos nuevas tecnologías, la robótica en la nube (cloud robotics) y el aprendizaje en profundidad (deep learning) podrían retroalimentarse del crecimiento de las tecnologías básicas y generar un círculo virtuoso de diversificación y aplicabilidad de la robótica durante los próximos años. La robótica en la nube permite a los robots aprender de la experiencia de otros robots, en especial a medida que crece su número. Los algoritmos de aprendizaje profundo son métodos pensados para que los robots aprendan y generalicen su aprendizaje sobre la base de conjuntos de adiestramientos muy grandes (grandes datos en la nube). Esta nueva fase de la robótica se sustenta en cuatro fundamentos principales:

- En primer lugar, la autonomía basada en la memoria. Los avances en el rendimiento de la computación y la capacidad de almacenaje de datos han permitido a los investigadores de la robótica explorar nuevos métodos basados en la memoria para resolver los tradicionales problemas de percepción, planificación y control que limitaban la autonomía de los robots. Gracias a los algoritmos de búsqueda rápida en internet y a la computación en la nube, hoy los robots pueden acceder a un gran número de experiencias previas que pueden ser utilizadas para guiar una respuesta. Si no hay memoria anterior coincidente, el robot 
puede pedir ayuda a las personas. Una vez ha recibido la ayuda, la respuesta se codifica y ya puede ser utilizada en forma de memoria por otros robots.

- En segundo lugar, la posibilidad de compartir experiencias a alta velocidad. A diferencia de las personas, por el momento imbatibles en su velocidad de comunicación interna (redes neuronales de su cerebro), los robots son claramente superiores en su capacidad de comunicación externa. Una combinación de comunicación inalámbrica a través de internet puede ser utilizada para que los robots compartan lo que van aprendiendo. Mientras que las personas tardan mucho más tiempo en aprender cosas suficientes para agregar de manera significativa a su compendio de conocimiento común, los robots pueden hacerlo mucho más rápida y eficientemente a través de la velocidad de comunicación externa.

- En tercer lugar, la posibilidad de aprender a través de la imaginación. Las personas utilizan la imaginación para practicar o prepararse para afrontar circunstancias futuras. Del mismo modo, un robot que usa sus capacidades de computación en la nube puede usar la simulación para explorar futuras circunstancias y experimentar soluciones. Rápidamente las soluciones exitosas pasarán a formar parte del bagaje de conocimiento acumulado de la robótica en la nube, lo que mejora el rendimiento de todos los robots.

- $\quad$, en cuarto lugar, la posibilidad de aprender de las personas. La percepción sigue siendo uno de los retos más importantes que la robótica debe afrontar para la mejora de la autonomía de los robots. A través de las recientes mejoras en la capacidad para el tratamiento y el análisis de grandes conjuntos de datos, la robótica puede avanzar muchísimo en este sentido. A título de ilustración, todo el conjunto de contenidos digitales que las personas compartimos en los medios de comunicación y redes sociales son un recurso enorme que, con la suficiente capacidad de computación, los robots utilizarán, por ejemplo para identificar, asimilar o verificar comportamientos.

Pero ¿cuáles son las implicaciones para la economía y el trabajo que puede tener esta revolución cámbrica que se espera para la robótica inteligente durante los próximos años? A continuación, las analizaremos.

\section{Robótica y empleo: ¿complementariedad o sustitución?}

Parece evidente que esta nueva generación de robots inteligentes podría contribuir a generar más valor y riqueza a través de nueva actividad, aumentos de productividad, nuevo empleo, y más salarios y demanda. En este contexto, durante los últimos años, la investigación ha consolidado una visión de efectos optimista, que 
entronca con la teoría clásica sobre el cambio tecnológico sesgador de habilidades y su posibilidad de crear puestos de trabajo y recolocar a los empleados excluidos a través de la formación, el aprendizaje y la política pública (Autor, 2015). Esta visión optimista esgrime un conjunto de tres argumentos básicos:

- En primer lugar, a pesar de que los ordenadores y los robots han asumido tareas vinculadas con el trabajo de oficina y los trabajos rutinarios, al mismo tiempo también han proliferado puestos de trabajo que requieren importantes dosis de creatividad y habilidades para la resolución de problemas. Estos nuevos puestos de trabajo vinculados con la innovación, en muchas ocasiones apoyados con tareas de computación y comunicación realizada por ordenadores e Internet, crecen en todo el mundo.

- En segundo lugar, en paralelo con el crecimiento de los puestos de trabajo de elevada cualificación, los empleos de baja cualificación también han aumentado para aquel conjunto de tareas que son difíciles de automatizar, como algunas de las tareas que realizan los empleados de la restauración, conserjes o tareas del hogar.

- Y, en tercer lugar, en general los resultados de la primera oleada tecnológica digital, la de las TIC e internet, han sido favorables sobre el empleo. La investigación sobre el cambio tecnológico digital sesgador de habilidades ha demostrado que el uso de ordenadores e internet se ha asociado con niveles más elevados de ocupación y salarios para los trabajadores con las competencias digitales y educativas necesarias. Sin embargo, como toda oleada de innovación tecnológica, la postura más optimista también reconoce que la robotización y la digitalización cambiarán profundamente los mercados de trabajo, en el sentido de que pueden generar grandes eficiencias que reduzcan los tiempos de trabajo. Ahora bien, esta liberación de tiempo, que requeriría la reestructuración y reeducación de muchos trabajadores, también podría acabar generando nuevos nichos de ocupación, por ejemplo en la industria del ocio, viajes y turismo. En todo caso, el flujo económico podría continuar generando nuevas oportunidades de empleo basadas en la creatividad y la innovación. Inclusive, es posible plantear escenarios de trabajo alternativo, contingente, donde buena parte de la generación de rentas provenga de la robótica y los trabajadores humanos puedan plantearse otros tipos de contribución económica y social.

Sin embargo, durante los últimos años también ha proliferado una aproximación más pesimista. Esta defiende que la nueva oleada de innovaciones tecnológicas digitales estaría destruyendo masivamente puestos de trabajo. Esta postura, contrastada principalmente para los mercados de trabajo en Estados Unidos, destaca diversos argumentos (Brynjolfsson y McAfee, 2012; 2014): 
- En primer lugar, que la recesión económica en Estados Unidos durante el período 2007-2010 consolidó pérdidas permanentes de puestos de trabajo. Es decir, que una vez superada la crisis y llegada la recuperación, la creación de puestos de trabajo no se aceleró. Este fenómeno se ha reconocido como recuperación sin creación de empleo (jobless recovery).

- En segundo lugar, se constata también una creciente divergencia entre los incrementos de productividad y los aumentos de ocupación en Estados Unidos desde el año 2000. A diferencia de lo sucedido en otros ciclos económicos, estas dos magnitudes no evolucionan en concordancia (la productividad crece y la ocupación se mantiene estable), de manera que las mejoras de eficiencia no se trasladan al mercado de trabajo. La tecnología digital sería la principal responsable de este desencaje.

- Y, en tercer lugar, la disminución de la ocupación ya no se limitaría solo a los puestos de trabajo de la industria deslocalizada en México o China. Los trabajadores de cuello blanco, y los profesionales y técnicos cualificados, ya no serían inmunes a las pérdidas permanentes de puestos de trabajo. Como consecuencia, los niveles medios de ingreso y renta disponible de los trabajadores no crecerían, a pesar de los aumentos del producto generado. Todo ello acabaría redundando en notables aumentos de la desigualdad, porque las rentas generadas por los avances en el ingreso se quedan en pocas manos. En perspectiva histórica se trataría de una gran paradoja: innovación y productividad en niveles récord y, al mismo tiempo, caídas de ingresos, menos puestos de trabajo y aumento de la desigualdad. Esta paradoja estaría relacionada con el hecho de que la nueva oleada tecnológica digital avanzaría tan rápido y abarcaría un conjunto tan amplio de nuevas aplicaciones que las habilidades de las personas y las organizaciones no podrían seguir su ritmo (Rotman, 2013).

A pesar de que la aproximación pesimista defiende la utilidad de las oleadas tecnológicas anteriores, que habrían mejorado ostensiblemente la ocupación, salarios, riqueza y calidad de vida en todo el mundo, en el caso de la oleada actual, se defiende justo lo contrario. Este argumento pesimista se asienta sobre un conjunto de premisas (Ford, 2015):

- En primer lugar, sobre la predicción de que alrededor de la mitad de los puestos de trabajo actuales podrían ser automatizados, aunque parcialmente (Frey y Osborne, 2013).

- En segundo lugar, las tendencias actuales en los mercados de trabajo, en especial los aumentos de la dispersión salarial, la disminución de la participación del trabajo en la renta nacional y los aumentos del paro estarían vinculados con la automatización y la digitalización. 
- En tercer lugar, la caída de precios de los ordenadores y el aumento de capacidad de los procesadores harían más atractiva la sustitución de trabajadores por robots.

- Y, en cuarto lugar, el actual progreso en robótica e inteligencia artificial dirigirían hacia una nueva dirección las tradicionales relaciones entre innovación tecnológica y trabajo. Los avances en tecnología robótica permitirían la creación de robots inteligentes, fáciles de programar y con capacidades para realizar un trabajo cognitivo que sustituiría masivamente el trabajo humano. En este contexto de sustitución masiva del empleo, para solventar los problemas sobre los mercados de trabajo de la oleada tecnológica vinculada con la robótica inteligente, se haría del todo necesaria una reestructuración en profundidad de todo el sistema económico. Las medidas compensatorias tradicionales, como las prestaciones de paro o las pensiones, inclusive la educación o la actualización de habilidades, resultarían insuficientes para resolver los problemas de los trabajadores desplazados.

En resumen, esta aproximación más pesimista sustenta que la velocidad de sustitución de habilidades humanas por parte de los robots puede generar situaciones de exclusión muy importantes, puesto que el tiempo de adaptación demandado a la fuerza de trabajo será mucho más rápido y la oferta de capacidades (cuerpos que hacen trabajo manual y mentes que hacen trabajo cognitivo) de las personas se irá reduciendo. De hecho, se postula que el aumento de las capacidades de los robots reducirá aceleradamente el valor del trabajo humano en muchos sectores de actividad, hasta el punto de que no habrá tiempo de recuperar el trabajo desplazado a través de la generación de nuevos empleos en nuevas empresas. En este contexto, se postula un futuro donde muchos de los bienes materiales que la mayoría de la gente demanda pueden ser producidos a bajo coste por robots. Esta economía podría evolucionar de varias maneras. Pero los problemas de desigualdad serían evidentes si pocas personas con talentos excepcionales y no replicables por parte de los robots recibieran ingresos muy elevados, mientras que la mayoría de personas tendrían que contentarse con unos niveles de ingresos muy bajos.

\section{Conclusión: recursos humanos y robots. ¿Es posible la co-robótica?}

Acabamos de constatar que se va acumulando evidencia acerca de los efectos positivos de la robótica inteligente sobre la productividad y con efectos mixtos sobre el empleo. Pero, más allá de los cambios en la composición de la fuerza de trabajo hacia una creciente polarización del empleo en ocupaciones cognitivas de eleva- 
dos ingresos y ocupaciones manuales de bajos ingresos, con un amplio espectro de crecimiento para la tecnología en los empleos rutinarios y de ingresos medios, el efecto de la nueva oleada tecnológica sobre el futuro del empleo está lejos de la certidumbre (Bessen, 2016).

Es verdad que la automatización, la digitalización y la robótica se expandirán a través de la sustitución del empleo rutinario y que este proceso es claramente ahorrador de empleo (Frey y Osborne, 2013). Ahora bien, no existe evidencia que demuestre que la revolución digital, la primera oleada de innovaciones tecnológicas disruptivas vinculadas con las TIC e internet, haya reducido la demanda global de empleo, más bien todo lo contrario. Inclusive, los sectores tecnológicamente menos avanzados de la economía, como algunos sectores públicos, o algunas dimensiones empresariales menos proclives a la digitalización, como las PYMES, siguen creando empleos a partir de la revolución digital. A medida que la automatización y la robótica se expandan hacia los sectores más tecnológicamente atrasados, la innovación y la productividad deberían generar incrementos de renta en forma de mayores salarios o mayor capacidad de compra de otros productos. Así pues, más allá de un desfase mayor que en el pasado entre ocupación perdida y ocupación generada en el corto plazo, nada sugiere que, en el largo plazo, la nueva oleada digital de la automatización robótica y la inteligencia artificial no sea capaz de explotar los beneficios para el empleo que ya ha aprovechado otras oleadas tecnológicas anteriores.

De hecho, muchas de las previsiones sobre la sustitución del trabajo a raíz de la nueva oleada de la digitalización no tienen presente la posibilidad de un cambio en la relación de habilidades entre personas y máquinas, lo que podría redundar en aumentos de eficiencia y reforzar las relaciones de complementariedad por encima de las relaciones de sustitución. En este sentido, la co-robótica, es decir la posibilidad de que los robots y las personas trabajen juntos y mejoren conjuntamente la eficiencia de su trabajo (por encima de las tareas realizadas por separado), ya empieza a ser una realidad. Por otra parte, la investigación también ha puesto de relieve la importancia del nivel general de demanda (Autor, 2015). A pesar de la sustitución de tareas generada por la tecnología, los vínculos entre las personas en las tareas no sustituidas tienden a reforzarse. La nueva oleada de la robótica inteligente tiende a eliminar empleos (puestos de trabajo, ocupaciones o tareas), pero no el trabajo. El cambio tecnológico, junto con las otras formas del cambio económico, es un determinante importante de los puestos de trabajo, las industrias y las personas afectadas por el paro y la descualificación. Pero el nivel general de demanda de bienes y servicios es el factor más importante que determina cuántas personas se ven afectadas, por cuánto tiempo estarán en el paro y lo difícil que es para los nuevos integrantes del mercado de trabajo encontrar un empleo. 
En esta aproximación dinámica, la relación entre la nueva oleada digital, la robótica y el empleo también se matizaría en el sentido de que en la economía habría fuerzas de autocorrección que compensarían los efectos negativos identificados (Acemoglu y Restrepo, 2015). En especial, se ha señalado que el proceso innovador vinculado con la automatización y el trabajo más cognitivo podrían ir en paralelo, y que la inversión en robótica reduciría la relación entre el salario y la tasa de rendimiento de las empresas, lo que podría hacer más atractiva la inversión en trabajo humano cognitivo. Del mismo modo, estas fuerzas autocorrectoras (compensación en la inversión entre trabajo cognitivo y no cognitivo) se podrían también en marcha para compensar algunas de las desigualdades generadas entre los trabajadores con distintas habilidades.

Pero más allá de los modelos, investigaciones y predicciones, la investigación pone de relieve que la dinámica de los mercados de trabajo es muy compleja y obedece a un amplio conjunto de fuerzas impulsoras y detractoras. A pesar de las diferencias de visión detectadas sobre las tareas, empleos y actividades económicas que se verán más afectadas por la nueva oleada digital de la robótica inteligente, existe un claro consenso que señala que la fuerza de trabajo -actual y futura- debería dotarse de las suficientes habilidades y cualificaciones para que las personas puedan aprovechar las mejores condiciones de trabajo y salarios que impulsan la automatización, la computarización, la robótica y la inteligencia artificial. Esta tarea de equiparar las generaciones actuales y futuras de trabajadores con las habilidades necesarias para trabajar con los robots, y con todo tipo de maquinaria y aplicaciones digitales de nueva generación, recae tanto en las personas como en las empresas.

Sin duda, el reto que plantea la nueva oleada digital y la robótica inteligente es mayúsculo, tanto para las personas como para las empresas. Las posibilidades de que las empresas se suban a esta nueva oleada digital, y sean capaces de aumentar su competitividad y su capacidad de generación de nuevo empleo y con mayor calidad, son importantes. Sin embargo, los riesgos de pérdida de puestos de trabajo, exclusión de ocupaciones, caídas de la calidad del empleo y aumentos de la desigualdad también son evidentes si la balanza de la utilización de la robótica y la nueva oleada digital se decanta hacia la sustitución del trabajo. Una nueva orientación estratégica de los recursos humanos hacia la incorporación de la nueva oleada tecnológica, y nuevos sistemas y prácticas de gestión para capacitar y desarrollar a los empleados en el contexto de la co-robótica, parecen inevitables. 


\section{Referencias bibliográficas}

ACEMOGLOU, D.; RESTREPO, P. (2015). The race between man and machine: Implications of technology for growth, factor shares and employment. Paper no publicado. Cambridge, MA: MIT Press.

AUTOR, D. H. (2015). «Why are there still so many jobs? The history and future of workplace automation». Journal of Economic Perspectives. Vol. 29, núm. 3, págs. 3-30.

BESSEN, J. (2016). «Computers don't kill jobs but do increase inequality». Harvard Business Review (marzo).

BRYNJOLFSSON, E.; McAFEE, A. (2012). Race against the machine: How the digital revolution is accelerating innovation, driving productivity, and irreversibly transforming employment and the economy. Cambridge, MA: MIT Press.

BRYNJOLFSSON, E.; McAFEE, A. (2014). The second machine age: work, progress, and prosperity in a time of brilliant technologies. Nueva York: W. W. Norton \& Company.

FORD, M. (2015). Rise of the robots. Technology and the threat of a jobless future. Nueva York: Basic Books.

FREY, C. B.; OSBORNE, M. (2013). The future of employment: How susceptible are jobs to computerisation? Oxford: Oxford Martin School.

INTERNATIONAL FEDERATION OF ROBOTICS (2017). The impact of robots on productivity, employment and jobs. A positioning paper by the International Federation of Robotics. Frankfurt am Main: IFR.

PRATT, G. A. (2015). «ls a Cambrian explosion coming for robotics?». Journal of Economic Perspectives. Vol. 29, núm. 3, págs. 51-60.

ROTMAN, D. (2013). «How technology is destroying jobs». MIT Technology Review. Vol. 116, núm. 4, pags. 27-35.

TORRENT-SELLENS, J. (2015). "Knowledge products and network externalities. Implications for the business strategy». Journal of the Knowledge Economy. Vol. 6, núm. 1, págs. 138-156.

TORRENT-SELLENS, J.; FICAPAL-CUSÍ, P. (2009). TIC, conocimiento, redes y trabajo. Barcelona: Ediciones de la UOC. 


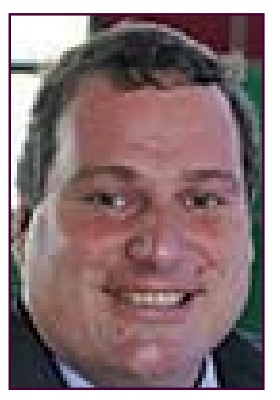

\section{Joan Torrent-Sellens jtorrent@uoc.edu Profesor de los Estudios de Economía y Empresa (UOC)}

Licenciado en Ciencias Económicas y Empresariales (UAB), máster en Análisis de Economía Aplicada (UAB) y doctor en Economía (Programa Sociedad Información y el Conocimiento) por la UOC. Director del grupo de investigación interdisciplinaria sobre las TIC, i2TIC (http://i2TIC. net) y profesor agregado (ámbito de economía) en los Estudios de Economía y Empresa de la UOC. Especialista en el análisis de las tecnologías de la información y la comunicación (TIC), la economía del conocimiento, y la empresa y el trabajo en red, temática sobre la que ha publicado veinticinco libros y setneta y cinco artículos en revistas de investigación indexadas.

Los textos publicados en esta revista están sujetas -salvo que se indique el contrario- a una licencia de Reconocimiento 3.0 España de Creative Commons. Podéis copiarlos, distribuirlos, comunicarlos públicamente y hacer obras derivadas siempre que reconozcáis los créditos de las obras (autoría, nombre de la revista, institución editora) de la manera especificada por los autores o por la revista. La licencia completa se puede consultar en http://creativecommons.org/licenses/by/3.0/es/deed.ca.

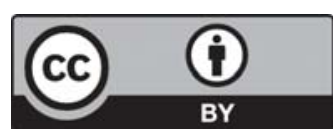




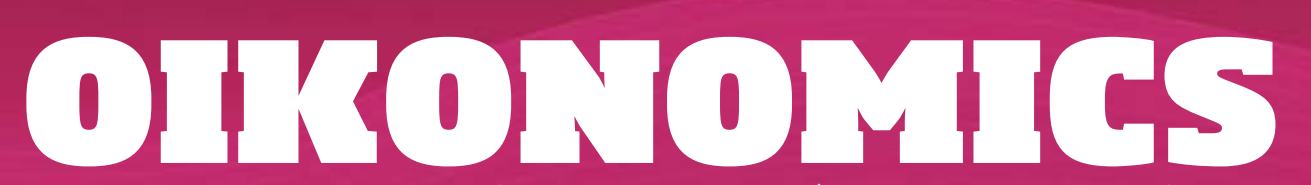

Revista de economía, empresa y sociedad

DESDE LA PERSPECTIVA DEL MARKETING

\section{La influencia de las Sense Girls en las mujeres de entre 25 y 45 años 1}

\section{Marina Sánchez Marcos}

Alumni Grado de Marketing e Investigación de Mercados (UOC)

RESUMEN La pérdida de influencia de los medios convencionales debido a la aparición de internet ha incrementado la preocupación de las marcas por conocer cómo influenciar a los diferentes segmentos existentes en España. Pero hay algo que continúa influenciando a las personas: las opiniones de terceros (antes of-fline y ahora también on-line). Por lo tanto, resulta interesante para las marcas analizar las nuevas opiniones transmitidas en línea por terceras personas, las cuales pueden provenir también de influencers, que son precisamente el foco de este estudio.

Por ello, esta investigación se centra en conocer cuál es la percepción que tienen las mujeres de entre veinticinco y cuarenta y cinco años (un segmento de la sociedad española, el público objetivo) de las Sense Girls (como influencers principales en los sectores de moda, belleza y Fitness/Life\&Style, importantes para el público objetivo) en YouTube e Instagram, y se interesa por cómo se comunican y cómo deberían ser tenidas en cuenta en el ámbito del marketing/comunicación.

Debido a la imposibilidad de conocer esta información gracias a fuentes secundarias, se ha realizado una investigación ad hoc (cuantitativa-cuestionario-y cualitativa-focus group, entrevistas en profundidad, análisis de canales-).

1. Depositado en el Repositorio Institucional de la UOC (O2) <http://hdl.handle. net/10609/61465>, el portal que recoge, difunde y preserva las publicaciones digitales en acceso abierto de los miembros de la UOC, elaboradas en el desarrollo de sus actividades de investigación, docencia y gestión. 
Gracias a su desarrollo, se puede concluir que las Sense Girls deberían ser utilizadas en las estrategias de marketing de las marcas y se deberían diferenciar los tipos de comunicación para cada uno de los clústeres en los que se dividen las mujeres de entre veinticinco y cuarenta y cinco años.

PALABRAS CLAVE investigación de mercados; sense girls; mujeres 25 45; influencers; marketing; estrategia

\section{The influence of Sense Girls on women aged between 25 and 45}

ABSTRACT The loss of influence of conventional media, due to the emergence of the Internet, has increased the concerns of brands in terms of ascertaining how to influence different segments that exist in Spain. However, there is a factor that continues to influence people: the opinions of third parties (formerly offline and now also online). Therefore, it is interesting for brands to analyse new opinions transmitted online by third parties, that may also be influencers and who are the focus of this study.

With this in mind, this research focuses on the perception of women between 25 and 45 years old, (a segment of Spanish society - the target group) of the Sense Girls (as key influencers in the fashion, beauty and Fitness/Life \& Style sectors, important for the target group) on YouTube and Instagram, focusing on how they communicate and how they could be taken into account in the field of marketing/communication.

Since this information could not be obtained from secondary sources, an ad hoc quantitative (questionnaire) and qualitative (focus group, in-depth interviews, channel analysis) investigation has been carried out.

As a result of this research, it can be concluded that the Sense Girls should be used in the marketing strategies of brands, differentiating communication types for each of the clusters into which women between 25 and 45 are divided.

KEYWORDS market research; sense girls; women 25-45; influencers, marketing; strategy 


\section{Introducción}

La sociedad está cambiando a pasos agigantados, principalmente debido a la aparición de las nuevas tecnologías. La conectividad ha hecho que los comportamientos de las personas se vean modificados, tanto las relaciones sociales como las maneras de consumir los medios de comunicación y la información (definidos por quererlo todo "aquí y ahora»). Por lo tanto, las marcas tienen que buscar nuevas maneras para poder contactar con sus públicos objetivo, porque con el antiguo modelo es cada vez más difícil hacerles llegar los mensajes que se les quieren transmitir. Ante esta situación, es necesario el estudio de nuevas maneras de poder contactar con los diferentes targets, principalmente buscando formatos que ayuden a conseguir, por un lado hacer llegar nuestros mensajes, y por otro, hacerlo de la manera más creíble posible.

Por todo esto, la investigación realizada analizaba un segmento de la sociedad relevante para multitud de marcas: las mujeres entre veinticinco y cuarenta y cinco años, tratando de buscar una manera efectiva y eficaz para poder comunicarse con ellas. ¿Cómo? Por medio de análisis de dichas vías alternativas de comunicación, concretamente analizando si se debería implementar en las estrategias de marketing el uso de influencers (más en concreto, las Sense Girls²) y cómo debería realizarse para establecer una comunicación con las mujeres entre veinticinco y cuarenta y cinco años.

\section{Objetivos de la investigación}

El principal objetivo de recabar esta información era tener argumentos y conclusiones suficientes para conocer si se debería o no implementar una estrategia utilizando a las Sense Girls, y cómo se debería realizar concretamente. Por lo tanto, los objetivos principales y sus consiguientes específicos eran:

2. Aquellas mujeres de entre vienticinco y cuarenta y cinco años con una relevancia en redes sociales que son expertas en estética, moda y tendencias, con una virtuous perception. Son refinadas, independientes, elegantes y exóticas, sus intereses son trabajar, comprar y todo lo relativo al arte y la moda, además de tener conciencia social (se preocupan por la ecología y el desarrollo sostenible). 
Tabla 1. Objetivos de la investigación

\section{Conocer las características del target 25-45}

a. Detectar si existen diferentes clústeres dentro del target y cómo afectaría su existencia a la hora de definir las características del target.

b. Definir su perfil demográfico y cultural.

c. Definir sus intereses, valores, gustos y aficiones.

d. Definir su consumo de medios (off y on-line, con especial énfasis en los medios digitales).

e. Definir cuál es la percepción de las Sense Girls.

\section{Conocer las características de las Sense Girls}

a. Conocer el listado de las Sense Girls más conocidas de España.

b. Definir sus intereses, valores, gustos y aficiones.

c. Definir cuál es su relación con las diferentes marcas del mercado.

d. Definir cómo se comunican con el resto de la población (su poder de influencia).

\section{Cómo podrían ser utilizadas en las estrategias a corto-medio plazo}

a. Descubrir y definir los valores, funcionalidades, atributos y beneficios de la utilización de las Sense Girls en las estrategias de marketing.

b. Definir cuáles son los modos que el target de mujeres 25-45 años considera mejor para que las marcas se acerquen a ellas.

c. Definir cómo deberían ser dichas estrategias a corto-medio plazo.

\section{Fuentes de información}

Las fuentes de información para desarrollar este proyecto de investigación fueron:

1. Fuentes secundarias de información: se utilizó el $\mathrm{INE}^{3}$ para definir el universo objeto de estudio (mujeres 25-454).

3. INE: Instituto Nacional de Estadística (http://www.ine.es).

4. Finalmente, se descartaron fuentes como EUROSTAT (http://ec.europa.eu/eurostat/data/ database), CIS (http://www.cis.es/cis/opencms/ES/index.html) y el Observatorio Nacio- 
2. Fuentes primarias: debido a la imposibilidad de encontrar información sobre la percepción de las mujeres 25-45 sobre las Sense Girls, e información relevante para conocer a este tipo de influencers, se llevaron a cabo investigaciones tanto cuantitativas como cualitativas para obtener dicha información:

a) Mujeres 25-45: se llevó a cabo una investigación cuantitativa y posteriormente una investigación cualitativa para profundizar en cuestiones más subjetivas y extraer insights relevantes para la investigación, gracias a la realización de entrevistas en profundidad y un focus group.

b) Sense Girls: para poder definir este target, se necesitó obtener un listado de las Sense Girls en España para posteriormente analizar los canales de las más relevantes (aquellas con un mayor número de seguidores).

\section{Metodología}

Se plantearon dos tipos de investigaciones diferentes, tanto cualitativas como cuantitativas:

1. En cuanto a la investigación cuantitativa, se llevó a cabo un muestreo por conveniencia, mediante una encuesta en línea a 401 personas con Google Forms (tanto en internet como con encuestas presenciales en diferentes puntos de Madrid para conseguir tener una muestra suficiente). En dicho cuestionario, las tres primeras preguntas eran de filtro (si no se cumplía que el entrevistado fuese mujer, de entre veinticinco y cuarenta y cinco años, y decisor de la compra de las categorías especificadas, no se continuaba con el cuestionario) y si pasaba dicho filtro, se les realizaban preguntas sobre su nivel de gasto, sus intereses, sus valores, su estilo de vida, su consumo de medios (con especial interés en internet), la influencia de dichos medios a la hora de sus decisiones de compra, si siguen a influencers o no, a cuáles seguían, por qué las seguían o por qué no lo hacían, de qué temas les gustaría que hablasen o de qué temas les gusta que hablen, si comprarían productos recomendados por ellos, cómo

nal de las Telecomunicaciones y de la SI (http://www.ontsi.red.es/ontsi/es/estudios-informes) debido a la imposibilidad de poder diferenciar las mujeres que están interesadas en moda y/o las que lo están por la belleza/estilo de vida. Y también Kantar (http://es.kantar. com/archivo/) al no encontrar ningún artículo relevante para nuestro caso, ni WARC (http:// www.warc.com/Pages/CaseStudies/CaseFinder.aspx) al no encontrar ningún case study para este caso. También se han descartado finalmente AIMC Marcas, el Estudio General de Medios y Navegantes en la Red. 
creen que es su comunicación y cómo les gustaría que se comunicasen con ellos. Con toda esta información, se pudieron detectar cuatro grupos dentro del target gracias a un análisis de clúster por medio de las variables actitudinales del cuestionario.

2. En cuanto a las investigaciones cualitativas, llevé a cabo diferentes tipos según el target que se debía analizar:

a) Para conocer a las mujeres de entre veinticinco y cuarenta y cinco años, realicé cuatro entrevistas en profundidad y un focus group con un guion semiestructurado para profundizar en algunos temas extraídos de la investigación cuantitativa. Tras su realización, se realizó una transcripción de las grabaciones para llevar cabo un análisis inicial con la intención de identificar las secciones relacionadas con la investigación y un análisis del contenido de las transcripciones para describir el contenido del texto, establecer categorías y asignar los comentarios a diferentes categorías/temas: qué impacto tienen las influencers, el proceso de compra y consumo de medios, los motivos para seguir o no seguir a las Sense Girls, la relación con las marcas y las ventas de productos y cómo veían el futuro de las influencers. Posteriormente, realicé un análisis en profundidad de cada uno de estos temas según los objetivos de la investigación.

b) Y para conocer a las Sense Girls, se realizó fue un listado de estas en España en YouTube y en Instagram. Para ello se recurrió a contactos del sector para que nos facilitasen información, que se completó posteriormente:

- El de youtubers con un muestro de bola de nieve con los perfiles sugeridos en YouTube y completándolo con aquellos resultantes de la investigación cuantitativa.

- El de instagramers con los resultados de la investigación cuantitativa.

Una vez obtenido el listado, se comprobó que estas tuviesen entre veinticinco y cuarenta y cinco años y que hablasen de las categorías seleccionadas. Una vez realizado dicho paso en ambos listados, y tras filtrar únicamente por aquellos que cumplían con las características de las Sense Girls, se consultaron todos los canales de dichas influencers para ver cuáles tenían abiertos y el números de seguidores en cada uno de ellos. Posteriormente, para llevar a cabo el resto del análisis, se seleccionaron aquellas que más seguidoras tuviesen en la red social analizada para llevar a cabo un análisis cualitativo de canales (se seleccionaron aquellos con mayor número de seguidores sin dejar fuera a ninguno de los diez canales más seguidos por la muestra del cuestionario). Finalmente, se analizaron once canales de YouTube y catorce de Instagram y se observó qué temáticas trataban, el lenguaje y la estética que utilizaban, y cómo recomendaban productos. 
Tabla 2. Canales analizados

\begin{tabular}{|l|l|}
\multicolumn{1}{|c|}{ Youtubers } & \multicolumn{1}{c|}{ Instagramers } \\
\hline 1. Patry Jordan & 1. Paula Echevarría \\
\hline 2. Dulceida (Aída Domenech) & 2. Dulceida (Aída Domenech) \\
\hline 3. Verdeliss & 3. Lovely Pepa \\
\hline 4. A Little Too Often & 4. Collage Vintage \\
\hline 5. HAPPY SUNNY FLOWERS (Grace) & 5. Gala González \\
\hline 6. Dare to DIY (Sylvia Salas) & 6. Trendy Taste Channel (Natalia Cabezas) \\
\hline 7. Marta Riumbau & 7. Verdeliss \\
\hline 8. Isasaweis & 8. Vikika fitness \\
\hline 9. Ratolina & 9. Marta Riumbau \\
\hline 10. Vik Guirao & 10. Vik Guirao \\
\hline 11. Balamoda & 11. HAPPY SUNNY FLOWERS (Grace) \\
\hline & 12. Isasaweis \\
\hline
\end{tabular}

Fuente: elaboración propia.

\section{Principales conclusiones}

Se concluyó que las Sense Girls influyen en las opiniones de las mujeres entre vienticinco y cuarenta y cinco años debido a que más del 60 \% de la población podría estar influenciada por ellas. Por lo tanto, fue posible definir cómo podrían ser utilizadas este tipo de influencers en las campañas de marketing, y se tuvieron en cuenta los diferentes clústeres detectados en el target mujeres 25-45 años (treending boosters ${ }^{5}$, alpha

5. Este clúster ha sido denominado treending boosters, ya que reconocen que les gusta estar a la última en todo (trending) y les encanta ver y compartir contenido en redes sociales (boosters). Su consumo de redes sociales se asemeja mucho al de los adolescentes (siempre al día, constantemente conectados), además de estar formado por mujeres jóvenes (de ahí que la denominemos teens). 
$2.0^{6}$, old-fashioned restrained ${ }^{7}$ y off the retro ${ }^{8}$ ), ya que estas influencers influencian en diferente medida y manera a cada clúster.

Tabla 3. Resumen información obtenida de los clústeres

\begin{tabular}{|c|c|c|c|c|}
\hline $\begin{array}{l}\text { Fuente: } \\
\text { Elaboración }\end{array}$ & $36,75 \%$ & $25,5 \%$ & $11,5 \%$ & $26,25 \%$ \\
\hline P & ALPHA 2.0 & $\begin{array}{l}\text { TRENDING } \\
\text { BOOSTERS }\end{array}$ & $\begin{array}{l}\text { OLD-FASHIONED } \\
\text { RESTRAINED }\end{array}$ & OFF THE RETRO \\
\hline EDAD & $25-34$ & $25-29$ & $25-45$ & $34-45$ \\
\hline $\begin{array}{c}7 \\
\text { ESTADO } \\
\text { CIVIL }\end{array}$ & SOLTERAS & SOLTERAS & SOLTERAS & CASADAS \\
\hline$\sum_{\text {ESTUDIOS }}$ & SUPERIORES & SUPERIORES & SUPERIORES & BAJO \\
\hline $\begin{array}{l}\text { SITUACIÓN } \\
\text { LABORAL }\end{array}$ & $\begin{array}{l}\text { TRABAJAN } \\
\text { CUENTA } \\
\text { AJENA }\end{array}$ & $\begin{array}{l}\text { TRABAJAN } \\
\text { CUENTA } \\
\text { A.JENA }\end{array}$ & $\begin{array}{l}\text { TRABAJAN } \\
\text { CUENTA } \\
\text { AJENA }\end{array}$ & $\begin{array}{l}\text { TRABAJAN } \\
\text { CUENTA } \\
\text { AJENA }\end{array}$ \\
\hline RESIDENCIA & $\begin{array}{l}\text { GRANDES } \\
\text { CIUDADES }\end{array}$ & $\begin{array}{l}\text { GRANDES } \\
\text { CIUDADES }\end{array}$ & $\begin{array}{l}\text { PEQUEÑAS } \\
\text { CIUDADES }\end{array}$ & URBANITAS \\
\hline
\end{tabular}

6. Una mujer alpha es definida por ser ambiciosa, independiente, atractiva, segura y asertiva. Esta definición encaja perfectamente con cómo son las mujeres de este clúster: solteras, trabajadoras por cuenta propia, independientes, optimistas, consideran que los medios no les influyen (pese a que realmente sí que lo hagan). Por otro lado, y aunque utilizan internet y las redes sociales a diario y varias veces al día, su consumo está un paso por detrás de las treending boosters, ya que pese a que son heavy users de las redes sociales y siguen a influencers, no tienen por costumbre seguir a muchas de ellas (aunque previsiblemente lo harán en un futuro). De ahí que las denominemos 2.0.

7. Se denomina a este clúster old-fashioned porque, aunque tienen interés en moda, no la siguen ni se preocupan de elegir outfits. Además se observa que se contienen mucho a la hora de comprar, de ahí que las denominemos restrained.

8. Se ha realizado una analogía con la expresión off the record, ya que se encuentran fuera de los cánones al consumir más medios of-fline (de ahí que también nos encaje la palabra off) que on-line. Además, aunque les interesa la moda (además de otros muchos intereses), no se definen por un alto gasto en moda ni en seguir tendencias, de ahí que las denominemos «retro». 


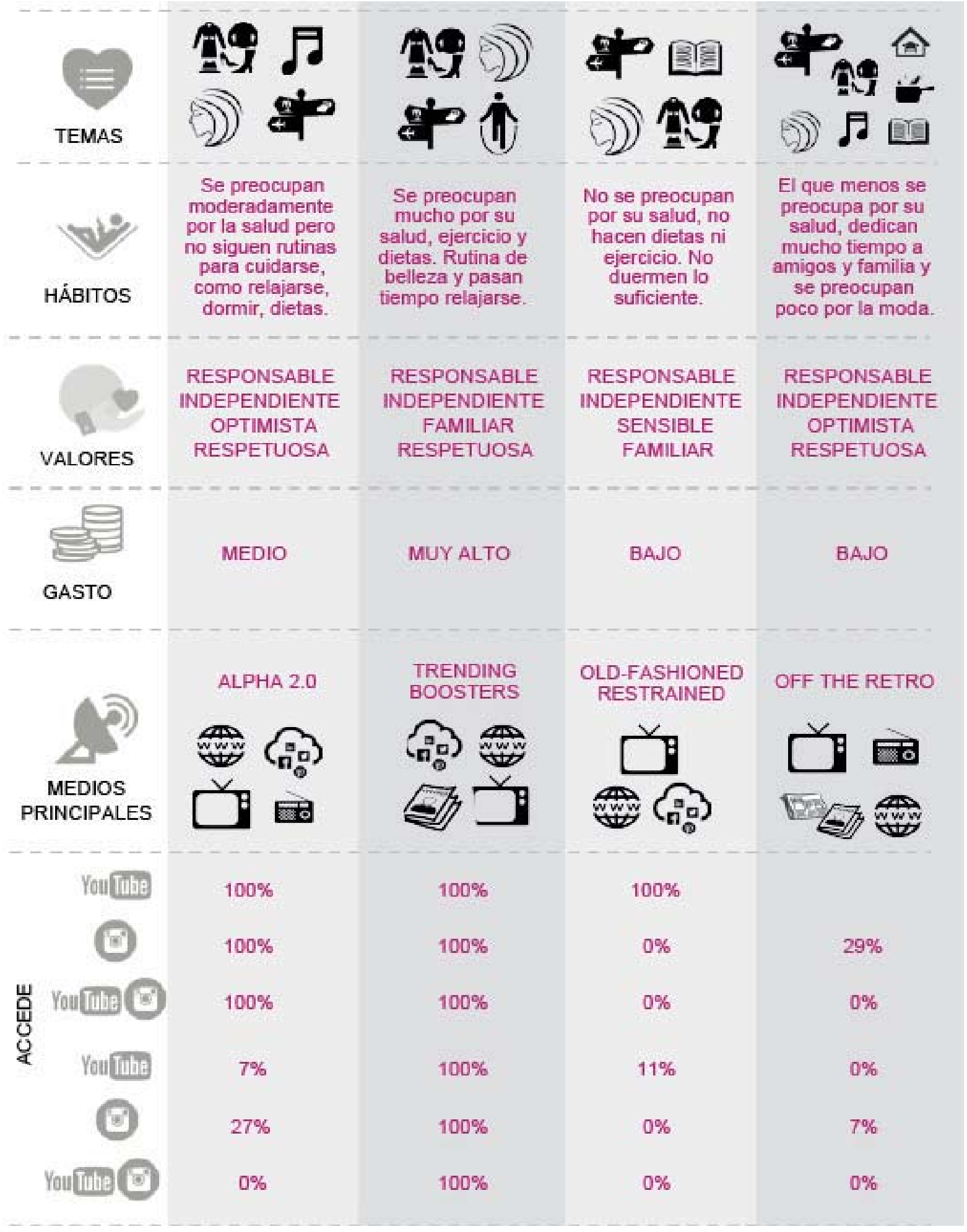




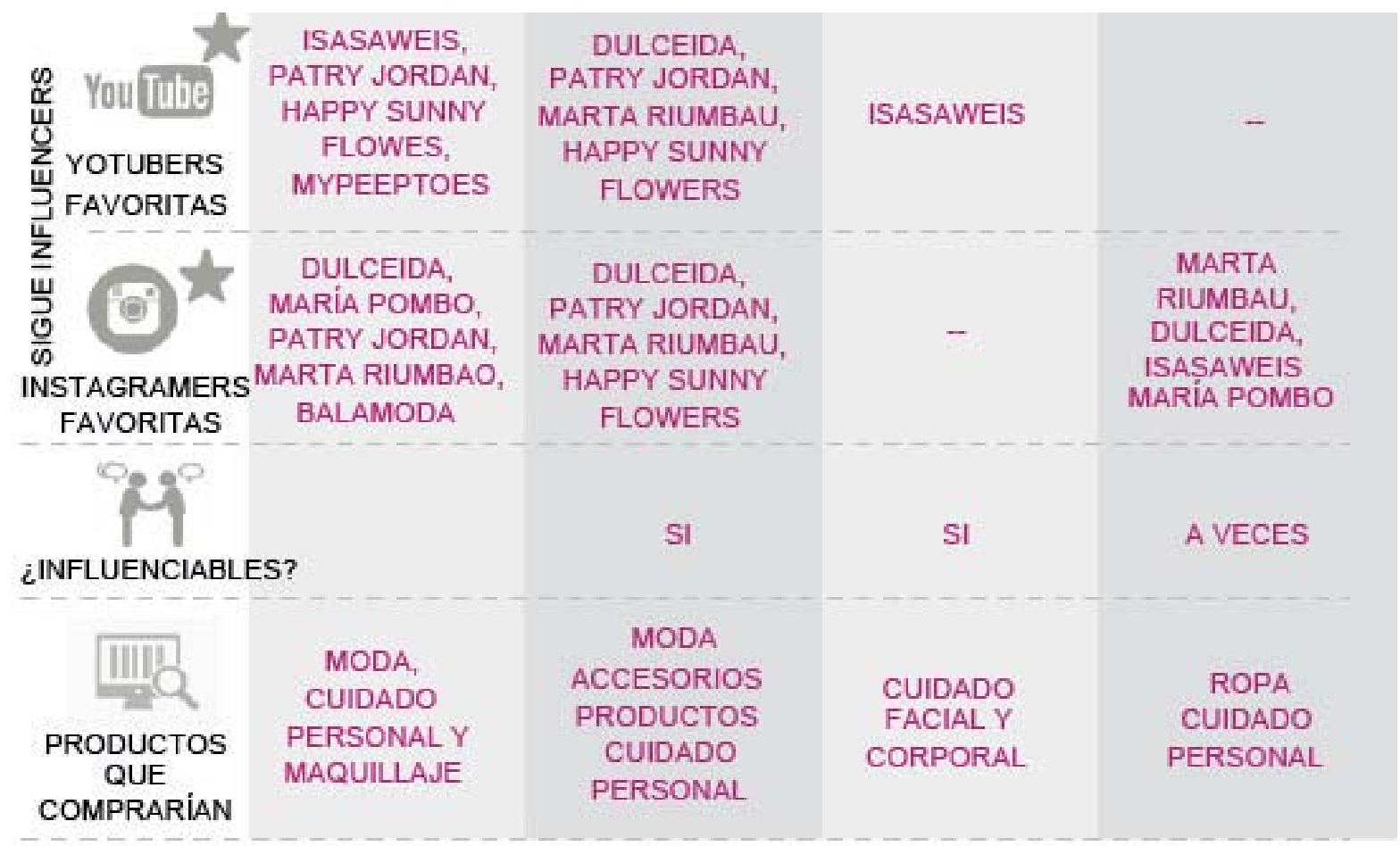

Fuente: elaboración propia.

Con toda esta información, concluí que cada clúster era interesante de diferente manera para las marcas, y los más fácilmente alcanzables por las influencers (y, por lo tanto, más interesantes para las marcas) eran las treending boosters y las alpha 2.0. Pero para alcanzar de manera efectiva al resto de la población, deberíamos combinar otras estrategias. Por lo tanto, se recomendaría combinar una estrategia con medios convencionales con una estrategia bien definida de influencers para llegar al total de las mujeres 25-45.

Por otro lado, gracias al análisis de canales, se pudo elaborar una matriz para ver qué redes sociales se deberían utilizar en función de la categoría y en qué canales deberían hacer su comunicación. 
Tabla 4. Matriz de canales que se deben utilizar según el clúster y categoría de productos

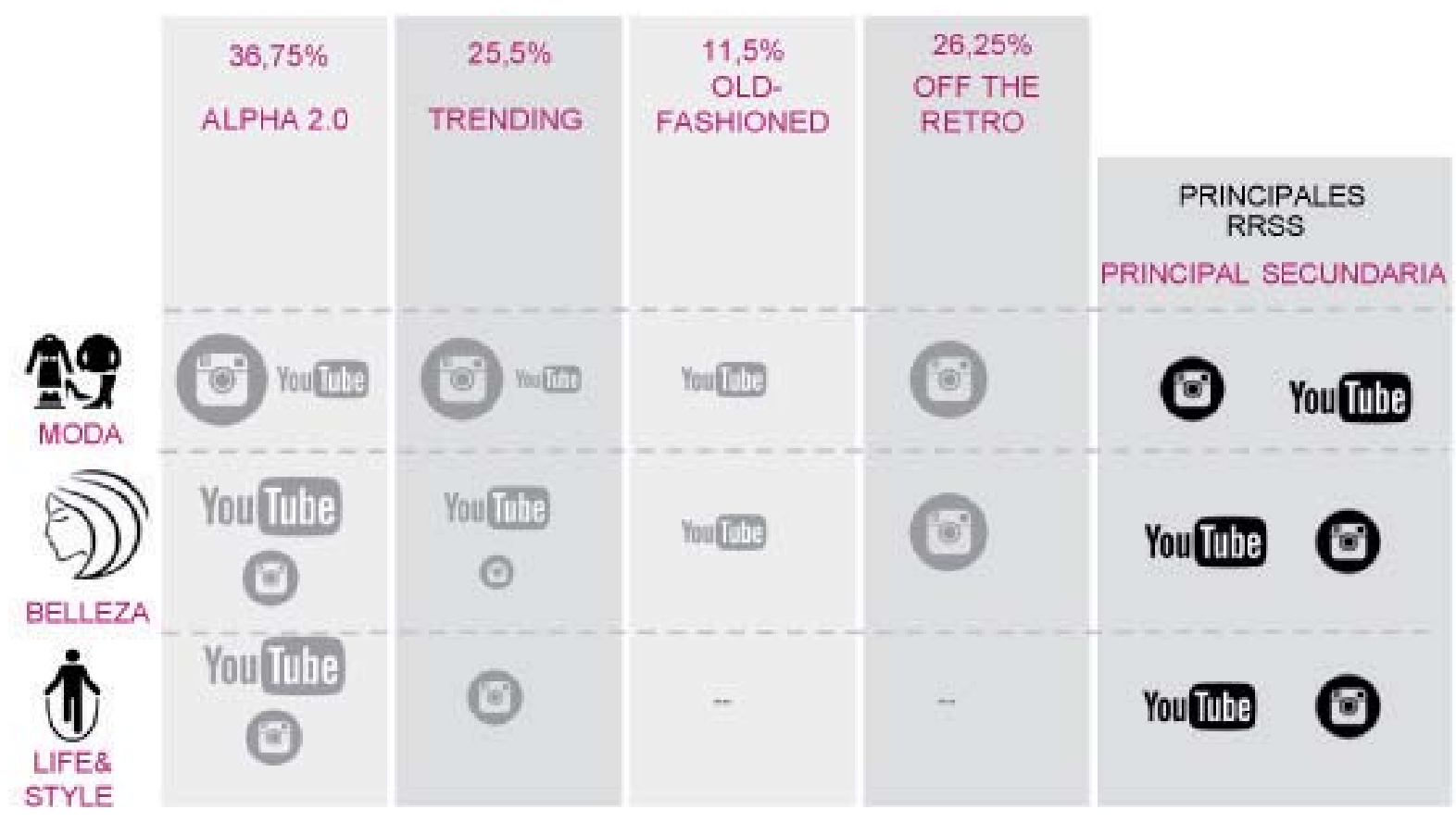

Fuente: elaboración propia.

Además, pude concluir cómo debería ser su comunicación: sincera, imparcial (sin verse influenciada por opiniones de las marcas), confiable, creíble y cercana (como si fuesen amigas, de tú a tú); el contenido presentado tiene que ser relevante para ellas, se debería especificar si la comunicación realizada es pagada o no lo es...

También es muy relevante que se pudo definir una matriz para saber qué Sense Girls eran más relevantes para cada una de las categorías analizadas. 
Tabla 5. Matriz de Sense Girls según nivel de influencia, canal y categoría de productos

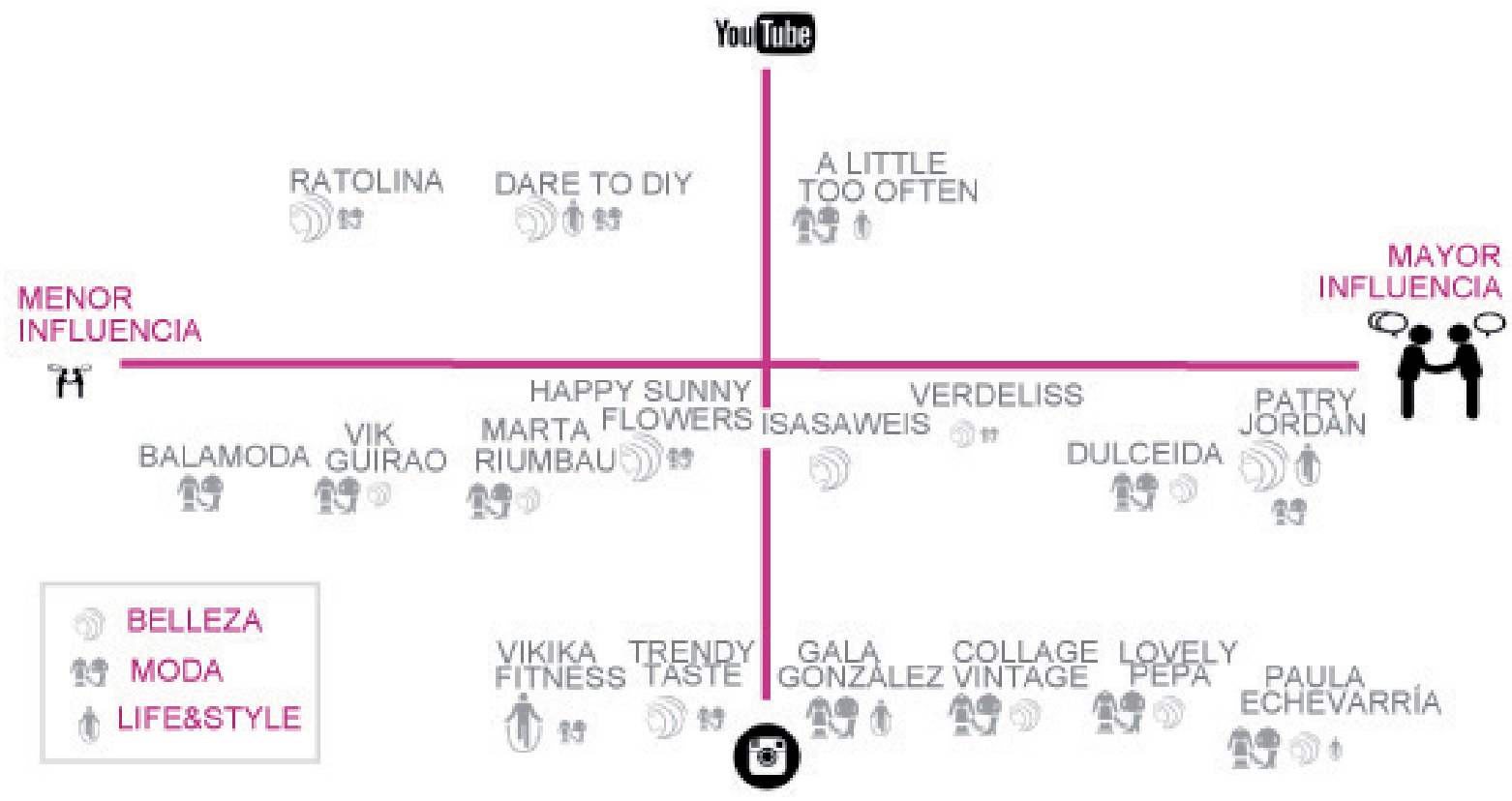

Fuente: elaboración propia.

Y, por último, también se detectaron futuras vías de investigación interesantes para las marcas, como analizar otra redes sociales (como Facebook o Pinterest), hacer una investigación más centrada en la temática «viajes» o realizar esta investigación en un ámbito más amplio (a nivel europeo o incluso mundial). 


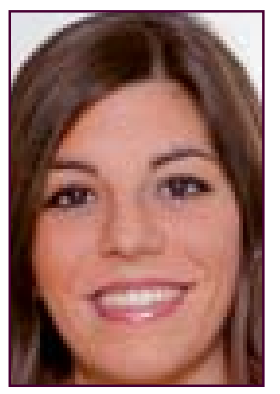

\section{Marina Sánchez Marcos} marina.sanchez.marcos@gmail.com Alumni Grado de Marketing e Investigación de Mercados (UOC)

Graduada en Marketing e Investigación de Mercados por la Universitat Oberta de Catalunya (UOC), amante de la planificación de medios, sector en el cual lleva trabajando los últimos ocho años. Actualmente, se dedica a la estrategia de medios y es Account Manager en Carat. trabajando en las estrategias a nivel Europeo de The Coca-Cola Company.

Los textos publicados en esta revista están sujetas -salvo que se indique el contrario- a una licencia de Reconocimiento 3.0 España de Creative Commons. Podéis copiarlos, distribuirlos, comunicarlos públicamente y hacer obras derivadas siempre que reconozcáis los créditos de las obras (autoría, nombre de la revista, institución editora) de la manera especificada por los autores o por la revista. La licencia completa se puede consultar en http://creativecommons.org/licenses/by/3.0/es/deed.ca.

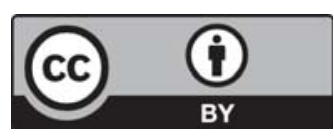

